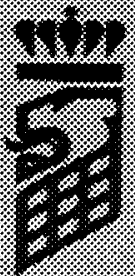

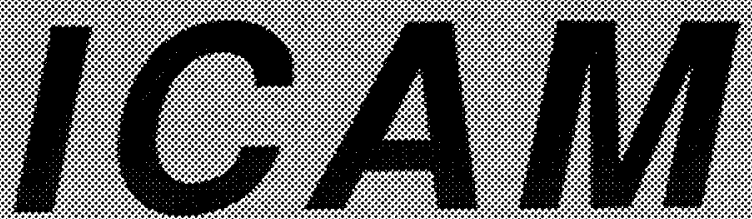

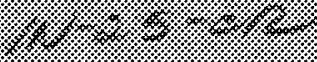

\section{Institute for Computational and Applied Mechanics}

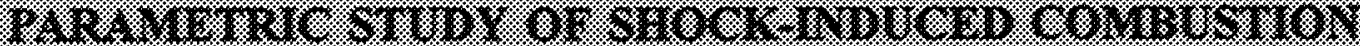

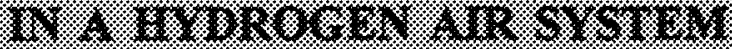

V.:

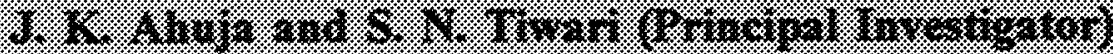

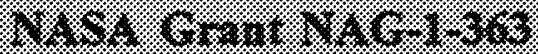

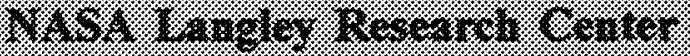

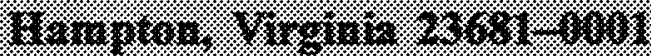

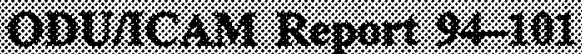

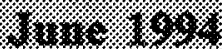

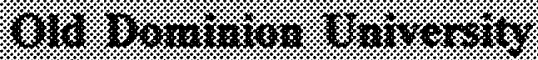

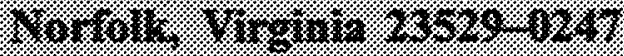

(NASA-CR-197134) PARAMETRIC STUDY

OF SHOCK-INDUCED COMBUSTION IN A

HYOROGEN AIR SYSTEM PrOgreSS

Report, Jun. - Dec. 1993 (old

Dominion Univ.) $62 \mathrm{p}$ 


\section{FOREWORD}

This research work was conducted in cooperation with the Theoretical Flow Physics Branch of the Fluid Mechanics Division of NASA Langley Research Center and the Institute for Computational and Applied Mechanics (ICAM) of Old Dominion University. The study was

a part of the research project on "Analysis and Computation of Internal Flow Field in a Scramjet Engine." Specific work on this study was conducted during the period June through December 1993. During this period, attention was directed to "Parametric Study of ShockInduced Combustion in a Hydrogen Air System." Important results of this study were presented at the 32nd Aerospace Sciences Meeting, Reno, Nevada, January 10-13, 1994; AIAA Paper No. 94-0674, January 1994 (see Appendix A).

The authors are indebted to Dr. Ajay Kumar of the Theoretical Flow Physics Branch for his cooperation and technical assistance.

This work was supported, in part, by the Old Dominion University's ICAM Program through NASA Grant NAG-1-363. The grant was monitored by Mr. Edwin J. Prior, University Affairs Officer, NASA Langley Research Center, Hampton, Virginia 23681-0001. 


\title{
A PARAMETRIC STUDY OF SHOCK-INDUCED COMBUSTION IN A HYDROGEN-AIR SYSTEM
}

\author{
J. K. Ahuja ${ }^{*}$ and S. N. Tiwari ${ }^{\dagger}$ \\ Old Dominion University \\ Norfolk, VA 23529
}

\begin{abstract}
A numerical parametric study is conducted to simulate shock-induced combustion under various free-stream conditions and varying blunt body diameter. A steady combustion front is established if the free-stream Mach number is above the Chapman-Jouguet speed of the mixture, whereas an unsteady reaction front is established if the free-stream Mach number is below or at the Chapman-Jouguet speed of the mixture. The above two cases have been simulated for Mach 5.11 and Mach 6.46 with a projectile diameter of $15 \mathrm{~mm}$. Mach 5.11, which is an underdriven case, shows an unsteady reaction front, whereas Mach 6.46, which is an overdriven case, shows a steady reaction front. Next for Mach 5.11, reducing the diameter to $2.5 \mathrm{~mm}$ causes the instabilities to disappear, whereas for Mach 6.46, increasing the diameter of the projectile to $225 \mathrm{~mm}$ causes the instabilities to reappear, indicating that Chapman-Jouguet speed is not the only deciding factor for these instabilities to trigger. The other key parameters are the projectile diameter, induction time, activation energy and the heat release. The appearance and disappaerance of the instabilities have been explained by the one-dimensional wave interaction model.
\end{abstract}

\footnotetext{
Graduate Research Assistant, AIAA Student Member
}

$\dagger \quad$ Eminent Professor, AIAA Associate Fellow 


\section{TABLE OF CONTENTS}

$\underline{\text { Page }}$

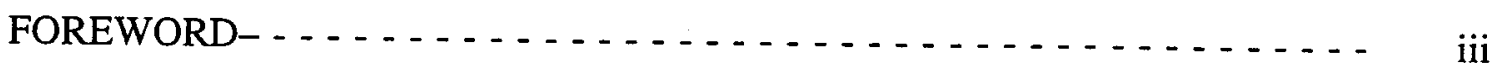

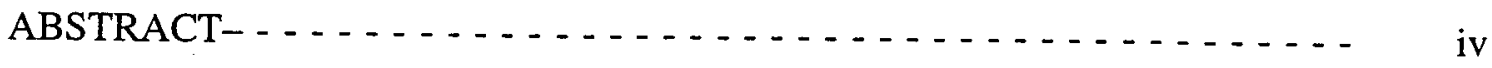

LIST OF FIGURES $\ldots \ldots \ldots \ldots \ldots \ldots \ldots \ldots \ldots$ vi

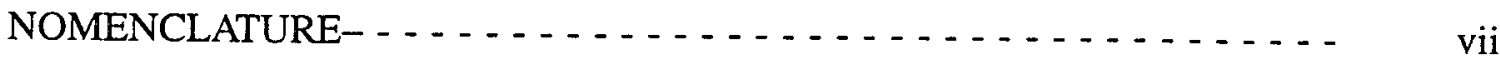

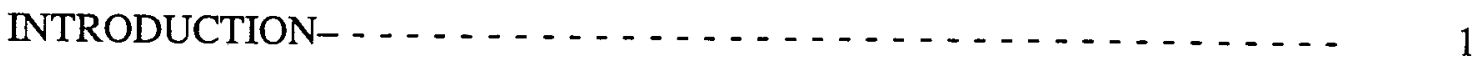

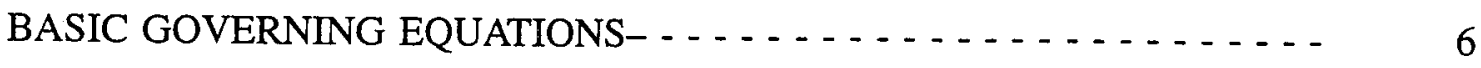

CHEMISTRY AND THERMODYNAMIC MODELS $\ldots \ldots \ldots$

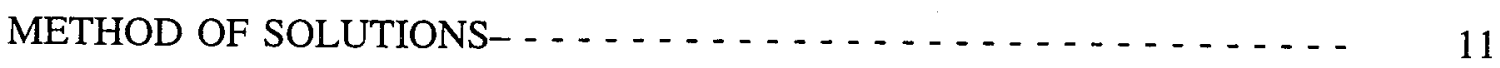

RESULTS AND DISCUSSIONS . . . . . . . . . . . . . . . 12

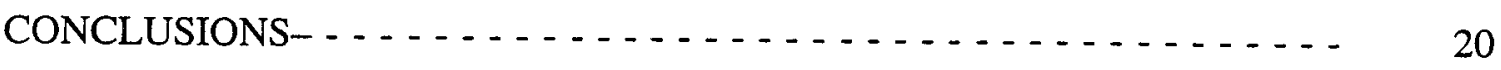

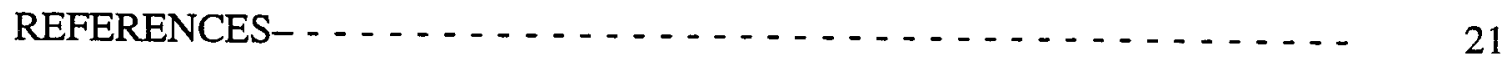

APPENDIX A: AIAA-94-0674 . . . . . . . . . . . . . 37 


\section{LIST OF FIGURES}

Figure

Page

1. Shadowgraph of a spherical nose projectile moving at Mach

5.11 into a premixed stoichiometric hydrogen-air mixture

2. Shadowgraph of a spherical nose projectile moving at Mach 6.46

into a premixed stoichiometric hydrogen-air mixture

3. Contour plot of temperature for Mach 5.11 and projectile

diameter $15 \mathrm{~mm}$

4. Contour plot of water mass fraction for Mach 5.11 and

projectile diameter $15 \mathrm{~mm}$

5. Contour plot of density for Mach 5.11 and projectile diameter $15 \mathrm{~mm}$

6. Contour plot of temperature for Mach 5.11 and projectile

diameter $2.5 \mathrm{~mm}$

7. Contour plot of density for Mach 5.11 and projectile

diameter $2.5 \mathrm{~mm}$

8. Contour plot of water mass fraction for Mach 5.11 and projectile

diameter $2.5 \mathrm{~mm}$

9. Contour plot of density for Mach 6.46 and projectile diameter $15 \mathrm{~mm}$

10. Contour plot of temperature for Mach 6.46 and

projectile diameter $15 \mathrm{~mm}$

11. Enlarged view of contour plot of water mass fraction for Mach 6.46

32

and projectile diameter $150 \mathrm{~mm}$.

12. Enlarged view of contour plot of water mass fraction for Mach 6.46

and projectile diameter $225 \mathrm{~mm}$.

13. $x-t$ Plot of water mass fraction along stagnation streamline for

Mach 5.11 and projectile diameter $15 \mathrm{~mm}$

14. $x-t$ Plot of water mass fraction along stagnation streamline for

Mach 5.11 and projectile diameter $2.5 \mathrm{~mm}$ 


\section{NOMENCLATURE}
$A_{j} \quad$ reaction rate constant for the $j^{\text {th }}$ reaction
$\mathrm{C}_{\mathrm{i}} \quad$ concentration of $i^{\text {th }}$ species
$\mathrm{C}_{\mathrm{pi}} \quad$ constant pressure specific heat of $\mathrm{i}^{\text {th }}$ species
$\mathrm{D}_{\mathrm{ij}} \quad$ binary diffusion coefficient of $\mathrm{i}^{\text {th }}$ and $\mathrm{j}^{\text {th }}$ species
$\mathrm{D}_{\mathrm{p}} \quad$ projectile diameter
E total (internal and kinetic) energy
$\epsilon_{\mathrm{j}} \quad$ activation energy of $\mathrm{j}^{\mathrm{th}}$ reaction
$h_{i}{ }^{R} \quad$ base enthalpy of $i^{\text {th }}$ species
$\mathrm{k} \quad$ thermal conductivity
$\kappa_{\mathrm{fj}} \quad$ forward rate constant for $\mathrm{j}^{\text {th }}$ reaction
$\kappa_{\text {bj }} \quad$ backward rate constant for $j^{\text {th }}$ reaction
$\kappa_{\text {eqj }}$ equilibrium constant for $\mathrm{j}^{\text {th }}$ reaction
$\mathrm{M}_{\mathrm{i}} \quad$ molecular weight of $\mathrm{i}^{\text {th }}$ species
$\mathrm{N}_{\mathrm{s}} \quad$ number of chemical species
$\mathrm{N}_{\mathrm{r}} \quad$ number of chemical reactions
$\mathrm{p} \quad$ pressure
$R_{i} \quad$ gas constant of $i^{\text {th }}$ species
T temperature
$\mathrm{u} \quad \mathrm{x}$-component of the velocity
$\tilde{u}_{i} \quad \mathrm{x}$-component of the diffusion velocity of the $i^{\text {th }}$ component
v y-component of the velocity
$\tilde{v}_{i} \quad \mathrm{y}$-component of diffusion velocity of $\mathrm{i}^{\text {th }}$ species
$\mathrm{X}_{\mathrm{i}} \quad$ mole fraction of $\mathrm{i}^{\text {th }}$ species 
$\mathrm{x} \quad$ streamwise coordinate in the physical domain

y normal coordinate in the physical domain

$\alpha_{\mathrm{j}} \quad$ temperature coefficient in reaction rate expression for $\mathrm{j}^{\text {th }}$ reaction

$\Delta G_{R j}$ Gibbs free energy change for the $j^{\text {th }}$ reaction

$\Delta \mathrm{n}_{\mathrm{j}} \quad$ molar change for the $\mathrm{j}^{\text {th }}$ reaction

$\eta \quad$ normal coordinate in the computational

domain

$\lambda \quad$ second viscosity coefficient

$\mu \quad$ dynamic viscosity

$\nu_{j i}^{\prime} \quad$ stoichiometric coefficient of reactant

corresponding to $\mathrm{i}^{\text {th }}$ species and $\mathrm{j}^{\text {th }}$ reaction

$\nu_{j i}^{\prime \prime} \quad$ stoichiometric coefficient of product

corresponding to $\mathrm{i}^{\text {th }}$ species and $\mathrm{j}^{\text {th }}$ reaction

$\xi \quad$ streamwise coordinate in the computational

domain

$\rho \quad$ density

$\sigma_{\mathrm{x}} \quad$ normal stress in the $\mathrm{x}$-direction

$\sigma_{y} \quad$ normal stress in the y-direction

$\tau_{x y} \quad$ shear stress in the $x y$ plane

$\dot{\omega}_{i} \quad$ production rate of $i^{\text {th }}$ species 


\section{INTRODUCTION}

Some of the applications of supersonic research are the proposed National Aero-Space Plane, the ram accelerator and Trans Atmospheric Vehicles. All of these vehicles rely on air-breathing propulsion. The air-breathing engine removes the requirement to carry an oxidizer inside the vehicle. Further, there is a substantial savings in weight and, therefore, the payload is higher. An efficient propulsion system at hypersonic speeds requires that combustion take place at supersonic speeds, i.e., combustion at supersonic mean airstream speed. The supersonic combustion speed is required for airbreathers at high Mach numbers to reduce the unacceptable losses associated with inlet deceleration to subsonic conditions. The scramjet [1,2] is an integrated airframe-propulsion concept for a hypersonic airplane. Significantly increased propulsion efficiency in the Mach 6 to 15 range may be provided by the conventional diffusion-burning, air-breathing scramjet. For airbreathers above Mach 15, another propulsion approach is required, e.g., greatly enhanced (reduced loss) conventional scramjet and detonation wave engines.

Another proposed hypervelocity air-breathing propulsion scheme is the shock-induced combustion or oblique detonation wave engine (ODWE [3]) where a shock is employed to increase the temperature of the premixed fuel and air to a point that creates chemical reaction. The term detonation is applied to the process where a shock and reaction front follow each other very closely and are pressure coupled, while shock-induced combustion implies that the shock wave and reaction front are decoupled. Thus, detonation is a limiting case of shock-induced combustion. Up to about Mach 15, a scramjet has better performance than an ODWE, but after that, ODWE performs better. This engine requires even more extreme integration with the "airframe." To avoid preignition, the fuel is injected from the vehicle forebody/nose region, inside the shock layer but outside the boundary layer. The advantages of a shock-induced combustion propulsion system include lower inlet losses and significant reduction in combustion weight, size, heat transfer, and skin friction losses and cooling requirements. These advantages are due to forebody region fuel-air mixing which obviates the need to contain the fuel-air mixing process 
within a long combustor at high pressure.

Ballistic range experiments performed in the 1960's and 1970's provide an excellent source for studying supersonic combustion/detonation. The physics of these ballistic range flows are predominantly driven by reaction kinetics and convection phenomena. Thus, the complications and uncertainties of diffusion and mixing are removed from the problem. Any discrepancy between the experimental data and numerical calculations can be attributed to either numerical errors or the improperly modelled chemical kinetics. Zeldovich [4] suggested that combustion can be stabilized by the shock wave produced by bodies moving at supersonic speeds in combustible mixtures at various level of overdrive. In these experiments, projectiles were fired in different premixed fuel-air mixtures, and detonation structures around the projectiles were recorded. Every gas mixture has a detonation wave velocity known as the Chapman-Jouget (C-J) velocity, which is characteristic of the mixture. The detonation wave velocity is known as the C-J velocity of the mixture whenever the normal component of the flow velocity following the detonation wave is sonic. If the normal component of the flow velocity is subsonic, however, the detonation wave velocity is called overdriven and if supersonic, then it is known as underdriven. The free-stream velocity is referred to as superdetonative if the free-stream velocity of the projectile is above the C-J velocity of the reactive mixture. The detonation wave structure is highly unstable for projectile velocities that are less than the C-J velocity of the mixture. The detonation or reaction front structure shows a coupled shock-deflagration system near the stagnation line of the body if the projectile is flying above the C-J velocity of the gas mixture. These two fronts separate from each other as "one moves away from the stagnation line. The separation between the two fronts occurs as soon as the velocity component normal to the bow shock is equal to the detonation velocity. The separation between the bow shock and the reaction front is called the induction zone. Lehr's [5] experimental ballistic range shadowgraphs for Mach 5.11 and Mach 6.46 are shown in Figs. 1 and 2, respectively. A free-stream temperature of $292 \mathrm{~K}$ and a pressure of $42663.2 \mathrm{~N} / \mathrm{m}^{2}$ (320 $\mathrm{mm}$ of $\mathrm{Hg}$ ) are used along with a stoichiometric mixture of hydrogen and air 
in both cases. In Fig. 1 the projectile velocity is Mach 5.11 (which is also the C-J velocity of the mixture). It shows separation of two discontinuities by induction zone. The outer discontinuity is the bow shock, and the inner discontinuity is the reaction front. The separation between the two shocks is minimum near the stagnation region and increases downstream. The induction distance is increased as the shock wave becomes weak away from the stagnation region and the post-shock temperature reduces. Another feature to be noticed is the presence of instabilities in the reaction front. The frequencies of these pulsations were determined to be $1.96 \mathrm{MHz}$. It is seen in Fig. 2 that the reaction front for the Mach 6.46 case is coupled with the shock near the stagnation line. The coupling continues until about $60^{\circ}$ from the stagnation line, where the reaction front starts decoupling from the bow shock. This coupling is caused by very high post-shock temperatures, that cause a decrease in the induction distance. A close examination of the shadowgraphs reveals that there is an increase in density as the flow crosses the bow shock. The increase is noted by the color changes from light to dark. As the flow crosses the reaction front, however, the color changes from dark to light, indicating a decrease in density across the reaction front. This decrease is due to a large release of energy across the reaction front that causes an increase in the temperature; since the pressure remains relatively constant, the density must decrease.

By means of schlieren photography, Reugg and Dorsey [6] investigated the problems and effects of stabilizing combustion on a $20 \mathrm{~mm}$ diameter spherical projectile in a stoichiometric mixture of hydrogen and air at rest. Combustion produced detectable effects on the shapes and positions of shock waves at Mach numbers between 4 and 6.5 and above a pressure of one-tenth atmosphere. Strong combustion-driven oscillations were observed in front of the sphere with frequencies of one-tenth megacycle per second. These oscillations were observed when the Mach number was less than 6 for the one-half atmosphere pressure, and less than 5 for the one-quarter atmosphere pressure. They also reported the results with methane-air and pentane-air mixtures.

Similar experiments were performed by Behren et al. [7] by firing $9 \mathrm{~mm}$ diameter plastic 
spheres into hydrogen-air and hydrogen-oxygen mixture at velocities of $1500-3000 \mathrm{~m} / \mathrm{sec}$. Similar behaviour of transition from detonation wave stability to instability was observed when the projectile velocities were decreased to nearly C-J velocity of the mixture.

Chernyi [8] reported on the experiments of firing a sphere-nosed cylinder into hydrogenoxygen and hydrogen-air mixtures. As in the case for self-sustained detonation, the flow field is highly unstable under a wide range of conditions. In the case of blunt projectiles and exothermic gas mixtures, the instabilities generate a highly regular, periodic flow structure under certain conditions. He suggested the similarity of these instabilities to the cellular structure of flame.

McVey and Toong [9] conducted similar experiments where projectiles were fired into lean acetylene-oxygen and stoichiometric hydrogen-air mixtures. They developed the wave interaction model to explain the detonation wave structure instabilities. Their model explains how compression waves can be formed when a new reaction front develops in the induction zone between the normal segment of the bow shock and the original reaction front. These compression waves lead to a cyclic process which is compatible with most of the observed features of the flow. However, the compression wave strength remained unresolved in their wave-interaction model, which is an important factor in determining if such a model is physically possible. Alpert and Toong [10] included the effect of the compression wave strength and proposed a modified form of the wave-interaction model.

Several researchers [11-15] have recently attempted to numerically simulate Lehr's ballistic range experiments [5]. Youngster et al. [11] and Lee and Deiwart [12] simulated Lehr's experimental data for Machs 4.18, 5.11, and 6.46. They used Euler equations coupled with species equations to capture the shock and the reaction front. The reaction model used was a hydrogen-air mixture of six species and an inert gas such as Argon or Nitrogen and eight reactions. The flow field was found to be steady despite the experimental evidence that the flow field is unsteady. For the test conditions of stoichiometric hydrogen-air mixture, the detonation wave speed of the mixture is Mach 5.11. It has been demonstrated experimentally by Lehr that 
Machs 5.11 and 4.18 show detonation wave structural instabilities that disappear if the flight Mach number is increased beyond Mach 5.11. Further, the flow field was not well resolved. Their blunt body calculations used $32 \times 32$ and $57 \times 41$ size grids, respectively. These grids were not sufficient to resolve the flow field correctly.

Wilson and MacCormack [13] conducted a detailed numerical investigation of the shockinduced combustion phenomena. Euler equations and a 13-species, 33-reactions chemistry model was used. The validity of the reaction models and the importance of grid resolution needed to properly model the flow physics were also shown. Highly resolved calculations for Lehr's Mach 5.11 and Mach 6.46 cases with an adaptive grid were performed. The calculations were not time accurate; therefore, the unsteady behavior was not captured.

Sussman and Wilson [14] also studied the instabilities in the reaction front for a Mach number of 4.79. Euler equations and a 13-species, 33-reactions chemistry model was again used. They have proposed a new formulation based on logarithmic transformation. The number of grid points needed to properly resolve the reaction front is greatly reduced. They successfully simulated the unsteady case. However, the frequency was slightly underpredicted.

Matsuo and Fujiwara [15] have studied the instabilities of shock-induced combustion around an axisymmetric blunt body with Euler equations and a simplified two-step chemistry model. The growth of periodic instabilities by a series of simulations with various tip radii was investigated; these periodic instabilities are related to shock-standoff distance and induction length. They proposed a new model based on McVey and Toong's model [9] that explained the instabilities in the reaction front.

The appearance or disappearance of the instabilities in the structure of the reaction front with various Mach numbers has been studied in details, and a satisfactory explanation of the various flow phenomena have been explained by the wave-interaction model by McVey and Toong [9]. The instabilities originate in the induction zone that separates the bow shock and the exothermic reaction front in the nose region of the flow field and then spreads outwards. 
But the disappearance of instabilities by reducing the projectile diameter while keeping the same Mach number has not been clarified yet. The objective of this study is to isolate the various key parameters for the appearance and disappearance of these instabilities such as projectile diameter, induction time, heat release, activation energy and to explain the physics of the observed phenomena by a wave interaction model. In order to capture the physical instabilities, the calculations must be carried out for long times to ensure that all relevant time scales are being captured. Since all numerical schemes have some numerical diffusion, which is dependent on the grid resolution, a coarse grid may damp these oscillations. Further, the numerical damping added to the scheme in the reaction front vicinity may damp or alter the instability modes. The axisymmetric version of the SPARK2D code [16], which incorporates a 9-species, 18-reactions combustion model for hydrogen-air mixtures, is used to carry out the analysis.

\section{BASIC GOVERNING EQUATIONS}

The physical model for analyzing the flow field is described by the Navier-Stokes and species continuity equations. For two-dimensional axisymmetric flows, these equations are expressed in physical coordinates as [16]

$$
\frac{\partial U}{\partial t}+\frac{\partial F}{\partial x}+\frac{\partial G}{\partial y}=H
$$

where vectors $\mathrm{U}, \mathrm{F}, \mathrm{G}$, and $\mathrm{H}$ are written as

$$
U=\left[\begin{array}{c}
\rho \\
\rho u \\
\rho v \\
\rho E \\
\rho f_{i} \\
\cdot \\
\cdot
\end{array}\right]
$$




$$
\begin{aligned}
& F=\left[\begin{array}{c}
\rho u \\
\rho u^{2}-\sigma_{x} \\
\rho u v-\tau_{x y} \\
\left(\rho E-\sigma_{x}\right) u-\tau_{x y} v+q_{x} \\
\rho f_{i}\left(u+\tilde{u}_{i}\right) \\
\cdot \\
\cdot
\end{array}\right] \\
& G=\left[\begin{array}{c}
\rho v \\
\rho u v-\tau_{x y} \\
\rho v^{2}-\sigma_{y} \\
\left(\rho E-\sigma_{y}\right) v-\tau_{x y} u+q_{y} \\
\rho f_{i}\left(v+\tilde{v}_{i}\right) \\
\cdot \\
\cdot
\end{array}\right] \\
& H=\frac{1}{y}\left[\begin{array}{c}
\rho v \\
\left(\rho v u+\tau_{x y}\right) \\
\rho v^{2}+\tau_{y y}-\tau_{\theta \theta} \\
\left(\rho E+p+\tau_{y y}\right) v+\tau_{x y} u+q_{y} \\
\omega_{i} \\
\cdot
\end{array}\right]
\end{aligned}
$$


The other terms appearing in vectors F, G, and $\mathrm{H}$ are defined as

$$
\begin{aligned}
& \sigma_{x}=-p+2 \mu \frac{\partial u}{\partial x}+\lambda \nabla \cdot u \\
& \sigma_{y}=-p+2 \mu \frac{\partial v}{\partial y}+\lambda \nabla \cdot u \\
& \tau_{x y}=\mu\left[\frac{\partial u}{\partial y}+\frac{\partial v}{\partial x}\right] \\
& \tau_{y y}=-\frac{2}{3} \mu\left(2 \frac{\partial v}{\partial y}-\frac{v}{y}-\frac{\partial v}{\partial x}\right) \\
& \tau_{\theta \theta}=-\frac{2}{3} \mu\left(2 \frac{v}{y}-\frac{\partial v}{\partial y}-\frac{\partial u}{\partial x}\right) \\
& q_{x}=-k \frac{\partial T}{\partial x}+\rho \sum_{i=1}^{N_{s}} h_{i} f_{i} \tilde{u}_{i} \\
& q_{y}=-k \frac{\partial T}{\partial y}+\rho \sum_{i=1}^{N_{s}} h_{i} f_{i} \tilde{v}_{i} \\
& p=\rho R_{u} T \sum_{i=1}^{N_{s}} \frac{f_{i}}{M_{i}} \\
& h_{i}=h_{i}^{R}+\int_{T^{R}}^{T} C_{p_{i}} d T \\
& \frac{C_{p_{i}}}{R_{i}}=A_{i}+B_{i} T+C_{i} T^{2}+D_{i} T^{3}+E_{i} T^{4}
\end{aligned}
$$


In Eq. (1) only $\left(\mathrm{N}_{\mathrm{s}}-1\right)$ species equations need to be considered in the formulation since the mass fraction of the species is prescribed by satisfying the constraint equation

$$
\sum_{i=1}^{N} f_{i}=1
$$

The specific heat at constant pressure for each species is prescribed in Eq. (11) by a fourth-order polynomial in temperature. The diffusion velocity of the $i^{\text {th }}$ species is obtained by solving the Stefan-Maxwell equation, neglecting body force and thermal diffusion effects.

$$
\nabla X_{i}=\sum_{j=1}^{N_{s}}\left(\frac{X_{i} X_{j}}{D_{i j}}\right)\left(\tilde{V}_{j}-\tilde{V}_{i}\right)+\left(f_{i}-X_{i}\right)\left(\frac{\nabla p}{p}\right)
$$

This equation has to be applied only to $\left(\mathrm{N}_{\mathrm{S}}-1\right)$ species. The diffusion velocity for the remaining

species is prescribed by satisfying the constraint equation $\sum_{i=1}^{N_{s}} f_{i} \tilde{V}_{i}=0$, which ensures the consistency.

\section{CHEMISTRY AND THERMODYNAMIC MODELS}

Chemical reaction rate expressions are usually determined by summing the contributions from each relevant reaction path to obtain the total rate of change of each species. Each path is governed by a law of mass action expression in which the rate constants can be determined from a temperature dependent Arrhenius expression. In vector $\mathrm{H}$, the term $\omega_{i}=M_{i} C_{i}$ represents the net rate of production of species $i$ in all chemical reactions and is modelled as follows :

$$
\begin{gathered}
\sum_{i=1}^{N_{s}} \nu_{j i}^{\prime} S_{i} \rightleftharpoons \sum_{i=1}^{N_{s}} \nu_{j i}^{\prime \prime} S_{i} ; j=1, \ldots N_{r} \\
\omega_{i}=M_{i} \sum_{j=1}^{N_{r}}\left(\nu_{j i}^{\prime \prime}-\nu_{j i}^{\prime}\right)\left[\kappa_{f_{j}} \prod_{m=1}^{N_{s}} C_{m}^{\nu_{j m}^{\prime}}-\kappa_{b_{j}} \prod_{m=1}^{N_{s}} C_{m}^{\nu_{j m}^{\prime \prime}}\right]
\end{gathered}
$$

where Eq. (14) is a representation of an $N_{r}$-step chemical reaction and Eq. (15) is the production rate for the $i^{\text {th }}$ species, as determined from the law of mass action. The reaction constants $\kappa_{\mathrm{fj}}$ and $\kappa_{\mathrm{bj}}$ are calculated from the following equations

$$
\kappa_{f j}=A_{j} T^{\alpha j} \exp \left(\frac{-\epsilon_{j}}{R_{u} T}\right) ; j=1, \ldots N_{r}
$$




$$
\kappa_{b j}=\frac{\kappa_{f_{j}}}{\kappa_{e q_{j}}} ; j=1, \ldots . N_{r}
$$

The equilibrium constant appearing in Eq. (18) is given by

$$
\kappa_{e q_{j}}=\left(\frac{1}{R_{u} T}\right)^{\Delta n_{j}} \exp \left(\frac{-\Delta G_{f_{j}}}{R_{u} T}\right) ; j=1, \ldots . N_{r}
$$

where

$$
\begin{gathered}
\Delta n_{j}=\sum_{i=1}^{N_{s}} \nu_{j i}^{\prime \prime}-\sum_{i=1}^{N_{s}} \nu_{j i}^{\prime} ; j=1, \ldots N_{r} \\
\Delta G_{R_{j}}=\sum_{i=1}^{N_{s}} \nu_{j i}^{\prime \prime} g_{i}-\sum_{i=1}^{N_{s}} \nu_{j i}^{\prime} g_{i} ; j=1, \ldots N_{r} \\
\frac{g_{i}}{R_{i}}=A_{i} T(1-\ln T)-\left(\frac{B_{i}}{2}\right) T^{2}-\left(\frac{C_{i}}{6}\right) T^{3} \\
-\left(\frac{D_{i}}{12}\right) T^{4}-\left(\frac{E_{i}}{20}\right) T^{5}+F_{i}-G_{i} T ; i=1, \ldots . N_{s}
\end{gathered}
$$

The forward rate for each reaction is determined by Eq. (17) which is based on the Arrhenius law. The appropriate constants $\mathrm{A}_{j}, \alpha_{j}$, and $\epsilon_{\mathrm{j}}$ for the $\mathrm{H}_{2}$-air reaction system can be found in [17]. The reverse rate is then calculated from Eq. (18). The Gibb's free energy of each species in $g_{i}$ is obtained from the expression for $C_{p i}$.

The hydrogen-air combustion mechanism used in this work is based on the Jachimowski hydrogen-air model [17] which uses 9 species and 18 reactions. The species are $\mathrm{N}_{2}, \mathrm{O}_{2}, \mathrm{H}_{2}$, $\mathrm{OH}, \mathrm{H}, \mathrm{O}, \mathrm{H}_{2} \mathrm{O}, \mathrm{HO}_{2}$, and $\mathrm{H}_{2} \mathrm{O}_{2}$. Each of the 18 reactions can proceed in the forward and backward directions. The reactions are

1) $\mathrm{O}_{2}+\mathrm{H}_{2} \rightleftharpoons \mathrm{OH}+\mathrm{OH}$

2) $\mathrm{O}_{2}+\mathrm{H} \rightleftharpoons \mathrm{OH}+\mathrm{O}$

3) $\mathrm{H}_{2}+\mathrm{OH} \rightleftharpoons \mathrm{H}_{2} \mathrm{O}+\mathrm{H}$

4) $\mathrm{H}_{2}+\mathrm{O} \rightleftharpoons \mathrm{OH}+\mathrm{H}$

5) $\mathrm{OH}+\mathrm{OH} \rightleftharpoons \mathrm{H}_{2} \mathrm{O}+\mathrm{O}$

6) $\mathrm{OH}+\mathrm{H}+\mathrm{M} \rightleftharpoons \mathrm{H}_{2} \mathrm{O}+\mathrm{M}$

7) $\mathrm{H}+\mathrm{H}+\mathrm{M} \rightleftharpoons \mathrm{H}_{2}+\mathrm{M}$ 
8) $\mathrm{H}+\mathrm{O}_{2}+\mathrm{M} \rightleftharpoons \mathrm{HO}_{2}+\mathrm{M}$

9) $\mathrm{HO}_{2}+\mathrm{OH} \rightleftharpoons \mathrm{H}_{2} \mathrm{O}+\mathrm{M}$

10) $\mathrm{HO}_{2}+\mathrm{M} \rightleftharpoons \mathrm{H}_{2}+\mathrm{O}_{2}$

11) $\mathrm{HO}_{2}+\mathrm{H} \rightleftharpoons \mathrm{OH}+\mathrm{OH}$

12) $\mathrm{HO}_{2}+\mathrm{O} \rightleftharpoons \mathrm{OH}+\mathrm{O}_{2}$

13) $\mathrm{HO}_{2}+\mathrm{HO}_{2} \rightleftharpoons \mathrm{H}_{2} \mathrm{O}_{2}+\mathrm{O}_{2}$

14) $\mathrm{HO}_{2}+\mathrm{H}_{2} \rightleftharpoons \mathrm{H}_{2} \mathrm{O}_{2}+\mathrm{H}$

15) $\mathrm{H}_{2} \mathrm{O}_{2}+\mathrm{OH} \rightleftharpoons \mathrm{H}_{2} \mathrm{O}+\mathrm{HO}_{2}$

16) $\mathrm{H}_{2} \mathrm{O}_{2}+\mathrm{H} \rightleftharpoons \mathrm{H}_{2} \mathrm{O}+\mathrm{OH}$

17) $\mathrm{H}_{2} \mathrm{O}_{2}+\mathrm{O} \rightleftharpoons \mathrm{HO}_{2}+\mathrm{OH}$

18) $\mathrm{H}_{2} \mathrm{O}_{2}+\mathrm{M} \rightleftharpoons \mathrm{OH}+\mathrm{OH}+\mathrm{M}$

\section{METHOD OF SOLUTION}

The governing equations are transformed from the physical domain $(\mathrm{x}, \mathrm{y})$ to a computational domain $(\xi, \eta)$ using an algebraic grid generation technique. In the computational domain, Eq. (1) is expressed as

$$
\frac{\partial \hat{U}}{\partial t}+\frac{\partial \hat{F}}{\partial \xi}+\frac{\partial \hat{G}}{\partial \eta}=\hat{H}
$$

where

$$
\begin{gathered}
\hat{U}=U J, \hat{F}=F y_{\eta}-G x_{\eta} \\
\hat{G}=G x_{\xi}-F y_{\xi}, \hat{H}=H J \\
J=x_{\xi} y_{\eta}-y_{\xi} x_{\eta}
\end{gathered}
$$

MacCormack's [18] method is used to solve the governing equations. The scheme is second-order accurate in time and space, which results in a spatially and temporally discrete, simultaneous system of equations at each grid point. The system of equations is solved subject to initial and boundary conditions. At the supersonic inflow boundary, all flow quantities are specified as freestream conditions. At the supersonic outflow boundary, all flow quantities are extrapolated from 
interior grid points. Although full Navier-Stokes (N-S) equations are used, the slip conditions are used to numerically simulate the inviscid flow. A flow tangency or slip boundary condition is implied on solid wall. The wall temperature and pressure are extrapolated from interior grid points. Initial conditions are obtained by specifying free-stream conditions throughout the flow field; the resulting set of equations is marched in time.

The Lax-Wendroff type schemes are inherently unstable and, hence, higher order numerical dissipation terms are often necessary to get a stable solution. For a non-reacting flow field, an artificial viscosity based on temperature and/or pressure is traditionally used, but in chemically reacting flows, in addition to temperature and pressure gradients, there may be strong species concentration gradients. To suppress the numerical oscillations in the induction zone (where the gradients in the concentration of reactants and products are very strong), additional artificial viscosity based on $\mathrm{H}_{2} \mathrm{O}$ mass fraction similar to the one used by Singh et al. [19] is used.

\section{RESULTS AND DISCUSSIONS}

The key parameters for the onset of periodic unsteadiness have been identified as (1) induction time, (2) reaction rate constant, (3) activation energy, (4) heat release and (5) projectile nose radius. In this study we shall be discussing the effect of various nose radii on the stability of the reaction front while keeping the first four parameters constant by choosing a particular reaction model and by fixing the free-stream Mach number.

When a blunt body is moving through a reactive mixture at hypersonic speeds, a bow shock is formed ahead of the body, and the temperature of the fuel-air mixture, after the bow shock, is sufficiently high to initiate the reaction. Once ignition starts, chemical energy is released and another discontinuity known as the reaction front is formed. In the induction zone, temperature and pressure remain relatively constant at the post shock conditions, while the concentrations of radicals build up very rapidly. The flow attains equilibrium due to large residence time in the stagnation zone, while away from the stagnation zone, the flow is in a state of non-equilibrium. 
The numerical simulation is carried out for the free-stream conditions given in Table 1 .

Table 1

Free-stream conditions and different nose radii used

\begin{tabular}{|l|l|l|l|}
\hline $\mathbf{M}_{\infty}$ & $\mathbf{D}_{\mathbf{p}}, \mathrm{mm}$ & $\mathbf{P}_{\infty}, \mathrm{N} / \mathrm{m}^{2}$ & $\mathbf{T}_{\infty}, \mathrm{k}$ \\
\hline 5.11 & i) 15 & $42663.22(320 \mathrm{~mm})$ & 292 \\
& ii) 2.5 & & \\
\hline 6.46 & iii) 15 & $42663.22(320 \mathrm{~mm})$ & 292 \\
& iv) 150 & & \\
& & & \\
& & & \\
& & & \\
\end{tabular}

The premixed fuel oxidizer mixture is taken as $2 \mathrm{H}_{2}+\mathrm{O}_{2}+3.76 \mathrm{~N}_{2}$, and the stoichiometric chemical reaction for the system can be written as

$2 \mathrm{H}_{2}+\mathrm{O}_{2}+3.76 \mathrm{~N}_{2} \rightarrow 2 \mathrm{H}_{2} \mathrm{O}+3.76 \mathrm{~N}_{2}$

Calculations have been carried out for a grid with 197 points in the circumferential direction and 152 points in the normal direction. This grid was chosen based on the earlier work by Ahuja et al. [20] where the flow field was shown to be adequately resolved with this grid. For the present stoichiometric hydrogen-air mixture, the C-J velocity is Mach 5.11. Thus, for the Mach 6.46 case, the projectile speed is significantly above the detonation velocity of the mixture. If the free-stream velocity of the projectile is around the C-J detonation velocity of the mixture, unsteady flow phenomenon can occur. As given in Table 1, we shall be discussing five cases, two cases with Mach 5.11 and projectile diameters of $15 \mathrm{~mm}$ and $2.5 \mathrm{~mm}$, and the remaining three cases with a Mach number of 6.46 and projectile diameters of $15 \mathrm{~mm}, 150 \mathrm{~mm}$, and 225 mm. In all the calculations the residuals dropped by three orders in 12,000 iterations and then remained constant. 


\section{Case (i): Mach 5.11 and projectile diameter of $15 \mathrm{~mm}$}

First the projectile diameter was chosen as $15 \mathrm{~mm}$ for the free-stream Mach number of 5.11. Figure 3 shows the contour plot of temperature, and Fig. 4 shows the contour plot of water mass fraction. The bow shock is very smooth, but the reaction front shows oscillations, which is more clearly seen in the inset enlarged view. The bow shock and the reaction front are separated from each other by the induction distance as is clearly seen in Fig. 5 which is the contour plot of density. The separation is minimum at the stagnation line and increases away from it because of low post-shock temperature away from the stagnation region. A comparison with Fig. 1 shows that all flow features are very well captured. The calculated frequencies of these oscillations [20] were found to be in good agreement with the experimentally observed frequency $[5,21]$.

\section{Case (ii): Mach 5.11 and projectile diameter of $2.5 \mathrm{~mm}$}

Next the diameter of the projectile was reduced to $2.5 \mathrm{~mm}$ while keeping the same free-stream Mach number of 5.11. Other free-stream conditions were also kept the same. Figure 6 shows the temperature contours, and Fig. 7 shows the density contours. Both the shock and the reaction front are very smooth. This is much more clear from the water mass fraction contours shown in Fig. 8 with an inset enlarged view showing smooth reaction front. Thus, reducing the projectile diameter caused the instabilities to disappear.

\section{Case (iii): Mach 6.46 and projectile diameter of $15 \mathrm{~mm}$}

In this case the incoming Mach number was increased to 6.46 , making it a superdetonative case, while keeping the projectile diameter of $15 \mathrm{~mm}$ as in case (i). Figure 9 shows the contour plot of density for Mach 6.46. The bow shock and the reaction front can be clearly seen in the

figure. They are coupled with each other near the stagnation line and up to about 60 degrees from the nose, at which point they start decoupling from each other by the induction distance. 
This occurs because bow shock is almost normal near the stagnation line and the post-shock temperature is maximum. For Mach 6.46, a very small induction distance occurs as a result of the post-shock temperature remaining significantly high up to some distance near the stagnation zone. Away from the stagnation line, the induction distance is increased as a result of decreasing shock strength and post-shock temperature. A comparison with Fig. 2 shows that all the flow features are very well captured. Figure 10 shows the contour plot of temperature. A comparison with Fig. 3 shows that when the Mach number is increased from a C-J Mach number of 5.11 to a superdetonative Mach number of 6.46 , while keeping the same projectile diameter, the instabilities in the reaction front disappear. Thus, for the Mach 6.46 case with projectile diameter of $15 \mathrm{~mm}$, both the bow shock and the reaction front have a smooth profile.

\section{Case (iv): Mach 6.46 and projectile diameter of $150 \mathrm{~mm}$}

Next the projectile diameter was increased to $150 \mathrm{~mm}$ while keeping the same Mach number of 6.46. Figure 11 shows the enlarged view of contour plot of water mass fraction for Mach 6.46 , but with projectile diameter of $150 \mathrm{~mm}$. The figure shows the waviness of the reaction front, indicating that the reaction front is turning towards instability.

\section{Case (v): Mach 6.46 and projectile diameter of $225 \mathrm{~mm}$}

Next, the diameter of the projectile was increased to $225 \mathrm{~mm}$ while keeping the same freestream Mach number of 6.46 as in the previous case. Figure 12 shows the enlarged view of the water mass fraction contours, and the periodic instabilities of the reaction front are clearly evident. Thus, increasing the projectile diameter from $15 \mathrm{~mm}$ to $150 \mathrm{~mm}$ and then to $225 \mathrm{~mm}$, while keeping the same superdetonative Mach number of 6.46 , causes the transition of a stable reaction front to an unstable one. The results of the above five cases have been summarized in Table 2 . 
Table 2

Summary of five test cases

\begin{tabular}{|l|l|l|}
\hline $\mathrm{M}_{\infty}$ & Projectile Diameter & Profile of Reaction Front \\
\hline 5.11 & D & \\
& (i) $15 \mathrm{~mm}$ & Unstable \\
& (ii) $2.5 \mathrm{~mm}$ & Stable \\
\hline 6.46 & (iii) $15 \mathrm{~mm}$ & Stable \\
& (iv) $150 \mathrm{~mm}$ & Slightly Unstable \\
& (v) $225 \mathrm{~mm}$ & Unstable \\
\hline
\end{tabular}

In order to have a clear understanding of the origin and propagation of the instabilities, an $\mathrm{x}-\mathrm{t}$ diagram for water mass fraction on the stagnation streamline between the bow shock and the reaction front is drawn.

Figure 13 shows the $x-t$ plot of water mass fraction along the stagnation line for the Mach 5.11 for a $15 \mathrm{~mm}$ projectile diameter with an overlay of pressure to show the location of shock front. Fig. 14 shows the x-t plot of water mass fraction along the stagnation line for Mach 5.11, but with a projectile diameter of $2.5 \mathrm{~mm}$. In the former case the reaction front clearly shows periodic oscillations, whereas the later case shows a smooth reaction front. The instabilities for Mach numbers lower than the C-J Mach number are due to the ignition delay. What causes these instabilities to disappear for the same Mach number of 5.11 but lower projectile diameter will be explained in subsequent paragraphs. A similar trend which was observed for the superdetonative case of Mach 6.46, where increasing the diameter causes the instabilities to reappear, shall also be discussed. A qualitative study of the frequencies, shock structure, pressure, and stagnation temperature associated with the projectile velocities, shows that the reciprocal frequencies or 
periods of oscillation are equal to the induction time for the ignition of hydrogen-air mixtures.

Many features of the non-steady flow regimes appear to originate from near the stagnation region behind the normal segment of the bow shock. Also, there is clearly a relationship between the periodicity of these flow features and the magnitude of the chemical induction time. The appearance and disappearance of these instabilities with various nose diameters have been explained with a wave interaction model as proposed by McVey and Toong [9]. Figure 15 shows a schematic $x-t$ diagram for the wave interaction model for Mach 5.11 and with projectile diameters of $15 \mathrm{~mm}$ and $2.5 \mathrm{~mm}$. For the diameter of $15 \mathrm{~mm}$, the beginning of the cycle is shown at a time when the overtaking of the bow shock by a compression wave in the induction zone takes place. Since chemical induction time is exponentially dependent on the gas temperature, the contact discontinuity $\left(\mathrm{DC}_{1}\right)$ generated when the incident compression wave overtakes the bow shock has an important effect on the location of a reaction front. Exothermic reaction takes place on the upstream side of the contact discontinuity $\left(\mathrm{DC}_{1}\right)$ before beginning on the downstream side due to the difference in the gas temperature on the upstream and downstream sides of the contact discontinuity. It is this beginning of exothermic reaction on only one side of the contact discontinuity which constitutes the formation of a new reaction front. The ratio of chemical induction time across the discontinuity is a measure of where the new reaction front will be located relative to the original reaction front. Since the gases are hot on the upstream side of the contact discontinuity, they begin to react, generating compression waves which propagate upstream and downstream. This is shown in the figure by $\left(\mathrm{CW}_{2}\right)$ and $\left(\mathrm{CW}_{3}\right)$. At a somewhat later time, the contact discontinuity reaches the position of the original reaction front, extinguishing the reaction at this front and generating rarefaction waves $\left(R W_{1}\right)$ and $\left(R W_{2}\right)$. The upstreamfacing compression wave $\left(\mathrm{CW}_{2}\right)$ eventually overtakes the bow shock and thus results in the generation of another contact discontinuity $\left(\mathrm{DC}_{2}\right)$. Presence of both rarefaction and compression waves in the induction zone makes it possible for a periodic wave interaction process.

It is clear from the above discussion that a compression wave moving towards the bow shock 
is overtaken by a rarefaction wave in each cycle of the wave-interaction process. During this process the compression wave gets attenuated by a rarefaction wave. If $M_{s 1}$ is the Mach number of the incident compression wave $\left(\mathrm{CW}_{1}\right)$ or weak shock, then $\left(\mathrm{M}_{\mathrm{s}}\right)_{\max }$ is generally of the order of 1.01. A wave interaction process cannot be initiated by an unattenuated compression wave since the Mach number $\left(M_{s 1}\right)$ of such a wave is much greater than $\left(M_{s 1}\right)_{\max }$. On the other hand, if a sufficiently weak compression wave does initiate the wave interaction process, the attenuation of the first and each subsequent compression wave by a rarefaction wave must be sustained in order that the Mach number of each reaction shock, which finally overtakes the bow shock, be less than $\left(\mathrm{M}_{\mathrm{s} 1}\right)_{\max }$. When this condition is satisfied, then only the cyclic process is feasible. The validation of this phenomena with a shock-fitting method shall be presented in future studies.

The importance of a compression wave reflecting off the projectile nose has not been clarified in the McVey and Toong model. The compression wave which travels towards the projectile reflects from it and finally overtakes the bow shock. This overtaking of the bow shock by the reflected compression wave from the projectile takes place almost at the same time that a newly formed compression wave from the new reaction front has overtaken the bow shock. Consequently, this contributes to strengthening the compression wave coming from the reaction front.

Thus, when we compare the unstable Mach 5.11 case with a projectile diameter of $15 \mathrm{~mm}$ with the stable case of a projectile diameter of $2.5 \mathrm{~mm}$, it is clear that the $15 \mathrm{~mm}$ diameter case has greater shock stand-off distance than that with a diameter of $2.5 \mathrm{~mm}$. Thus, the reflected compression wave from the projectile nose coming back to overtake the bow shock to strengthen the compression wave originating at the reaction front, would have become quite weak. This is because it undergoes a large number of interactions with other compression waves between the reaction front and the projectile nose. As shown in the figure, the strength of the shock $P_{5} / P_{3}$ is less than the strength of the original reflected shock which is $P_{2} / P_{1}$. Now, if the shock standoff distance is larger, the reflected compression wave would encounter a greater number 
of interactions, and with every interaction, its strength would decrease. Although this reflected compression wave strengthens the compression wave originating at the reaction front, the $M_{S}$ is still less than $\left(\mathrm{M}_{\mathrm{s} 1}\right)_{\max }$ and, therefore, the periodic instabilities are sustained. On the other hand, when the projectile diameter is $2.5 \mathrm{~mm}$, the reflected compression wave has to travel a very short distance before it reaches the reaction front to strengthen the compression wave originating there. Moreover, because of the short shock stand-off distance, it does not encounter many interactions with other compression waves. Although $\mathrm{P}_{3} / \mathrm{P}_{2}$ of the reflected wave is less than $\mathrm{P}_{2} / \mathrm{P}_{1}$ of the compression wave reaching the projectile, it is still very strong by the time it reaches the reaction front. Thus, when it overtakes the bow shock, it strengthens the compression wave much more than the preceeding $15 \mathrm{~mm}$ diameter case. This causes $\mathrm{M}_{\mathrm{s}}$ of the compression wave to be much greater than $\left(\mathrm{M}_{\mathrm{s} 1}\right)_{\max }$, and this leads to unattenuated compression waves and, hence, periodicity disappears.

Again, when referring to the Mach 6.46 case with a projectile diameter of $15 \mathrm{~mm}$, a stable reaction front is observed, whereas increasing the diameter to $225 \mathrm{~mm}$ causes the instabilities to reappear. For the $225 \mathrm{~mm}$ case where the shock stand-off distance is much higher than the $15 \mathrm{~mm}$ case, the shock wave reflected off the projectile body becomes much weaker before strengthening the compression wave generated at the new reaction front. Thus, the compression wave generated at the new reaction front has $M_{S}$ less than $\left(M_{s 1}\right)_{\max }$ and, therefore, a cyclic process is sustained. On the other hand, for the projectile diameter of $15 \mathrm{~mm}$ where the shock stand-off distance is much smaller, the reflected compression wave from the projectile body strengthens the compression wave generated at the new reaction front much more and, therefore, leads to unattenuated compression waves. Consequently, the cyclic process for the $15 \mathrm{~mm}$ diameter and Mach 6.46 case cannot be sustained. 


\section{CONCLUSIONS}

Numerical studies with different projectile diameters and Mach numbers indicate that Chapman-Jouget velocity is not the only parameter for triggering the instabilities. The other

parameters are induction time, reaction rate constant, projectile diameter, activation energy and heat release. The reason for the appearance and disappearance of instabilities could be attributed to attenuated or unattenuated compression waves which depend upon the strength of the reflected compression wave from projectile body, the strength of which in turn depends upon the shock stand-off distance and, hence, the projectile diameter. Thus, it is concluded that a subdetonative case can also lead to a stable reaction front by having an appropriate small diameter projectile, and a superdetonative case can also lead to an unstable reaction front by having a larger diameter projectile.

\section{REFERENCES}

1. Cambier, J. L. and Adelman H., "Numerical Simulations of an Oblique Detonation Wave Engine," AIAA Paper 88-0063, January 1988.

2. White, M. E., Drummond, J. P., and Kumar, Ajay, "Evolution and Status of CFD Techniques for Scramjet Applications," AIAA Paper 86-0160, January 1986.

3. Atamanchuk, T. and Sislian J., "On-And-Off Design Performance Analysis of Hypersonic Detonation Wave Ramjets," AIAA Paper 90-2473, July 1990.

4. Zeldovich, Y. B., and Shlyapintokh, I. Y., "Ignition of Explosive Gaseous Mixtures in Shock Waves," Office of Technical Services, U. S. Department of Commerce, Washington, DC, OTS: $50-41,553,1960$.

5. Lehr, H. F., "Experiments on Shock-Induced Combustion," Acta Astronautica, Vol. 17, September 1972, pp. 589-586.

6. Ruegg, F. W. and Dorsey, W. W., "A Missile Technique for the Study of Detonation Waves," Journal of Research, Bureau of Standards, Vol. 66c, No. 1, January-March 1962, pp. $51-58$. 
7. Behrens, H., Struth, W., and Wecken F., "Studies of Hypervelocity Firings into Mixtures of Hydrogen with Air or with Oxygen," Tenth Symposium (International) on Combustion, 1965, pp. $245-252$.

8. Chernyi, G. G., "Supersonic Flow Past Bodies with Formation of Detonation and Combustion Fronts," Astro Acta, Vol. 13, 1968, pp. 467.

9. McVey, J. B. and Toong, T. Y., "Mechanism of Instabilities of Exothermic Hypersonic Blunt-Body Flows," Combustion Science and Technology, Vol. 3, 1971, pp. 63-76.

10. Alpert, L. R. and Toong, T. Y., "Periodicity in Exothermic Hypersonic Flows about Blunt Projectiles," Acta Astronautica, Vol. 17, September 1972, pp. 539-560.

11. Yungster, S., Eberhardt, S., and Bruckner, A. P., "Numerical Simulation of ShockInduced Combustion by High-Speed Projectiles in Detonable Gas Mixtures," AIAA Paper 89-0673, July 1989.

12. Lee, S. and Deiwert, G. S., "Calculation of Non-Equilibrium Hydrogen-Air Reaction with Implicit Flux Vector Splitting Method," AIAA Paper 89-1700, 1989.

13. Wilson, G. J. and MacCormack R. W., "Modelling Supersonic Combustion Using a Fully-Implicit Numerical Method," AIAA Paper 90-2307, July 1990.

14. Sussman, A. M. and Wilson, G. J., "Computation of Chemically Reacting Flow using a Logarithmic form of the Species Conservation Equations," Proceedings of Fourth International Conference on Numerical Combustion, Tampa, FL, December 2-4, 1991, pp. 224-227.

15. Matsuo, A. and Fujiwara T., "Numerical Simulations of Shock-Induced Combustion around an Axisymmetric Blunt Body," ALAA Paper 91-1414, June 1991.

16. Drummond, J. P., Rogers, R. C., and Hussaini, M. Y., "A Detailed Numerical Model of a Supersonic Reacting Mixing Layer," AIAA Paper 86-1427, June 1986.

17. Jachimowski, C. J., "An Analytical Study of the Hydrogen-Air Reaction Mechanism with Application to Scramjet Combustion," NASA TP-2791, 1988. 
18. MacCormack, R. W., "The Effect of Viscosity in Hypervelocity Impact Cratering," AIAA Paper 69-354, April-May 1969.

19. Singh, D. J., Carpenter, M. H., and Kumar, A., "Numerical Simulation of Shock-Induced Combustion/Detonation in a Premixed $\mathrm{H}_{2}$-Air Mixture Using Navier-Stokes Equations," AIAA Paper 91-3358, June 1991.

20. Ahuja, J. K., Tiwari, S. N., and Singh, D. J., "Investigation of Hypersonic Shock-Induced Combustion in a Hydrogen-Air System," AIAA Paper 92-0339, January 1992.

21. Anonymous, Rapport-Bericht CO 7/73, Institut Franco-Allenmand De Recherches De Saint-Louis, Kolloquium Uber Gasdetonationen, obgehalten im ISL am 22.10.1973, ISLBeitrage. 


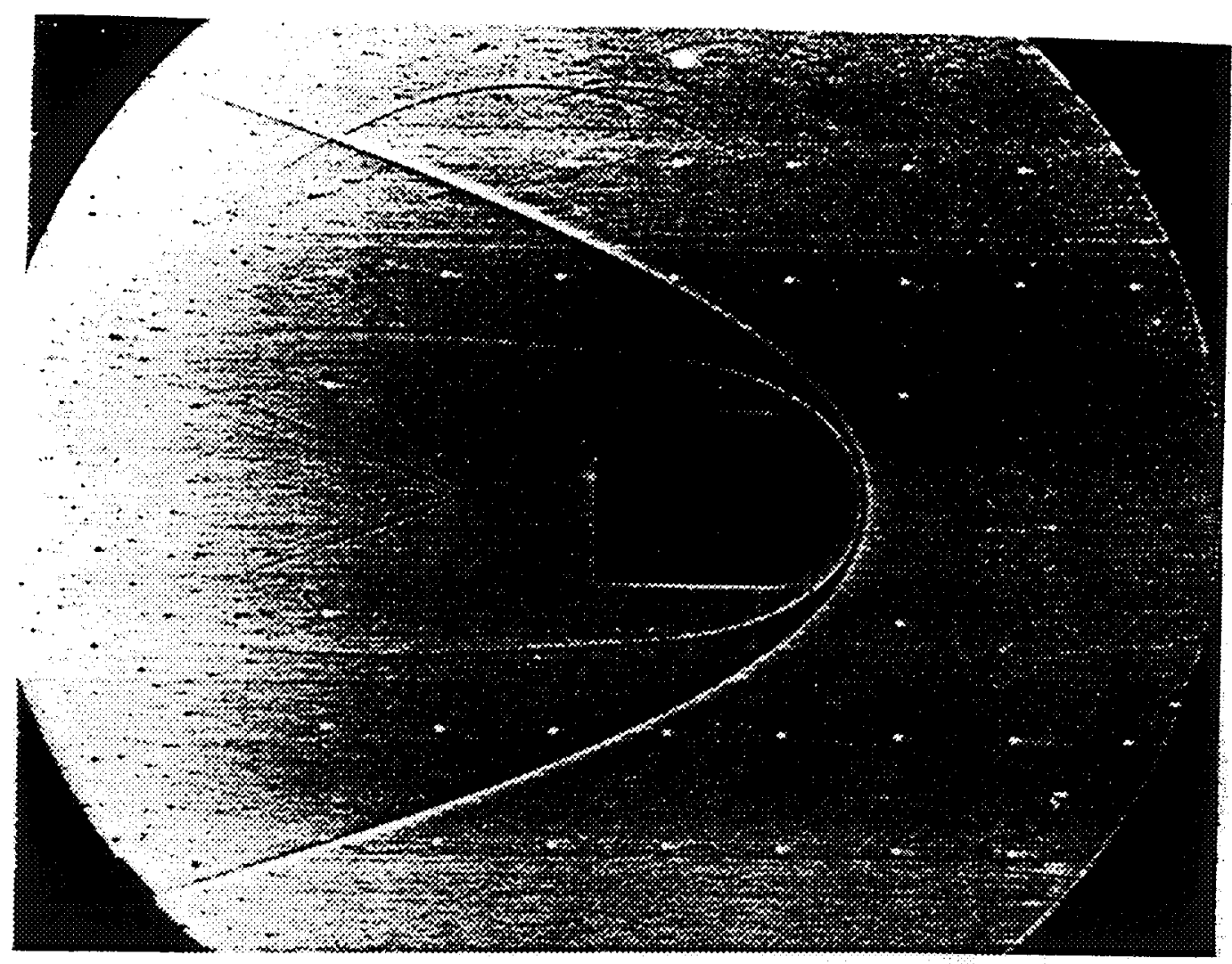

Figure 1 Shadowgraph of a spherical nose projectile moving at Mach 5.11 into a premixed stoichiometric hydrogen-air mixture.

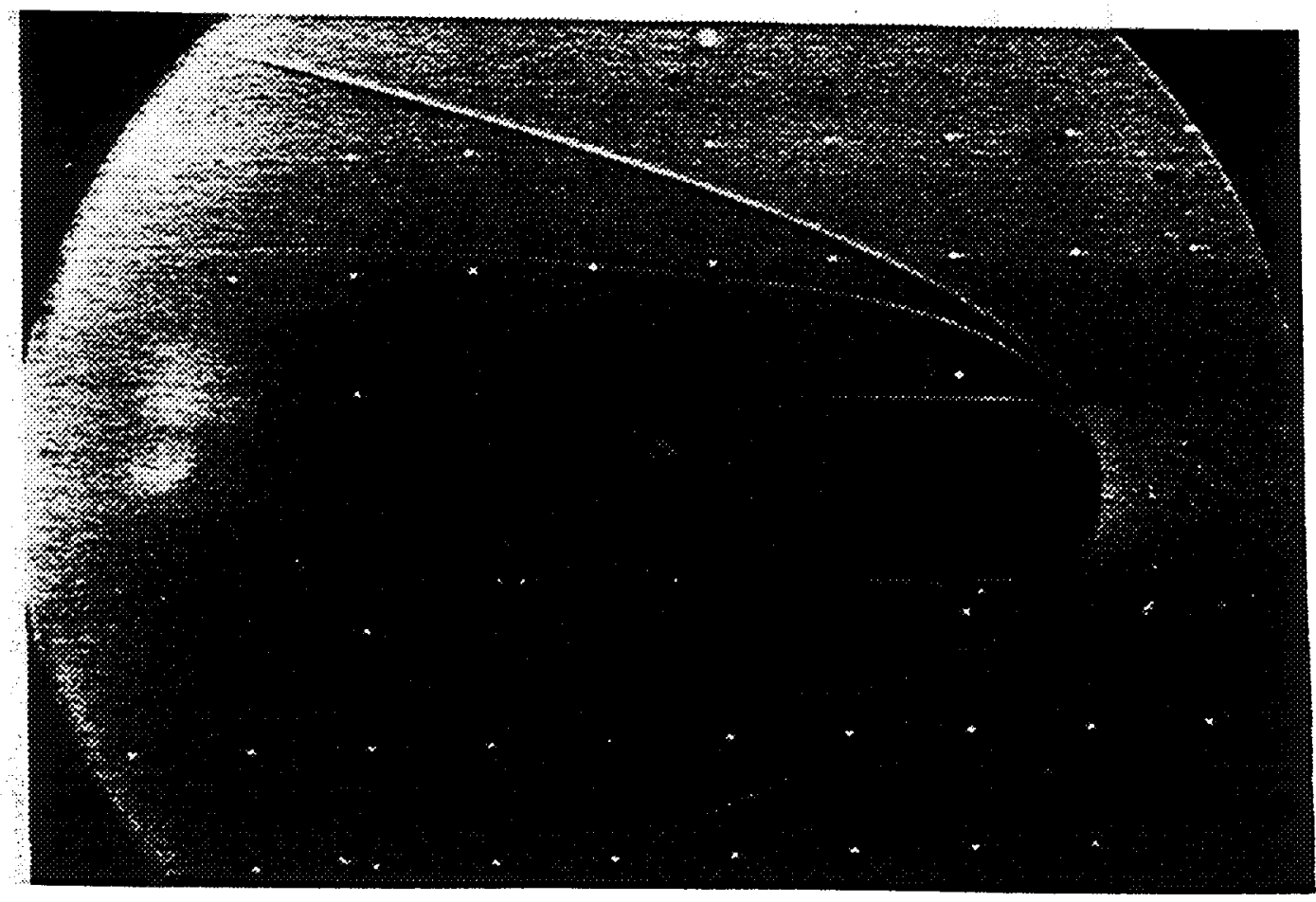

Figure 2 Shadowgraph of a spherical nose projectile moving at Mach 6.46 into a premixed stoichiometric hydrogen-air mixture. 


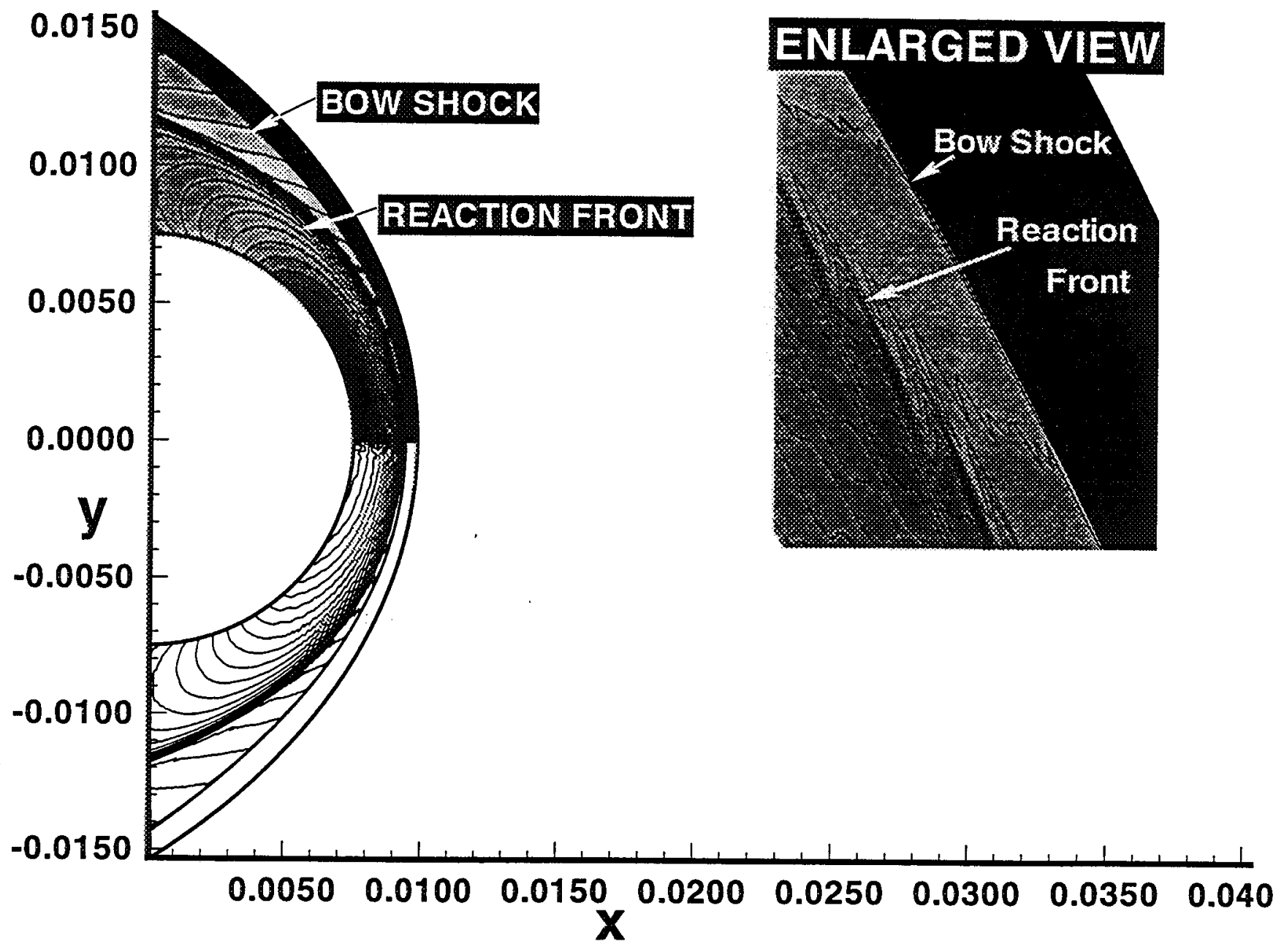

Figure 3 Contour plot of temperature for Mach 5.11 and projectile diameter $15 \mathrm{~mm}$. 


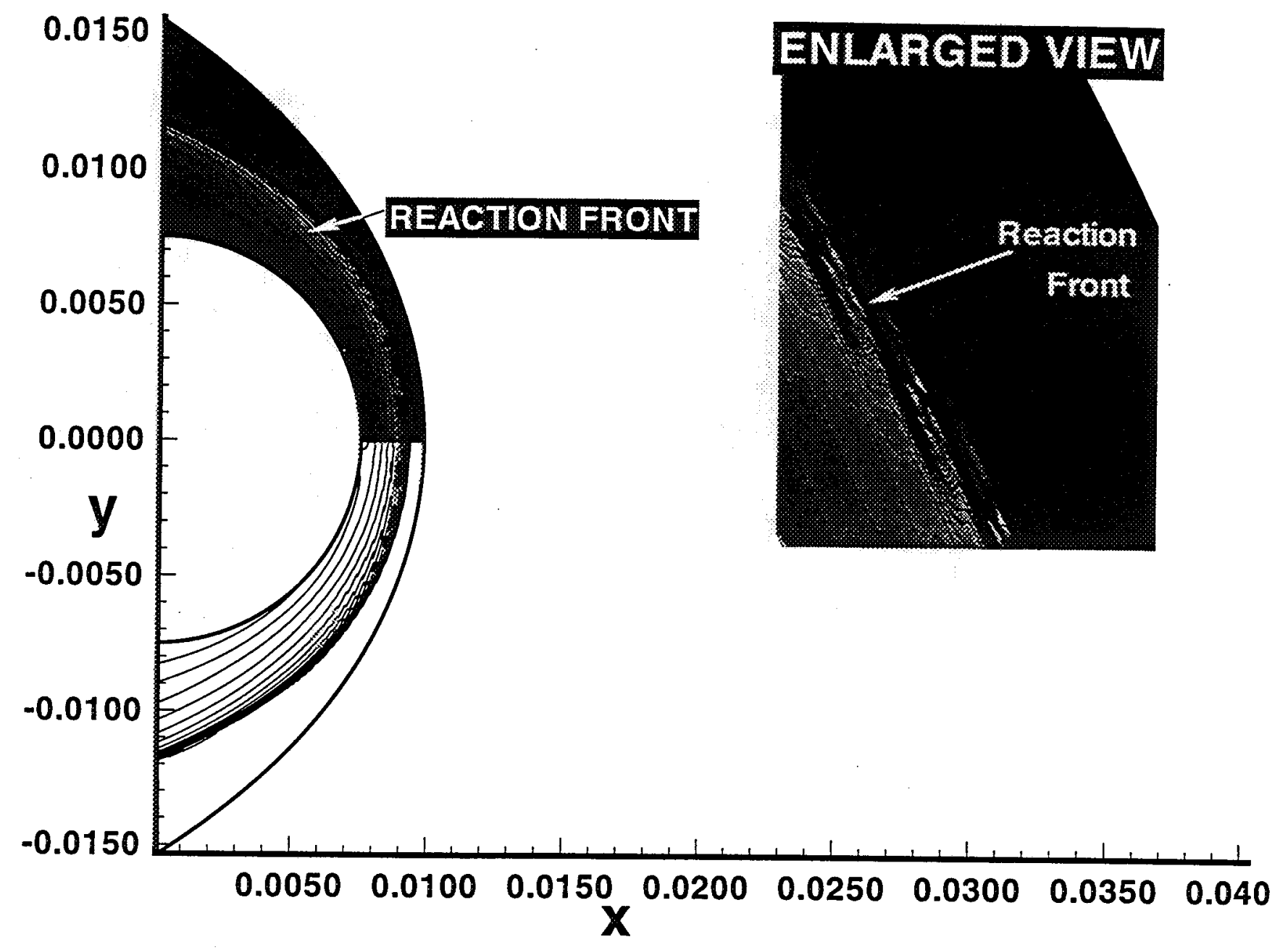

Figure 4 Contour plot of water mass fraction for Mach 5.11 and projectile diameter $15 \mathrm{~mm}$. 


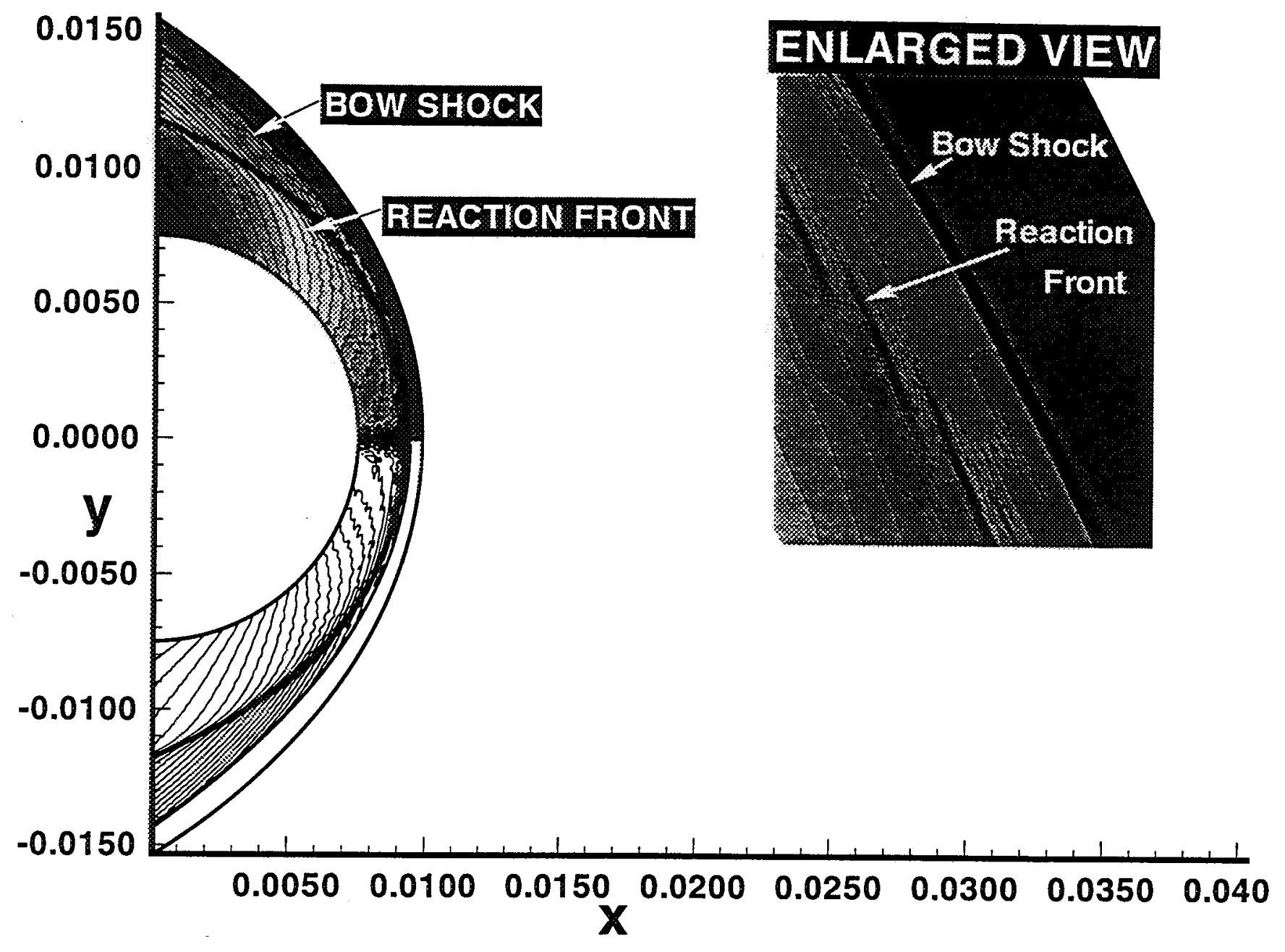

Figure 5 Contour plot of density for Mach 5.11 and projectile diameter $15 \mathrm{~mm}$. 


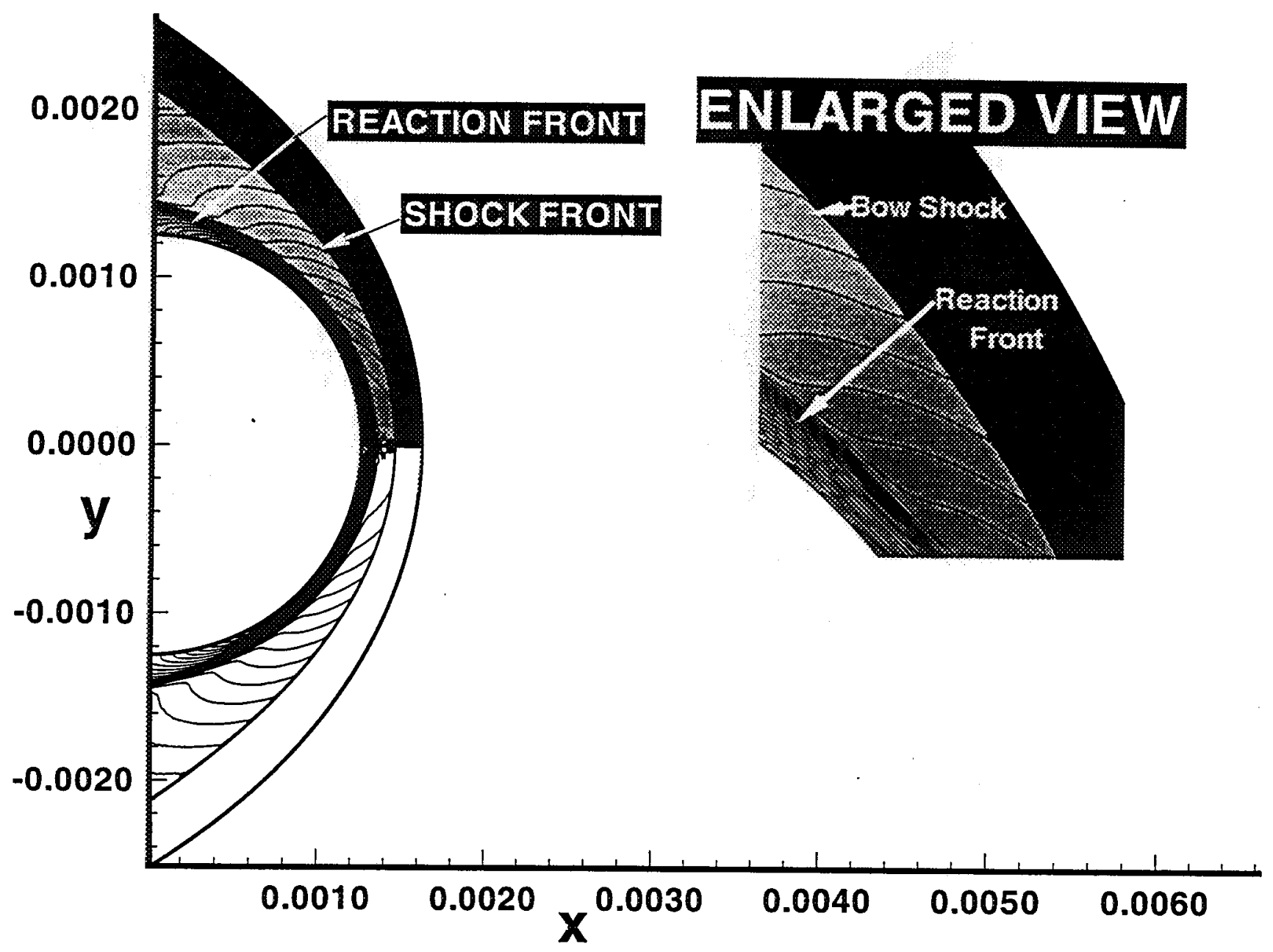

Figure 6 Contour plot of temperature for Mach 5.11 and projectile diameter $2.5 \mathrm{~mm}$. 


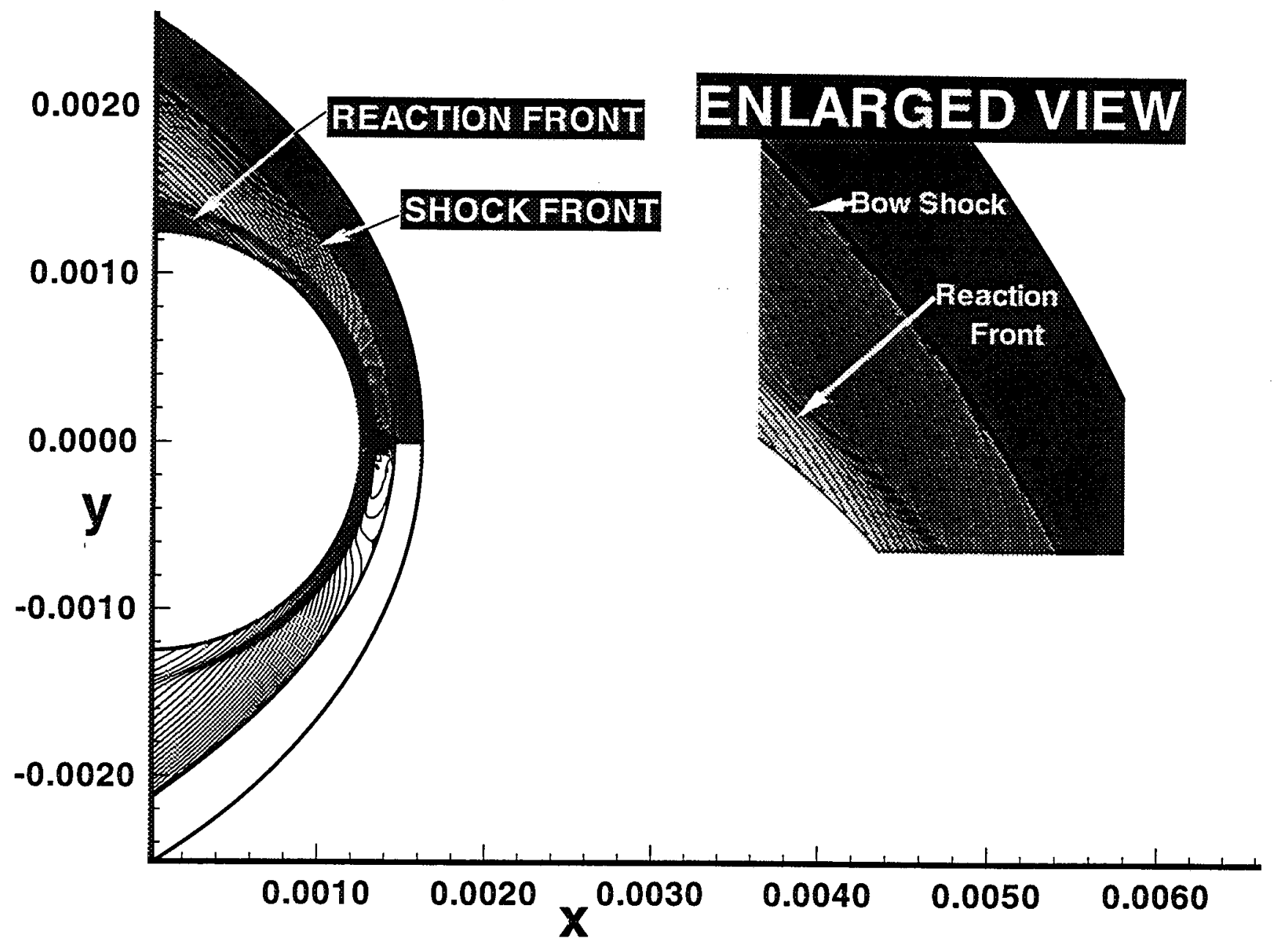

Figure 7 Contour plot of density for Mach 5.11 and projectile diameter $2.5 \mathrm{~mm}$. 


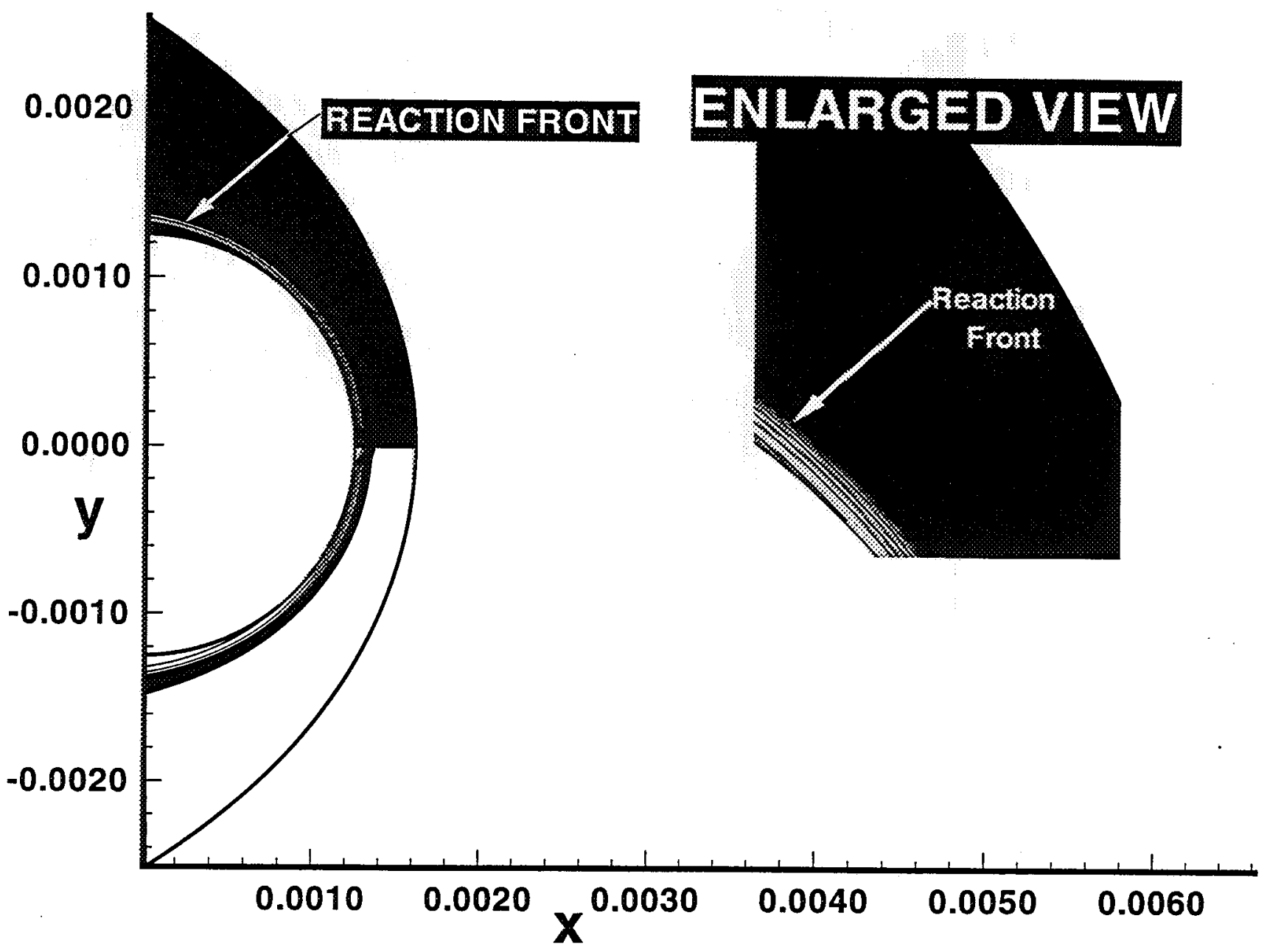

Figure 8 Contour plot of water mass fraction for Mach 5.11 and projectile diameter $2.5 \mathrm{~mm}$. 


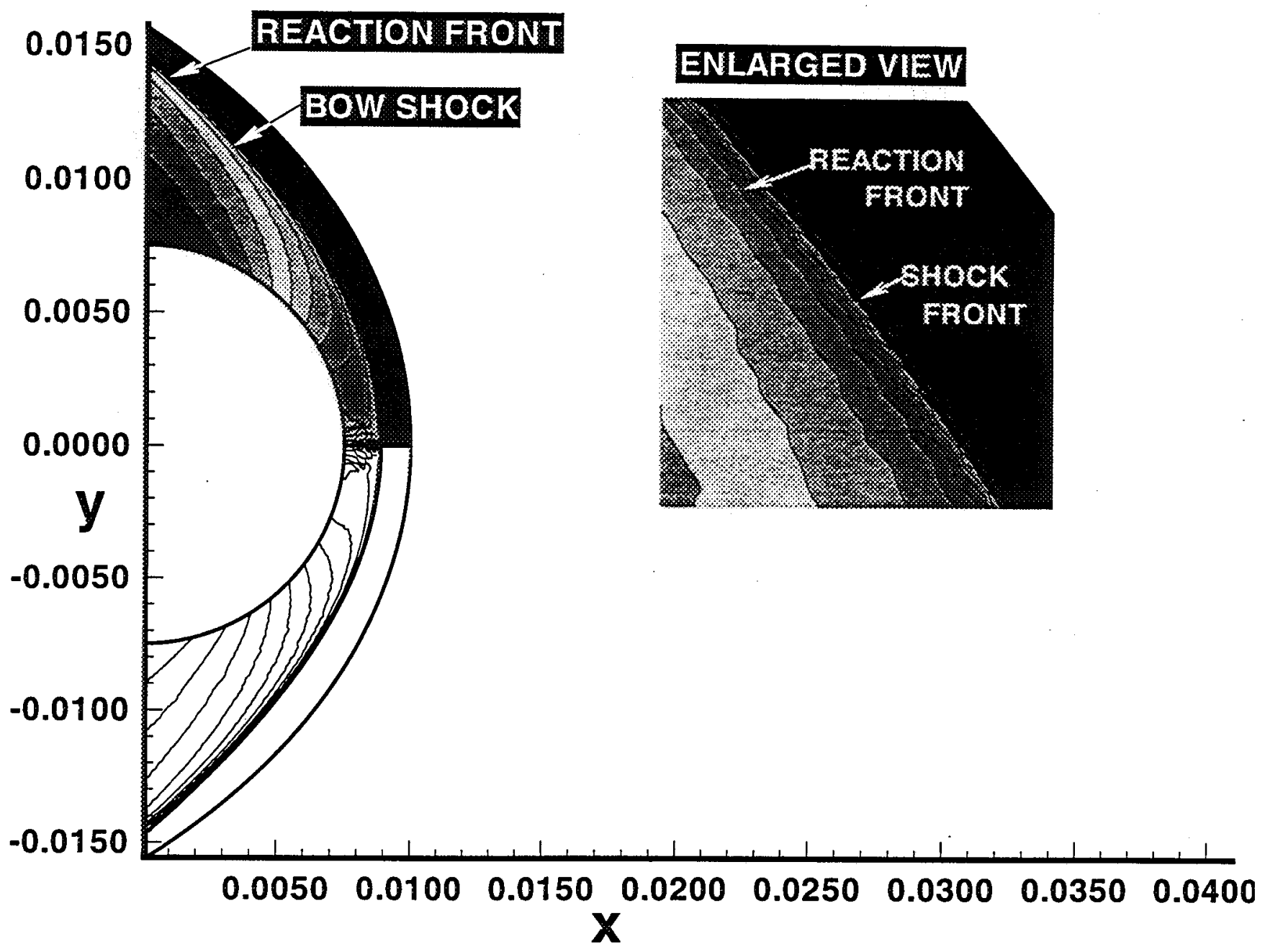

Figure 9 Contour plot of density for Mach 6.46 and projectile diameter $15 \mathrm{~mm}$. 


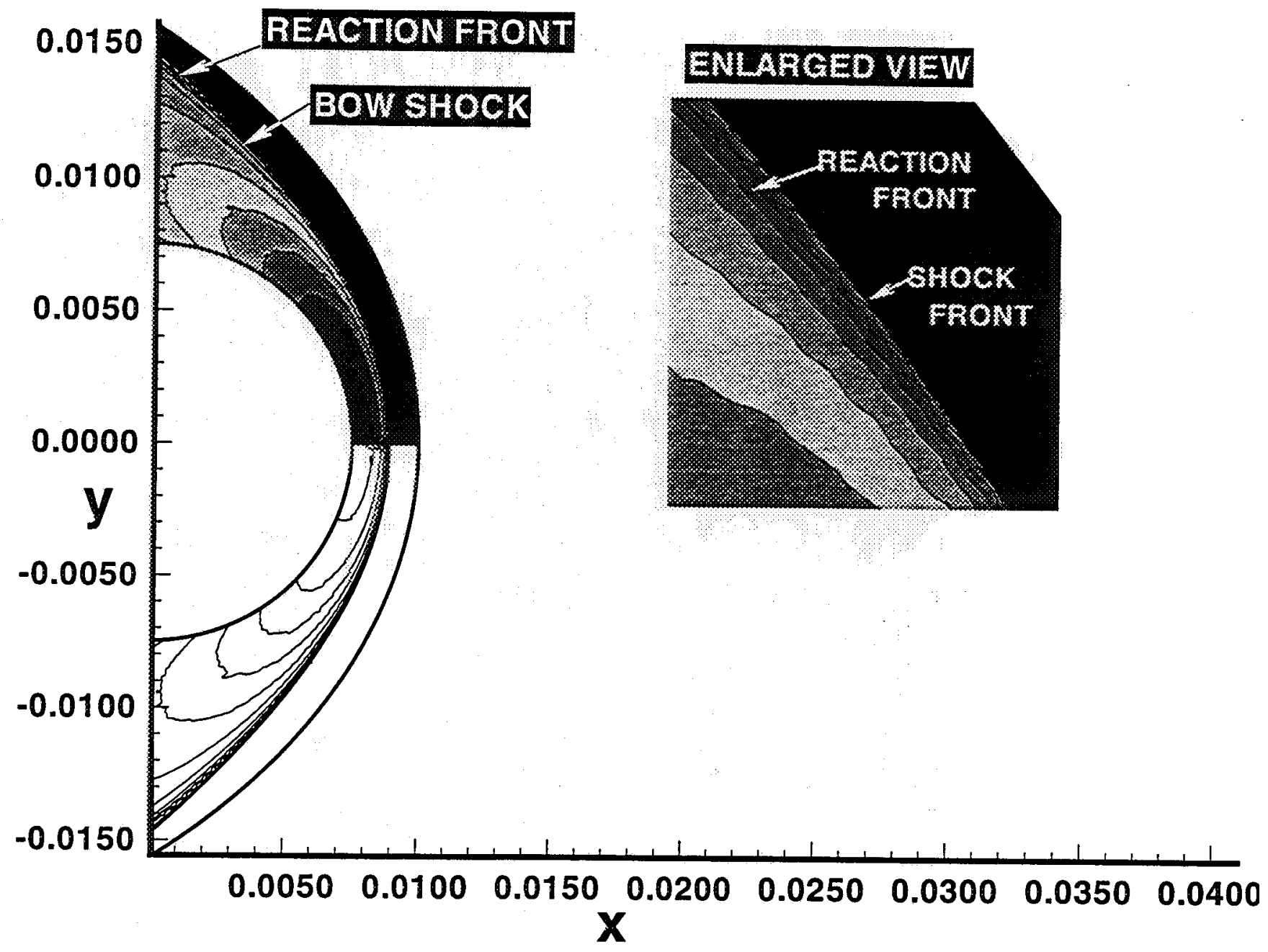

Figure 10 Contour plot of temperature for Mach 6.46 and projectile diameter $15 \mathrm{~mm}$. 


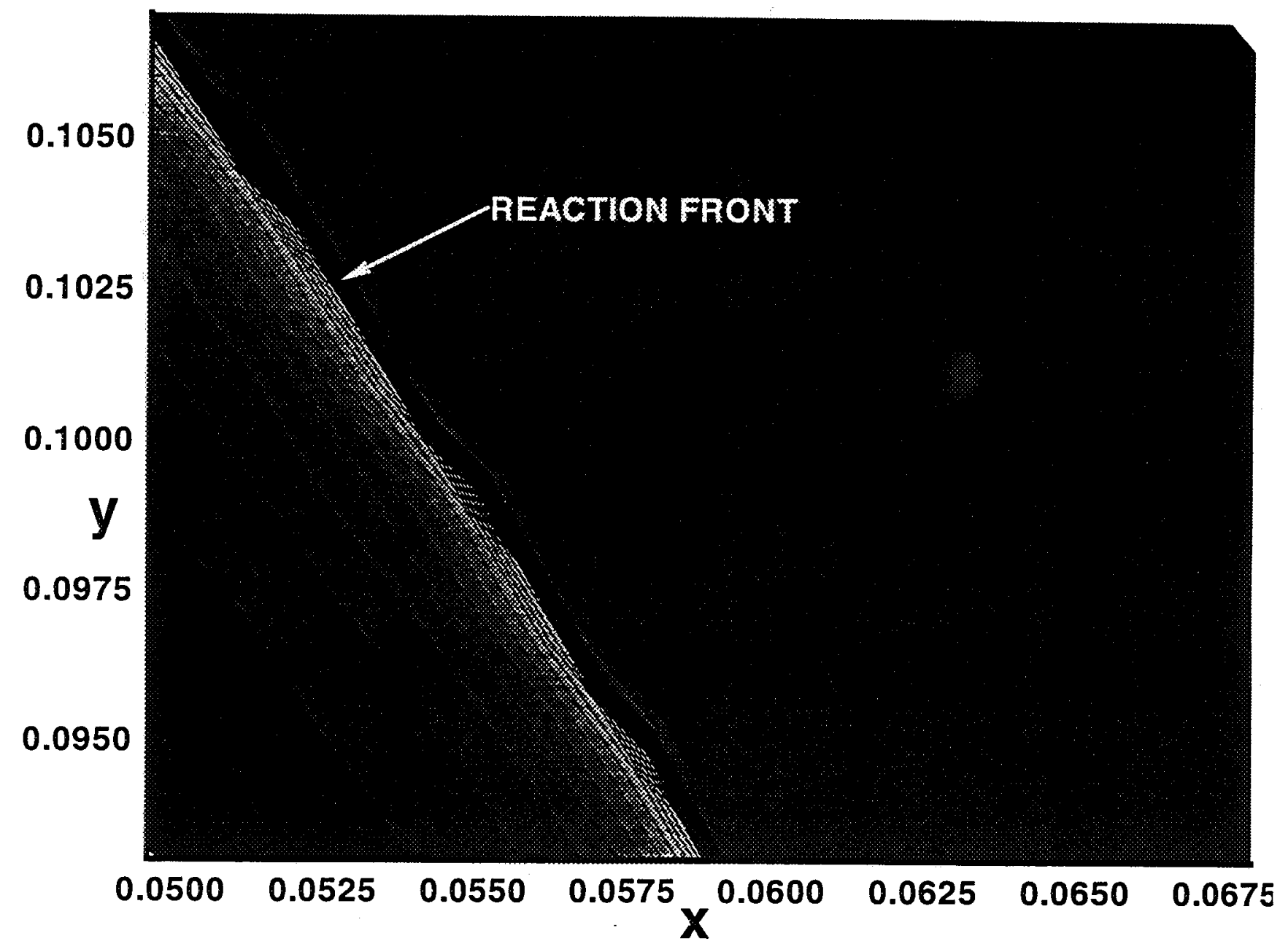

Figure 11 Enlarged view of contour plot of water mass fraction for Mach 6.46 and projectile diameter $150 \mathrm{~mm}$. 


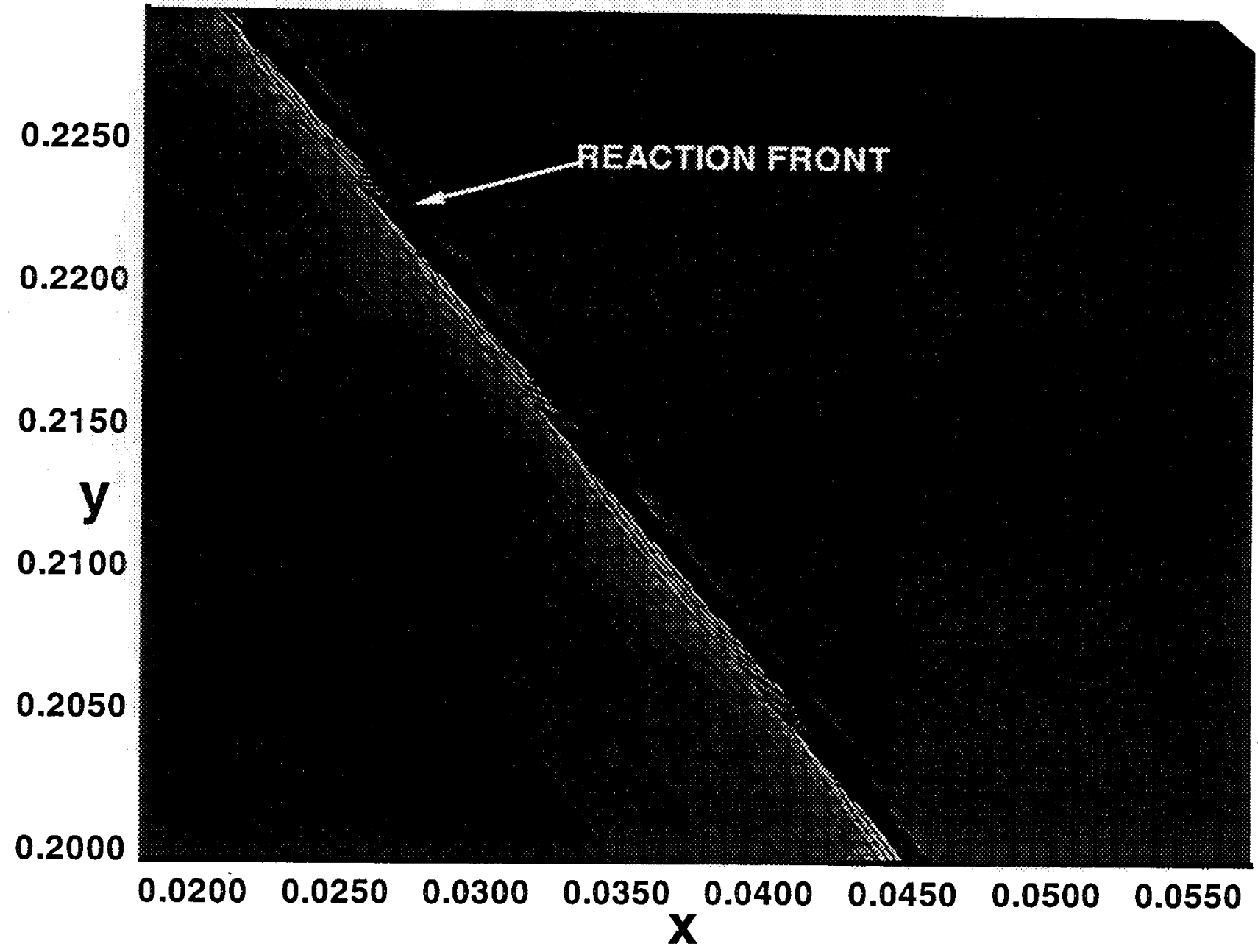

Figure 12 Enlarged view of contour plot of water mass fraction for Mach 6.46 and projectile diameter $225 \mathrm{~mm}$. 


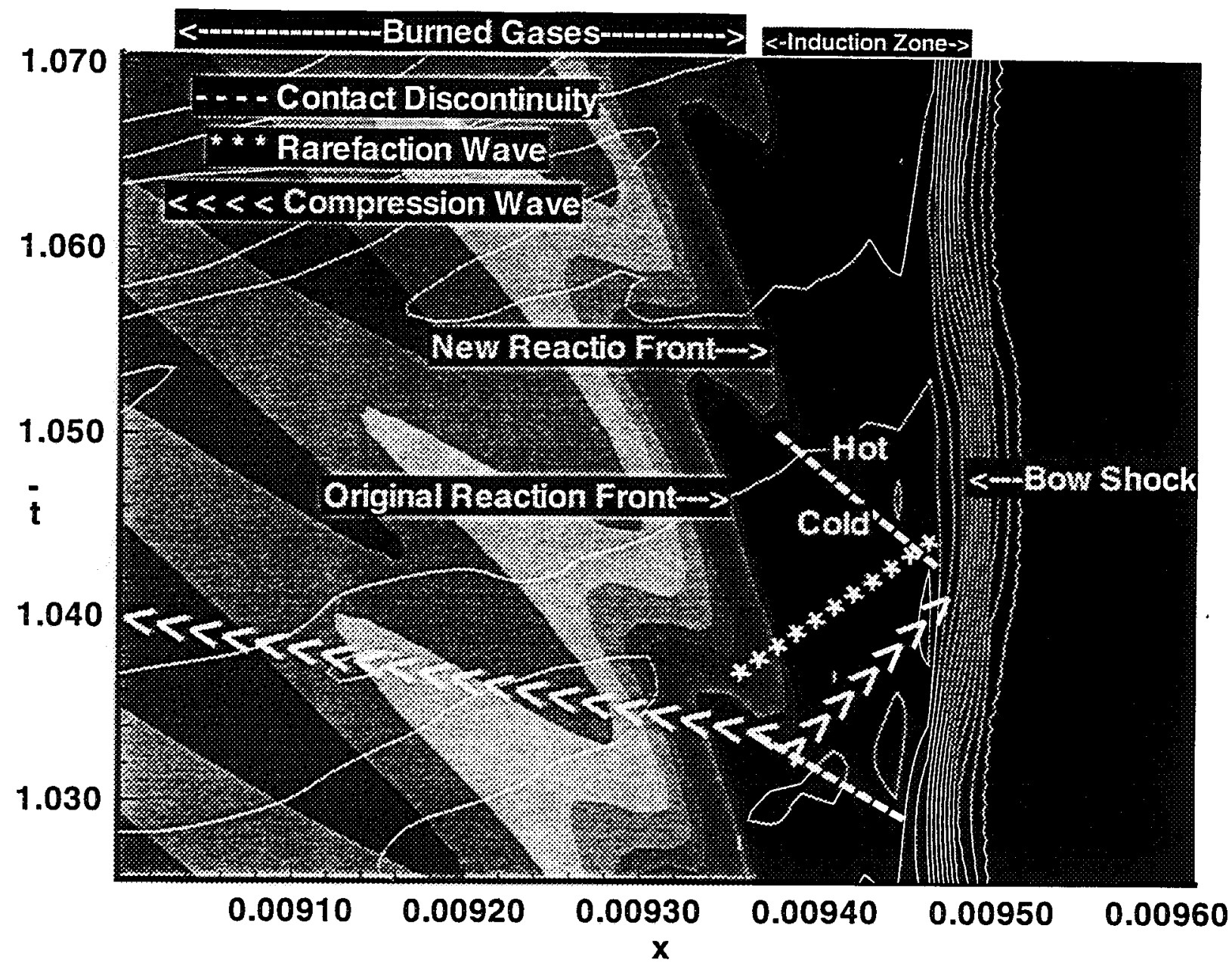

Figure $13 \mathrm{x}$-t Plot of water mass fraction along stagnation streamline for Mach 5.11 and Projectile diameter $15 \mathrm{~mm}$ 


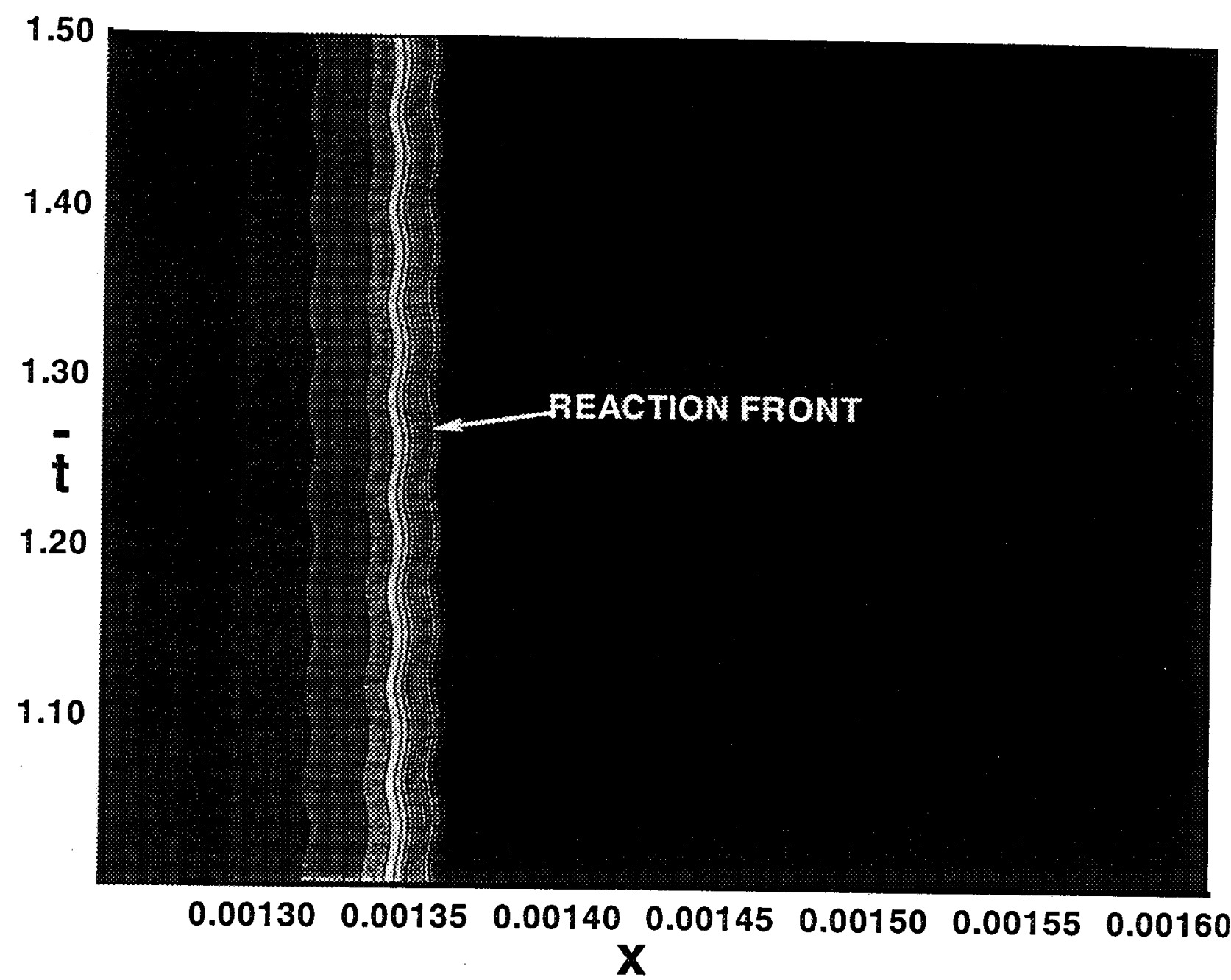

Figure $14 \mathrm{x}$-t Plot of water mass fraction along stagnation streamline for Mach 5.11 and Projectile diameter $2.5 \mathrm{~mm}$ 

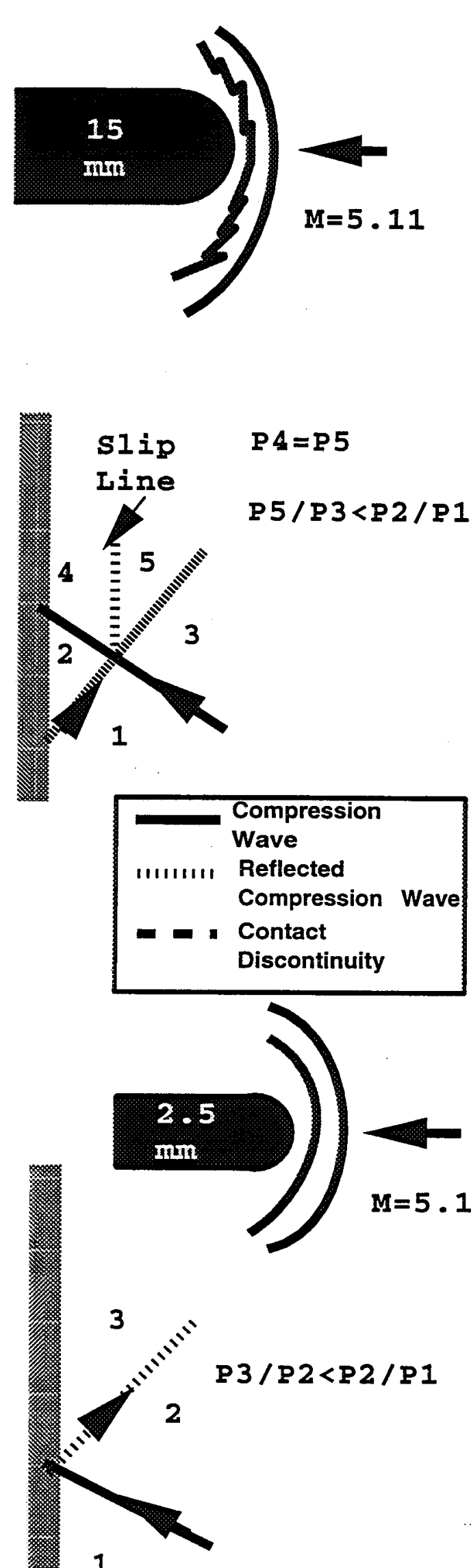

1

\section{$t$}

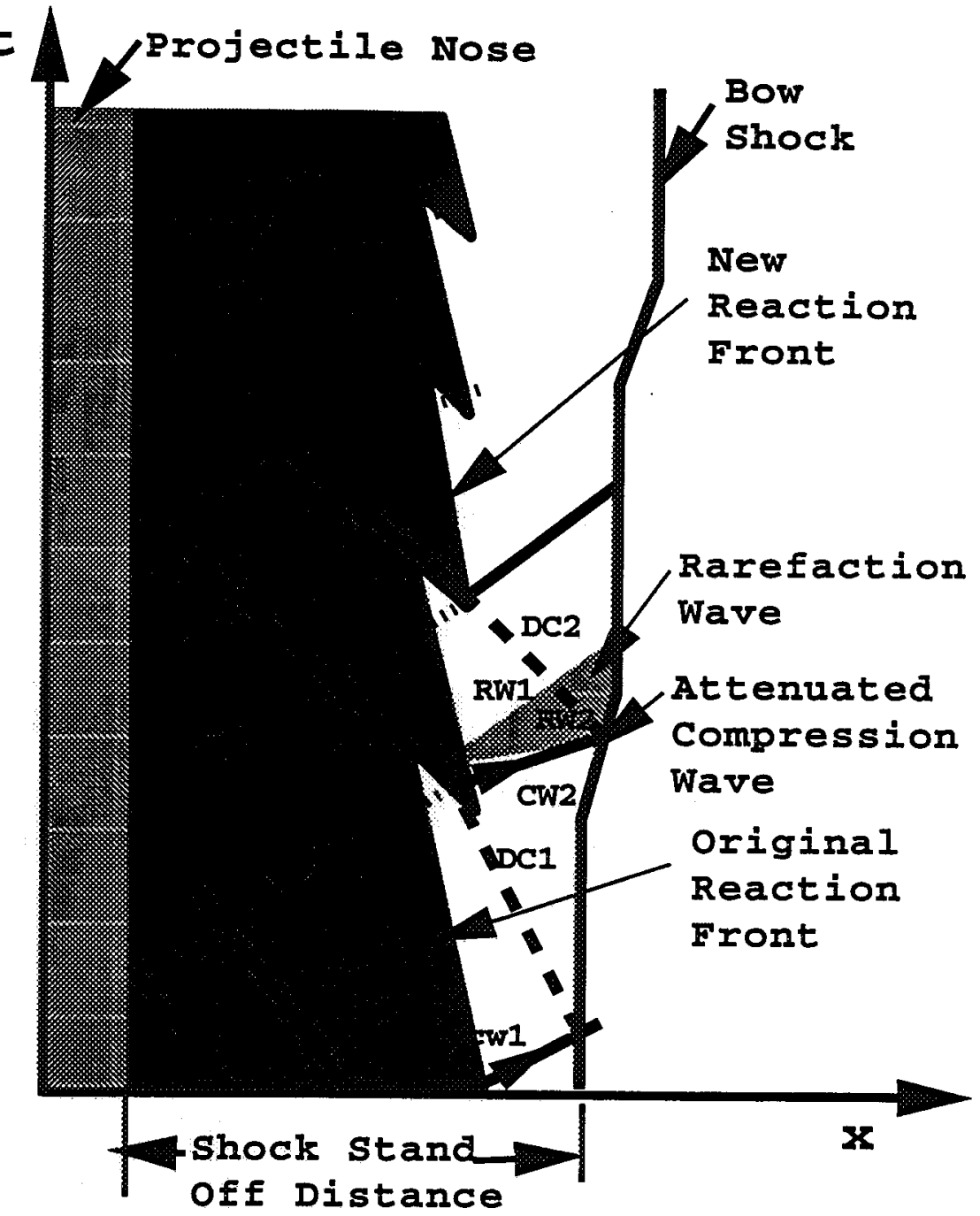

$t$

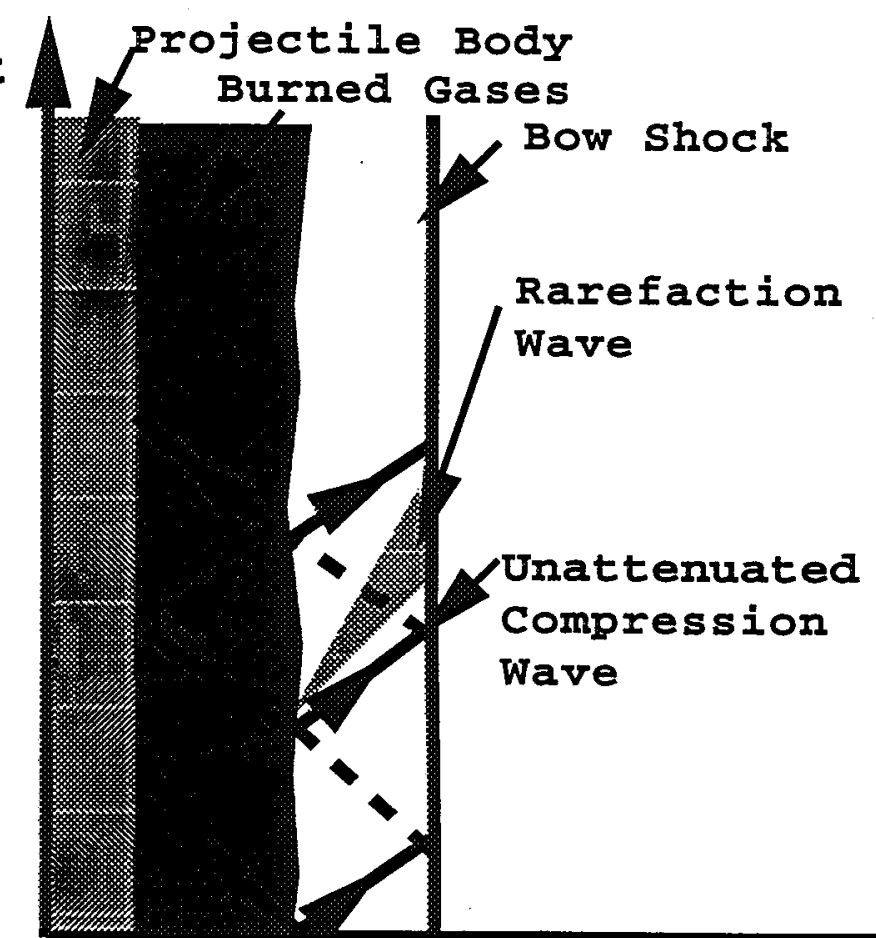

Figure $15 \mathrm{x}$-t Plot of wave-interaction model 


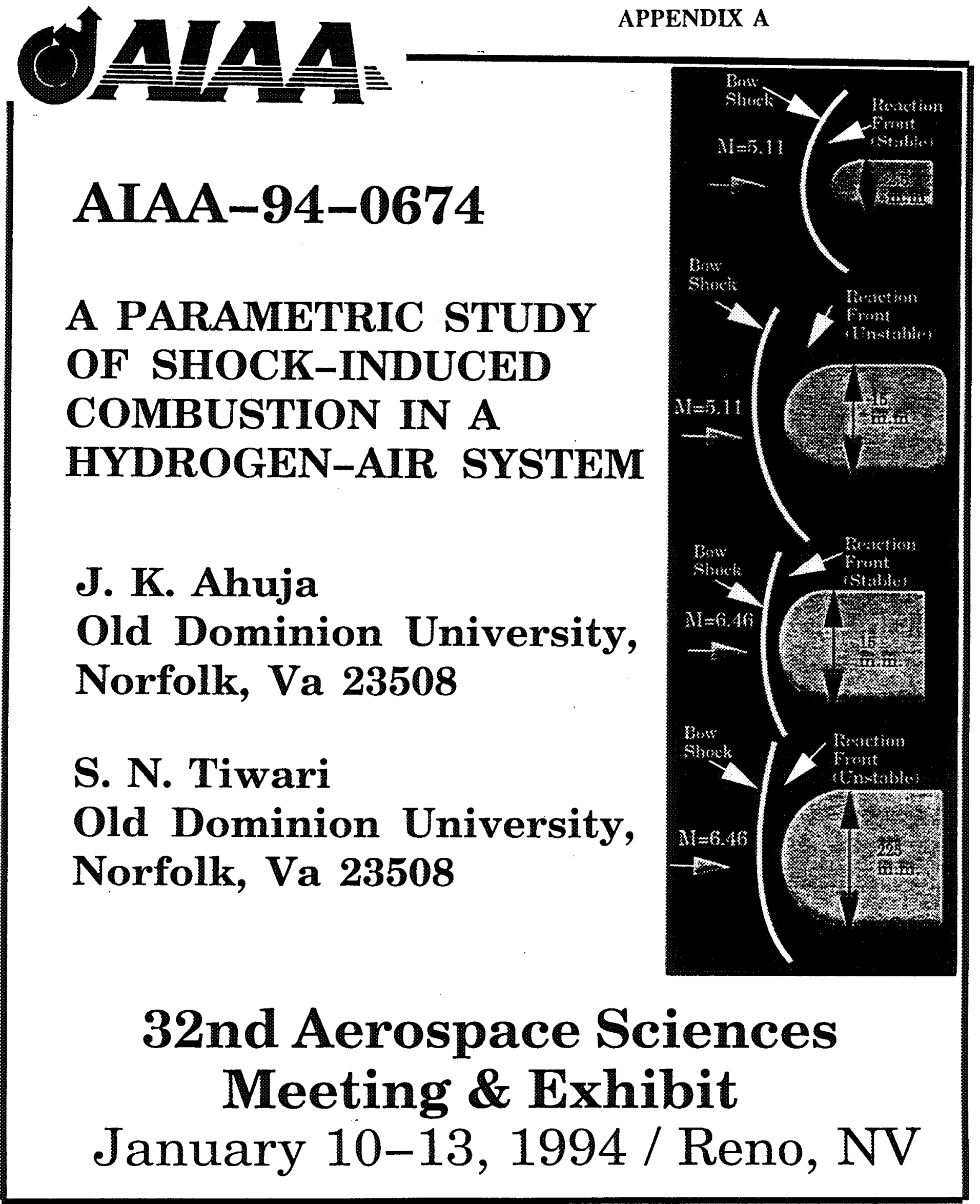

For permission to copy or republish, contact the American Institute of Aeronautics and Astronautics 370 L'Enfant Promenade, S.W., Washington, D.C. 20024 


\title{
A PARAMETRIC STUDY OF SHOCK-INDUCED COMBUSTION IN A HYDROGEN-AIR SYSTEM
}

\author{
J. K. Ahuja* and S. N. Tiwari ${ }^{\dagger}$ \\ Old Dominion University \\ Norfolk, VA 23529
}

\begin{abstract}
A numerical parametric study is conducted to simulate shock-induced combustion under various freestream conditions and varying blunt body diameter. A steady combustion front is established if the free-stream Mach number is above the Chapman-Jouguet speed of the mixture, whereas an unsteady reaction front is established if the free-stream Mach number is below or at the Chapman-Jouguet speed of the mixture. The above two cases have been simulated for Mach 5.11 and Mach 6.46 with a projectile diameter of $15 \mathrm{~mm}$. Mach 5.11, which is an underdriven case, shows an unsteady reaction front, whereas Mach 6.46, which is an overdriven case, shows a steady reaction front. Next for Mach 5.11 , reducing the diameter to $2.5 \mathrm{~mm}$ causes the instabilities to disappear, whereas for Mach 6.46, increasing the diameter of the projectile to $225 \mathrm{~mm}$ causes the instabilities to reappear, indicating that ChapmanJouguet speed is not the only deciding factor for these instabilities to trigger. The other key parameters are the projectile diameter, induction time, activation energy and the heat release. The appearance and disappaerance of the instabilities have been explained by the one-dimensional wave interaction model.
\end{abstract}

\section{NOMENCLATURE}

$A_{j} \quad$ reaction rate constant for the $j^{\text {th }}$ reaction

$\mathrm{C}_{i} \quad$ concentration of $i^{\text {th }}$ species

$\mathrm{C}_{\mathrm{pi}}$ constant pressure specific heat of $\mathrm{i}^{\text {th }}$ species

$D_{i j} \quad$ binary diffusion coefficient of $i^{\text {th }}$ and $j^{\text {th }}$ species

$\mathrm{D}_{\mathrm{p}} \quad$ projectile diameter

E total (internal and kinetic) energy

$\epsilon_{\mathrm{j}} \quad$ activation energy of $\mathrm{j}^{\text {th }}$ reaction

$h_{i}{ }^{R} \quad$ base enthalpy of $i^{\text {th }}$ species

$\mathrm{k}$ thermal conductivity

$\kappa_{\mathfrak{f j}} \quad$ forward rate constant for $\mathrm{j}^{\text {th }}$ reaction

$\kappa_{b j} \quad$ backward rate constant for $j^{\text {th }}$ reaction

$\kappa_{\text {eqj }} \quad$ equilibrium constant for $\mathrm{j}^{\text {th }}$ reaction

$M_{i} \quad$ molecular weight of $i^{\text {th }}$ species

$\mathrm{N}_{\mathrm{s}} \quad$ number of chemical species.

$N_{r} \quad$ number of chemical reactions

$\mathrm{p} \quad$ pressure

Graduate Research Assistant, AIAA Student Member

Eminent Professor, AIAA Associate Fellow

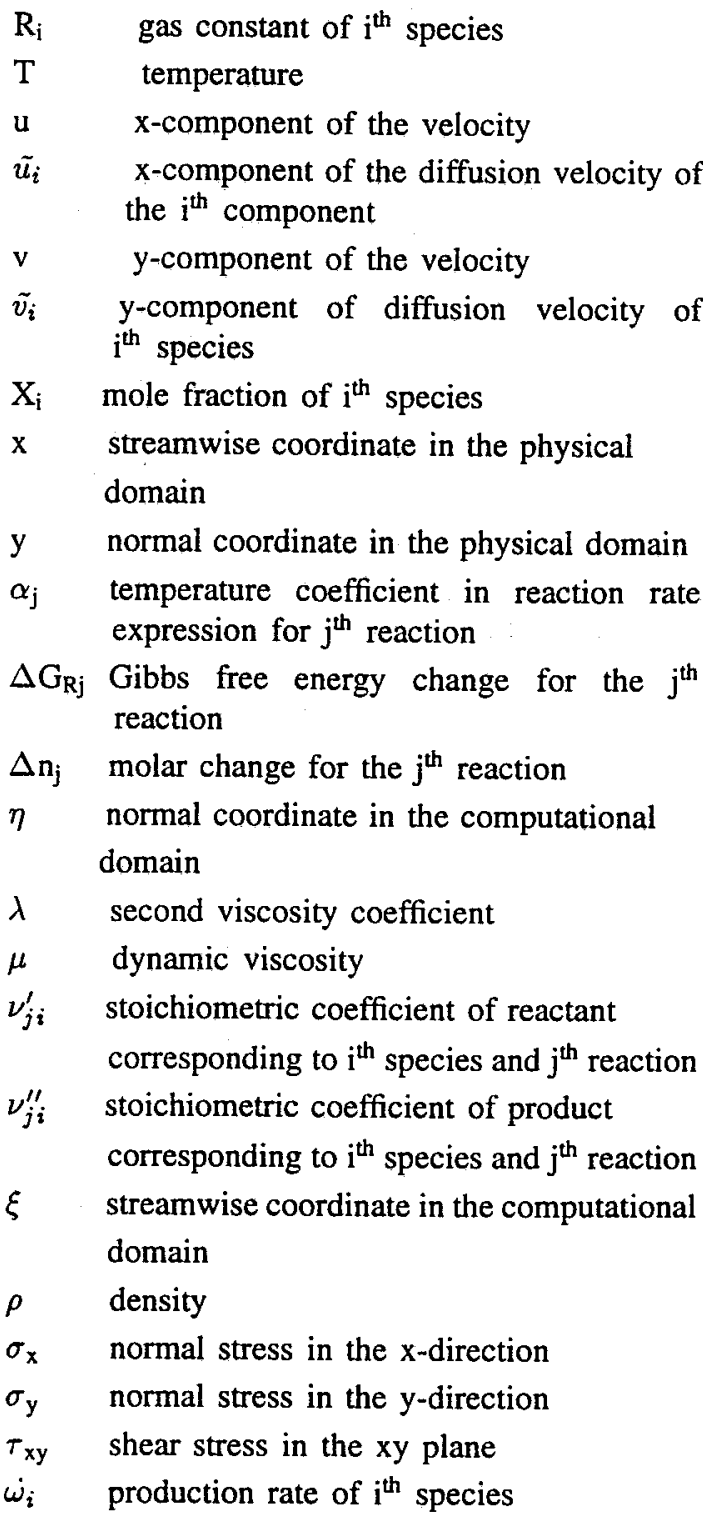

\section{INTRODUCTION}

Some of the applications of supersonic research are the proposed National Aero-Space Plane, the ram accelerator and Trans Atmospheric Vehicles. All of these vehicles rely on air-breathing propulsion. The air-breathing engine removes the requirement to carry an oxidizer inside the vehicle. Further, there is a substantial savings in weight and, therefore, the payload is higher. An efficient propulsion system at hypersonic speeds requires that combustion take place at supersonic speeds, i.e., combustion at supersonic mean 
airstream speed. The supersonic combustion speed is required for airbreathers at high Mach numbers to reduce the unacceptable losses associated with inlet deceleration to subsonic conditions. The scramjet $[1,2]$ is an integrated airframe-propulsion concept for a hypersonic airplane. Significantly increased propulsion efficiency in the Mach 6 to 15 range may be provided by the conventional diffusion-burning, air-breathing scramjet. For airbreathers above Mach 15, another propulsion approach is required, e.g., greatly enhanced (reduced loss) conventional scramjet and detonation wave engines.

Another proposed hypervelocity air-breathing propulsion scheme is the shock-induced combustion or oblique detonation wave engine (ODWE [3]) where a shock is employed to increase the temperature of the premixed fuel and air to a point that creates chemical reaction. The term detonation is applied to the process where a shock and reaction front follow each other very closely and are pressure coupled, while shock-induced combustion implies that the shock wave and reaction front are decoupled. Thus, detonation is a limiting case of shock-induced combustion. Up to about Mach 15, a scramjet has better performance than an ODWE, but after that, ODWE performs better. This engine requires even more extreme integration with the "airframe." To avoid preignition, the fuel is injected from the vehicle forebody/nose region, inside the shock layer but outside the boundary layer. The advantages of a shock-induced combustion propulsion system include lower inlet losses and significant reduction in combustion weight, size, heat transfer, and skin friction losses and cooling requirements. These advantages are due to forebody region fuel-air mixing which obviates the need to contain the fuel-air mixing process within a long combustor at high pressure.

Ballistic range experiments performed in the 1960 's and 1970's provide an excellent source for studying supersonic combustion/detonation. The physics of these ballistic range flows are predominantly driven by reaction kinetics and convection phenomena. Thus, the complications and uncertainties of diffusion and mixing are removed from the problem. Any discrepancy between the experimental data and numerical calculations can be attributed to either numerical errors or the improperly modelled chemical kinetics. Zeldovich [4] suggested that combustion can be stabilized by the shock wave produced by bodies moving at supersonic speeds in combustible mixtures at various level of overdrive. In these experiments, projectiles were fired in different premixed fuel-air mixtures, and detonation structures around the projectiles were recorded. Every gas mixture has a detonation wave velocity known as the Chapman-Jouget (C-J) velocity, which is characteristic of the mixture. The detonation wave velocity is known as the C-J velocity of the mixture whenever the normal component of the flow velocity following the detonation wave is sonic. If the normal component of the flow velocity is subsonic, however, the detonation wave velocity is called overdriven and if supersonic, then it is known as underdriven. The freestream velocity is referred to as superdetonative if the free-stream velocity of the projectile is above the C-J velocity of the reactive mixture. The detonation wave structure is highly unstable for projectile velocities that are less than the C-J velocity of the mixture. The detonation or reaction front structure shows a coupled shock-deflagration system near the stagnation line of the body if the projectile is flying above the C-J velocity of the gas mixture. These two fronts separate from each other as one moves away from the stagnation line. The separation between the two fronts occurs as soon as the velocity component normal to the bow shock is equal to the detonation velocity. The separation between the bow shock and the reaction front is called the induction zone. Lehr's [5] experimental ballistic range shadowgraphs for Mach 5.11 and Mach 6.46 are shown in Figs. 1 and 2, respectively. A free-stream temperature of $292 \mathrm{~K}$ and a pressure of $42663.2 \mathrm{~N} / \mathrm{m}^{2}$ $(320 \mathrm{~mm}$ of $\mathrm{Hg}$ ) are used along with a stoichiometric mixture of hydrogen and air in both cases. In Fig. 1 the projectile velocity is Mach 5.11 (which is also the C-J velocity of the mixture). It shows separation of two discontinuities by induction zone. The outer discontinuity is the bow shock, and the inner discontinuity is the reaction front. The separation between the two shocks is minimum near the stagnation region and increases downstream. The induction distance is increased as the shock wave becomes weak away from the stagnation region and the post-shock temperature reduces. Another feature to be noticed is the presence of instabilities in the reaction front. The frequencies of these pulsations were determined to be $1.96 \mathrm{MHz}$. It is seen in Fig. 2 that the reaction front for the Mach 6.46 case is coupled with the shock near the stagnation line. The coupling continues until about $60^{\circ}$ from the stagnation line, where the reaction front starts decoupling from the bow shock. This coupling is caused by very high post-shock temperatures, that cause a decrease in the induction distance. A close examination of the shadowgraphs reveals that there is an increase in density as the flow crosses the bow shock. The increase is noted by the color changes from light to dark. As the flow crosses the reaction front, however, the color changes from dark to light, indicating a decrease in density across the reaction front. This decrease is due to a large release of energy across the reaction front that causes an increase in the temperature; since the pressure remains relatively constant, the density must decrease.

By means of schlieren photography, Reugg and Dorsey [6] investigated the problems and effects of stabilizing combustion on a $20 \mathrm{~mm}$ diameter spherical projectile in a stoichiometric mixture of hydrogen 
and air at rest. Combustion produced detectable effects on the shapes and positions of shock waves at Mach numbers between 4 and 6.5 and above a pressure of one-tenth atmosphere. Strong combustion-driven oscillations were observed in front of the sphere with frequencies of one-tenth megacycle per second. These oscillations were observed when the Mach number was less than 6 for the one-half atmosphere pressure, and less than 5 for the one-quarter atmosphere pressure. They also reported the results with methane-air and pentane-air mixtures.

Similar experiments were performed by Behren et al. [7] by firing $9 \mathrm{~mm}$ diameter plastic spheres into hydrogen-air and hydrogen-oxygen mixture at velocities of $1500-3000 \mathrm{~m} / \mathrm{sec}$. Similar behaviour of transition from detonation wave stability to instability was observed when the projectile velocities were decreased to nearly C-J velocity of the mixture.

Chernyi [8] reported on the experiments of firing a sphere-nosed cylinder into hydrogen-oxygen and hydrogen-air mixtures. As in the case for self-sustained detonation, the flow field is highly unstable under a wide range of conditions. In the case of blunt projectiles and exothermic gas mixtures, the instabilities generate a highly regular, periodic flow structure under certain conditions. He suggested the similarity of these instabilities to the cellular structure of flame.

McVey and Toong [9] conducted similar experiments where projectiles were fired into lean acetyleneoxygen and stoichiometric hydrogen-air mixtures. They developed the wave interaction model to explain the detonation wave structure instabilities. Their model explains how compression waves can be formed when a new reaction front develops in the induction zone between the normal segment of the bow shock and the original reaction front. These compression waves lead to a cyclic process which is compatible with most of the observed features of the flow. However, the compression wave strength remained unresolved in their wave-interaction model, which is an important factor in determining if such a model is physically possible. Alpert and Toong [10] included the effect of the compression wave strength and proposed a modified form of the wave-interaction model.

Several researchers $[11-15]$ have recently attempted to numerically simulate Lehr's ballistic range experiments [5]. Youngster et al. [11] and Lee and Deiwart [12] simulated Lehr's experimental data for Machs 4.18, 5.11, and 6.46. They used Euler equations coupled with species equations to capture the shock and the reaction front. The reaction model used was a hydrogen-air mixture of six species and an inert gas such as Argon or Nitrogen and eight reactions. The flow field was found to be steady despite the experimental evidence that the flow field is unsteady. For the test conditions of stoichiometric hydrogen-air mixture, the detonation wave speed of the mixture is Mach 5.11. It has been demonstrated experimentally by Lehr that Machs 5.11 and 4.18 show detonation wave structural instabilities that disappear if the flight Mach number is increased beyond Mach 5,11. Further, the flow field was not well resolved. Their blunt body calculations used $32 \times 32$ and $57 \times 41$ size grids, respectively. These grids were not sufficient to resolve the flow field correctly.

Wilson and MacCormack [13] conducted a detailed numerical investigation of the shock-induced combustion phenomena. Euler equations and a 13-species, 33-reactions chemistry model was used. The validity of the reaction models and the importance of grid resolution needed to properly model the flow physics were also shown. Highly resolved calculations for Lehr's Mach 5.11 and Mach 6.46 cases with an adaptive grid were performed. The calculations were not time accurate; therefore, the unsteady behavior was not captured.

Sussman and Wilson [14] also studied the instabilities in the reaction front for a Mach number of 4.79. Euler equations and a 13-species, 33-reactions chemistry model was again used. They have proposed a new formulation based on logarithmic transformation. The number of grid points needed to properly resolve the reaction front is greatly reduced. They successfully simulated the unsteady case. However, the frequency was slightly underpredicted.

Matsuo and Fujiwara [15] have studied the instabilities of shock-induced combustion around an axisymmetric blunt body with Euler equations and a simplified two-step chemistry model. The growth of periodic instabilities by a series of simulations with various tip radii was investigated; these periodic instabilities are related to shock-standoff distance and induction length. They proposed a new model based on McVey and Toong's model [9] that explained the instabilities in the reaction front.

The appearance or disappearance of the instabilities in the structure of the reaction front with various Mach numbers has been studied in details, and a satisfactory explanation of the various flow phenomena have been explained by the wave-interaction model by McVey and Toong [9]. The instabilities originate in the induction zone that separates the bow shock and the exothermic reaction front in the nose region of the flow field and then spreads outwards. But the disappearance of instabilities by reducing the projectile diameter while keeping the same Mach number has not been clarified yet. The objective of this study is to isolate the various key parameters for the appearance and disappearance of these instabilities such as projectile diameter, induction time, heat release, activation energy and to explain the physics of the observed phenomena by a wave interaction model. In order to capture the 
physical instabilities, the calculations must be carried out for long times to ensure that all relevant time scales are being captured. Since all numerical schemes have some numerical diffusion, which is dependent on the grid resolution, a coarse grid may damp these oscillations. Further, the numerical damping added to the scheme in the reaction front vicinity may damp or alter the instability modes. The axisymmetric version of the SPARK2D code [16], which incorporates a 9-species, 18-reactions combustion model for hydrogen-air mixtures, is used to carry out the analysis.

\section{BASIC GOVERNING EQUATIONS}

The physical model for analyzing the flow field is described by the Navier-Stokes and species continuity equations. For two-dimensional axisymmetric flows, these equations are expressed in physical coordinates as [16]

$$
\frac{\partial U}{\partial t}+\frac{\partial F}{\partial x}+\frac{\partial G}{\partial y}=H
$$

where vectors $\mathrm{U}, \mathrm{F}, \mathrm{G}$, and $\mathrm{H}$ are written as

$$
\begin{aligned}
& U=\left[\begin{array}{c}
\rho \\
\rho u \\
\rho v \\
\rho E \\
\rho f_{i} \\
\cdot \\
\cdot
\end{array}\right] \\
& F=\left[\begin{array}{c}
\rho u \\
\rho u^{2}-\sigma_{x} \\
\rho u v-\tau_{x y} \\
\left(\rho E-\sigma_{x}\right) u-\tau_{x y} v+q_{x} \\
\rho f_{i}\left(u+\tilde{u}_{i}\right) \\
\cdot
\end{array}\right] \\
& G=\left[\begin{array}{c}
\rho v \\
\rho u v-\tau_{x y} \\
\rho v^{2}-\sigma_{y} \\
\left(\rho E-\sigma_{y}\right) v-\tau_{x y} u+q_{y} \\
\rho f_{i}\left(v+\tilde{v}_{i}\right) \\
\cdot
\end{array}\right] \\
& H=\frac{1}{y}\left[\begin{array}{c}
\rho v \\
\left(\rho v u+\tau_{x y}\right) \\
\rho v^{2}+\tau_{y y}-\tau_{\theta \theta} \\
\left(\rho E+p+\tau_{y y}\right) v+\tau_{x y} u+q_{y} \\
\omega_{i} \\
\cdot
\end{array}\right]
\end{aligned}
$$

The other terms appearing in vectors $\mathrm{F}, \mathrm{G}$, and $\mathrm{H}$ are defined as

$$
\begin{gathered}
\sigma_{x}=-p+2 \mu \frac{\partial u}{\partial x}+\lambda \nabla \cdot u \\
\sigma_{y}=-p+2 \mu \frac{\partial v}{\partial y}+\lambda \nabla \cdot u \\
\tau_{x y}=\mu\left[\frac{\partial u}{\partial y}+\frac{\partial v}{\partial x}\right]
\end{gathered}
$$

$$
\frac{C_{p_{i}}}{R_{i}}=A_{i}+B_{i} T+C_{i} T^{2}+D_{i} T^{3}+E_{i} T^{4}
$$

In Eq. (1) only $\left(\mathrm{N}_{\mathrm{s}}-1\right)$ species equations need to be considered in the formulation since the mass fraction of the species is prescribed by satisfying the constraint equation

$$
\sum_{i=1}^{N_{i}} f_{i}=1
$$

The specific heat at constant pressure for each species is prescribed in Eq. (11) by a fourth-order polynomial in temperature. The diffusion velocity of the $i^{\text {th }}$ species is obtained by solving the Stefan-Maxwell equation, neglecting body force and thermal diffusion effects.

$\nabla X_{i}=\sum_{j=1}^{N_{s}}\left(\frac{X_{i} X_{j}}{D_{i j}}\right)\left(\tilde{V}_{j}-\tilde{V}_{i}\right)+\left(f_{i}-X_{i}\right)\left(\frac{\nabla p}{p}\right)$ 
This equation has to be applied only to $\left(\mathrm{N}_{\mathrm{s}}-1\right)$ species. The diffusion velocity for the remaining species is prescribed by satisfying the constraint equation $\sum_{i=1}^{N_{i}} f_{i} \tilde{V}_{i}=$ 0 , which ensures the consistency.

\section{CHEMISTRY AND}

\section{THERMODYNAMIC MODELS}

Chemical reaction rate expressions are usually determined by summing the contributions from each relevant reaction path to obtain the total rate of change of each species. Each path is governed by a law of mass action expression in which the rate constants can be determined from a temperature dependent Arrhenius expression. In vector $\mathrm{H}$, the term $\omega_{i}=M_{i} C_{i}$ represents the net rate of production of species $i$ in all chemical reactions and is modelled as follows :

$$
\begin{gathered}
\sum_{i=1}^{N_{s}} \nu_{j i}^{\prime} S_{i} \rightleftharpoons \sum_{i=1}^{N_{s}} \nu_{j i}^{\prime \prime} S_{i} ; j=1, \ldots N_{r} \\
\omega_{i}=M_{i} \sum_{j=1}^{N_{r}}\left(\nu_{j i}^{\prime \prime}-\nu_{j i}^{\prime}\right)\left[\kappa_{f_{j}} \prod_{m=1}^{N_{s}} C_{m}^{\nu_{j m}^{\prime}}-\kappa_{b_{j}} \prod_{m=1}^{N_{s}} C_{m}^{\nu_{j m}^{\prime \prime}}\right]
\end{gathered}
$$

where Eq. (14) is a representation of an $N_{r}$-step chemical reaction and Eq. (15) is the production rate for the $i^{\text {th }}$ species, as determined from the law of mass action. The reaction constants $\kappa_{\mathrm{fj}}$ and $\kappa_{\mathrm{bj}}$ are calculated from the following equations

$$
\begin{gathered}
\kappa_{f j}=\mathrm{A}_{j} T^{\alpha j} \exp \left(\frac{-\epsilon_{j}}{R_{u} T}\right) ; j=1, \ldots . N_{r} \\
\kappa_{b j}=\frac{\kappa_{f_{j}}}{\kappa_{e q_{j}}} ; j=1, \ldots . N_{r}
\end{gathered}
$$

The equilibrium constant appearing in Eq. (18) is given by

$$
\kappa_{e q_{j}}=\left(\frac{1}{R_{u} T}\right)^{\Delta n_{j}} \exp \left(\frac{-\Delta G_{f_{j}}}{R_{u} T}\right) ; j=1, \ldots N_{r}
$$

where

$$
\begin{gathered}
\Delta n_{j}=\sum_{i=1}^{N_{s}} \nu_{j i}^{\prime \prime}-\sum_{i=1}^{N_{s}} \nu_{j i}^{\prime} ; j=1, \ldots N_{r} \\
\Delta G_{R_{j}}=\sum_{i=1}^{N_{s}} \nu_{j i}^{\prime \prime} g_{i}-\sum_{i=1}^{N_{s}} \nu_{j i}^{\prime} g_{i} ; j=1, \ldots N_{r} \\
\frac{g_{i}}{R_{i}}=\mathrm{A}_{i} T(1-\ln T)-\left(\frac{B_{i}}{2}\right) T^{2}-\left(\frac{C_{i}}{6}\right) T^{3} \\
-\left(\frac{D_{i}}{12}\right) T^{4}-\left(\frac{E_{i}}{20}\right) T^{5}+F_{i}-G_{i} T ; i=1, \ldots \ldots N_{s}
\end{gathered}
$$

The forward rate for each reaction is determined by Eq. (17) which is based on the Arrhenius law.
The appropriate constants $\mathrm{A}_{j}, \alpha_{j}$, and $\epsilon_{\mathrm{j}}$ for the $\mathrm{H}_{2}$ air reaction system can be found in [17]. The reverse rate is then calculated from Eq. (18). The Gibb's free energy of each species in $g_{i}$ is obtained from the expression for $\mathrm{C}_{p i}$.

The hydrogen-air combustion mechanism used in this work is based on the Jachimowski hydrogen-air model [17] which uses 9 species and 18 reactions. The species are $\mathrm{N}_{2}, \mathrm{O}_{2}, \mathrm{H}_{2}, \mathrm{OH}, \mathrm{H}, \mathrm{O}, \mathrm{H}_{2} \mathrm{O}, \mathrm{HO}_{2}$, and $\mathrm{H}_{2} \mathrm{O}_{2}$. Each of the 18 reactions can proceed in the forward and backward directions. The reactions are

1) $\mathrm{O}_{2}+\mathrm{H}_{2}=\mathrm{OH}+\mathrm{OH}$

2) $\mathrm{O}_{2}+\mathrm{H} \rightleftharpoons \mathrm{OH}+\mathrm{O}$

3) $\mathrm{H}_{2}+\mathrm{OH}=\mathrm{H}_{2} \mathrm{O}+\mathrm{H}$

4) $\mathrm{H}_{2}+\mathrm{O} \rightleftharpoons \mathrm{OH}+\mathrm{H}$

5) $\mathrm{OH}+\mathrm{OH} \rightleftharpoons \mathrm{H}_{2} \mathrm{O}+\mathrm{O}$

6) $\mathrm{OH}+\mathrm{H}+\mathrm{M} \rightleftharpoons \mathrm{H}_{2} \mathrm{O}+\mathrm{M}$

7) $\mathrm{H}+\mathrm{H}+\mathrm{M} \rightleftharpoons \mathrm{H}_{2}+\mathrm{M}$

8) $\mathrm{H}+\mathrm{O}_{2}+\mathrm{M} \rightleftharpoons \mathrm{HO}_{2}+\mathrm{M}$

9) $\mathrm{HO}_{2}+\mathrm{OH} \rightleftharpoons \mathrm{H}_{2} \mathrm{O}+\mathrm{M}$

10) $\mathrm{HO}_{2}+\mathrm{M} \rightleftharpoons \mathrm{H}_{2}+\mathrm{O}_{2}$

11) $\mathrm{HO}_{2}+\mathrm{H} \rightleftharpoons \mathrm{OH}+\mathrm{OH}$

12) $\mathrm{HO}_{2}+\mathrm{O} \rightleftharpoons \mathrm{OH}+\mathrm{O}_{2}$

13) $\mathrm{HO}_{2}+\mathrm{HO}_{2} \rightleftharpoons \mathrm{H}_{2} \mathrm{O}_{2}+\mathrm{O}_{2}$

14) $\mathrm{HO}_{2}+\mathrm{H}_{2} \rightleftharpoons \mathrm{H}_{2} \mathrm{O}_{2}+\mathrm{H}$

15) $\mathrm{H}_{2} \mathrm{O}_{2}+\mathrm{OH} \rightleftharpoons \mathrm{H}_{2} \mathrm{O}+\mathrm{HO}_{2}$

16) $\mathrm{H}_{2} \mathrm{O}_{2}+\mathrm{H} \rightleftharpoons \mathrm{H}_{2} \mathrm{O}+\mathrm{OH}$

17) $\mathrm{H}_{2} \mathrm{O}_{2}+\mathrm{O} \rightleftharpoons \mathrm{HO}_{2}+\mathrm{OH}$

18) $\mathrm{H}_{2} \mathrm{O}_{2}+\mathrm{M} \rightleftharpoons \mathrm{OH}+\mathrm{OH}+\mathrm{M}$

\section{METHOD OF SOLUTION}

The governing equations are transformed from the physical domain $(x, y)$ to a computational domain $(\xi$, $\eta)$ using an algebraic grid generation technique. In the computational domain, Eq. (1) is expressed as

$$
\frac{\partial \hat{U}}{\partial t}+\frac{\partial \hat{F}}{\partial \xi}+\frac{\partial \hat{G}}{\partial \eta}=\hat{H}
$$

where

$$
\begin{gathered}
\hat{U}=U J, \hat{F}=F y_{\eta}-G x_{\eta} \\
\hat{G}=G x_{\xi}-F y_{\xi}, \hat{H}=H J \\
J=x_{\xi} y_{\eta}-y_{\xi} x_{\eta}
\end{gathered}
$$

MacCormack's [18] method is used to solve the governing equations. The scheme is second-order accurate in time and space, which results in a spatially and temporally discrete, simultaneous system of equations at each grid point. The system of equations is solved subject to initial and boundary conditions. At the supersonic inflow boundary, all flow quantities are specified as free-stream conditions. At the supersonic outflow 
boundary, all flow quantities are extrapolated from interior grid points. Although full Navier-Stokes (N-S) equations are used, the slip conditions are used to numerically simulate the inviscid flow. A flow tangency or slip boundary condition is implied on solid wall. The wall temperature and pressure are extrapolated from interior grid points. Initial conditions are obtained by specifying free-stream conditions throughout the flow field; the resulting set of equations is marched in time.

The Lax-Wendroff type schemes are inherently unstable and, hence, higher order numerical dissipation terms are often necessary to get a stable solution. For a non-reacting flow field, an artificial viscosity based on temperature and/or pressure is traditionally used, but in chemically reacting flows, in addition to temperature and pressure gradients, there may be strong species concentration gradients. To suppress the numerical oscillations in the induction zone (where the gradients in the concentration of reactants and products are very strong), additional artificial viscosity based on $\mathrm{H}_{2} \mathrm{O}$ mass fraction similar to the one used by Singh et al. [19] is used.

\section{RESULTS AND DISCUSSIONS}

The key parameters for the onset of periodic unsteadiness have been identified as (1) induction time, (2) reaction rate constant, (3) activation energy, (4) heat release and (5) projectile nose radius. In this study we shall be discussing the effect of various nose radii on the stability of the reaction front while keeping the first four parameters constant by choosing a particular reaction model and by fixing the free-stream Mach number.

When a blunt body is moving through a reactive mixture at hypersonic speeds, a bow shock is formed ahead of the body, and the temperature of the fuelair mixture, after the bow shock, is sufficiently high to initiate the reaction. Once ignition starts, chemical energy is released and another discontinuity known as the reaction front is formed. In the induction zone, temperature and pressure remain relatively constant at the post shock conditions, while the concentrations of radicals build up very rapidly. The flow attains equilibrium due to large residence time in the stagnation zone, while away from the stagnation zone, the flow is in a state of non-equilibrium. The numerical simulation is carried out for the free-stream conditions given in Table 1.
Table 1

Free-stream conditions and different nose radii used

\begin{tabular}{|l|l|l|l|}
\hline $\mathbf{M}_{\infty}$ & $\mathbf{D}_{\mathbf{p}}, \mathrm{mm}$ & $\mathbf{P}_{\infty}, \mathrm{N} / \mathrm{m}^{2}$ & $\mathbf{T}_{\infty}, \mathrm{k}$ \\
\hline 5.11 & i) 15 & 42663.22 & 292 \\
& ii) 2.5 & $(320 \mathrm{~mm})$ & \\
\hline 6.46 & $\begin{array}{l}\text { iii) } 15 \\
\text { iv) } 150 \\
\text { v) } 225\end{array}$ & $\begin{array}{l}42663.22 \\
(320 \mathrm{~mm})\end{array}$ & 292 \\
\hline
\end{tabular}

The premixed fuel oxidizer mixture is taken as $2 \mathrm{H}_{2}+\mathrm{O}_{2}+3.76 \mathrm{~N}_{2}$, and the stoichiometric chemical reaction for the system can be written as

$$
2 \mathrm{H}_{2}+\mathrm{O}_{2}+3.76 \mathrm{~N}_{2} \rightarrow 2 \mathrm{H}_{2} \mathrm{O}+3.76 \mathrm{~N}_{2}
$$

Calculations have been carried out for a grid with 197 points in the circumferential direction and 152 points in the normal direction. This grid was chosen based on the earlier work by Ahuja et al. [20] where the flow field was shown to be adequately resolved with this grid. For the present stoichiometric hydrogen-air mixture, the C-J velocity is Mach 5.11. Thus, for the Mach 6.46 case, the projectile speed is significantly above the detonation velocity of the mixture. If the free-stream velocity of the projectile is around the C$\mathrm{J}$ detonation velocity of the mixture, unsteady flow phenomenon can occur. As given in Table 1, we shall be discussing five cases, two cases with Mach 5.11 and projectile diameters of $15 \mathrm{~mm}$ and $2.5 \mathrm{~mm}$, and the remaining three cases with a Mach number of 6.46 and projectile diameters of $15 \mathrm{~mm}, 150 \mathrm{~mm}$, and $225 \mathrm{~mm}$. In all the calculations the residuals dropped by three orders in 12,000 iterations and then remained constant. Case (i): Mach 5.11 and projectile diameter of 15 mm

First the projectile diameter was chosen as $15 \mathrm{~mm}$ for the free-stream Mach number of 5.11. Figure 3 shows the contour plot of temperature, and Fig. 4 shows the contour plot of water mass fraction. The bow shock is very smooth, but the reaction front shows oscillations, which is more clearly seen in the inset enlarged view. The bow shock and the reaction front are separated from each other by the induction distance as is clearly seen in Fig. 5 which is the contour plot of density. The separation is minimum at the stagnation line and increases away from it because of low postshock temperature away from the stagnation region. A comparison with Fig. 1 shows that all flow features are very well captured. The calculated frequencies of these oscillations [20] were found to be in good agreement with the experimentally observed frequency $[5,21]$.

Case (ii): Mach 5.11 and projectile diameter of 2.5 mm 
Next the diameter of the projectile was reduced to $2.5 \mathrm{~mm}$ while keeping the same free-stream Mach number of 5.11. Other free-stream conditions were also kept the same. Figure 6 shows the temperature contours, and Fig. 7 shows the density contours. Both the shock and the reaction front are very smooth. This is much more clear from the water mass fraction contours shown in Fig. 8 with an inset enlarged view showing smooth reaction front. Thus, reducing the projectile diameter caused the instabilities to disappear.

\section{Case (iii): Mach 6.46 and projectile diameter of 15} mm

In this case the incoming Mach number was increased to 6.46 , making it a superdetonative case, while keeping the projectile diameter of $15 \mathrm{~mm}$ as in case (i). Figure 9 shows the contour plot of density for Mach 6.46. The bow shock and the reaction front can be clearly seen in the figure. They are coupled with each other near the stagnation line and up to about 60 degrees from the nose, at which point they start decoupling from each other by the induction distance. This occurs because bow shock is almost normal near the stagnation line and the post-shock temperature is maximum. For Mach 6.46, a very small induction distance occurs as a result of the post-shock temperature remaining significantly high up to some distance near the stagnation zone. Away from the stagnation line, the induction distance is increased as a result of decreasing shock strength and post-shock temperature. A comparison with Fig. 2 shows that all the flow features are very well captured. Figure 10 shows the contour plot of temperature. A comparison with Fig. 3 shows that when the Mach number is increased from a C-J Mach number of 5.11 to a superdetonative Mach number of 6.46 , while keeping the same projectile diameter, the instabilities in the reaction front disappear. Thus, for the Mach 6.46 case with projectile diameter of 15 $\mathrm{mm}$, both the bow shock and the reaction front have a smooth profile.

\section{Case (iv): Mach 6.46 and projectile diameter of 150 mm}

Next the projectile diameter was increased to 150 $\mathrm{mm}$ while keeping the same Mach number of 6.46 . Figure 11 shows the enlarged view of contour plot of water mass fraction for Mach 6.46 , but with projectile diameter of $150 \mathrm{~mm}$. The figure shows the waviness of the reaction front, indicating that the reaction front is turning towards instability.

\section{Case (v): Mach 6.46 and projectile diameter of 225 mm}

Next, the diameter of the projectile was increased to $225 \mathrm{~mm}$ while keeping the same free-stream Mach number of 6.46 as in the previous case. Figure 12 shows the enlarged view of the water mass fraction contours, and the periodic instabilities of the reaction front are clearly evident. Thus, increasing the projectile diameter from $15 \mathrm{~mm}$ to $150 \mathrm{~mm}$ and then to $225 \mathrm{~mm}$, while keeping the same superdetonative Mach number of 6.46 , causes the transition of a stable reaction front to an unstable one. The results of the above five cases have been summarized in Table 2 .

Table 2

Summary of five test cases

\begin{tabular}{|c|c|c|}
\hline $\mathrm{M}_{\infty}$ & $\begin{array}{l}\text { Projectile } \\
\text { Diameter } \\
\text { D }\end{array}$ & $\begin{array}{l}\text { Profile of } \\
\text { Reaction Front }\end{array}$ \\
\hline 5.11 & $\begin{array}{l}\text { (i) } 15 \mathrm{~mm} \\
\text { (ii) } 2.5 \mathrm{~mm}\end{array}$ & $\begin{array}{l}\text { Unstable } \\
\text { Stable }\end{array}$ \\
\hline 6.46 & $\begin{array}{l}\text { (iii) } 15 \mathrm{~mm} \\
\text { (iv) } 150 \mathrm{~mm} \\
\text { (v) } 225 \mathrm{~mm}\end{array}$ & $\begin{array}{l}\text { Stable } \\
\text { Slightly } \\
\text { Unstable } \\
\text { Unstable }\end{array}$ \\
\hline
\end{tabular}

In order to have a clear understanding of the origin and propagation of the instabilities, an $x-t$ diagram for water mass fraction on the stagnation streamline between the bow shock and the reaction front is drawn.

Figure 13 shows the $x-t$ plot of water mass fraction along the stagnation line for the Mach 5.11 for a $15 \mathrm{~mm}$ projectile diameter with an overlay of pressure to show the location of shock front. Fig. 14 shows the $x-t$ plot of water mass fraction along the stagnation line for Mach 5.11, but with a projectile diameter of $2.5 \mathrm{~mm}$. In the former case the reaction front clearly shows periodic oscillations, whereas the later case shows a smooth reaction front. The instabilities for Mach numbers lower than the C-J Mach number are due to the ignition delay. What causes these instabilities to disappear for the same Mach number of 5.11 but lower projectile diameter will be explained in subsequent paragraphs. A similar trend which was observed for the superdetonative case of Mach 6.46, where increasing the diameter causes the instabilities to reappear, shall also be discussed. A qualitative study of the frequencies, shock structure, pressure, and stagnation temperature associated with the projectile velocities, shows that the reciprocal frequencies or periods of oscillation are equal to the induction time for the ignition of hydrogen-air mixtures.

Many features of the non-steady flow regimes appear to originate from near the stagnation region behind the normal segment of the bow shock. Also, there is clearly a relationship between the periodicity of these flow features and the magnitude of the chemical induction time. The appearance and disappearance of these instabilities with various nose diameters have been ex- 
plained with a wave interaction model as proposed by McVey and Toong [9]. Figure 15 shows a schematic $x$-t diagram for the wave interaction model for Mach 5.11 and with projectile diameters of $15 \mathrm{~mm}$ and 2.5 $\mathrm{mm}$. For the diameter of $15 \mathrm{~mm}$, the beginning of the cycle is shown at a time when the overtaking of the bow shock by a compression wave in the induction zone takes place. Since chemical induction time is exponentially dependent on the gas temperature, the contact discontinuity $\left(D C_{1}\right)$ generated when the incident compression wave overtakes the bow shock has an important effect on the location of a reaction front. Exothermic reaction takes place on the upstream side of the contact discontinuity $\left(\mathrm{DC}_{1}\right)$ before beginning on the downstream side due to the difference in the gas temperature on the upstream and downstream sides of the contact discontinuity. It is this beginning of exothermic reaction on only one side of the contact discontinuity which constitutes the formation of a new reaction front. The ratio of chemical induction time across the discontinuity is a measure of where the new reaction front will be located relative to the original reaction front. Since the gases are hot on the upstream side of the contact discontinuity, they begin to react, generating compression waves which propagate upstream and downstream. This is shown in the figure by $\left(\mathrm{CW}_{2}\right)$ and $\left(\mathrm{CW}_{3}\right)$. At a somewhat later time, the contact discontinuity reaches the position of the original reaction front, extinguishing the reaction at this front and generating rarefaction waves $\left(\mathrm{RW}_{1}\right)$ and $\left(\mathrm{RW}_{2}\right)$. The upstream-facing compression wave $\left(\mathrm{CW}_{2}\right)$ eventually overtakes the bow shock and thus results in the generation of another contact discontinuity $\left(D_{2}\right)$. Presence of both rarefaction and compression waves in the induction zone makes it possible for a periodic wave interaction process.

It is clear from the above discussion that a compression wave moving towards the bow shock is overtaken by a rarefaction wave in each cycle of the waveinteraction process. During this process the compression wave gets attenuated by a rarefaction wave. If $\mathrm{M}_{\mathrm{s} 1}$ is the Mach number of the incident compression wave $\left(\mathrm{CW}_{1}\right)$ or weak shock, then $\left(\mathrm{M}_{\mathrm{s} 1}\right)_{\max }$ is generally of the order of 1.01. A wave interaction process cannot be initiated by an unattenuated compression wave since the Mach number $\left(\mathrm{M}_{\mathrm{sl}}\right)$ of such a wave is much greater than $\left(M_{s 1}\right)_{\max }$. On the other hand, if a sufficiently weak compression wave does initiate the wave interaction process, the attenuation of the first and each subsequent compression wave by a rarefaction wave must be sustained in order that the Mach number of each reaction shock, which finally overtakes the bow shock, be less than $\left(M_{s 1}\right)_{\max }$. When this condition is satisfied, then only the cyclic process is feasible. The validation of this phenomena with a shock-fitting method shall be presented in future studies.

The importance of a compression wave reflecting off the projectile nose has not been clarified in the
McVey and Toong model. The compression wave which travels towards the projectile reflects from it and finally overtakes the bow shock. This overtaking of the bow shock by the reflected compression wave from the projectile takes place almost at the same time that a newly formed compression wave from the new reaction front has overtaken the bow shock. Consequently, this contributes to strengthening the compression wave coming from the reaction front.

Thus, when we compare the unstable Mach 5.11 case with a projectile diameter of $15 \mathrm{~mm}$ with the stable case of a projectile diameter of $2.5 \mathrm{~mm}$, it is clear that the $15 \mathrm{~mm}$ diameter case has greater shock standoff distance than that with a diameter of $2.5 \mathrm{~mm}$. Thus, the reflected compression wave from the projectile nose coming back to overtake the bow shock to strengthen the compression wave originating at the reaction front, would have become quite weak. This is because it undergoes a large number of interactions with other compression waves between the reaction front and the projectile nose. As shown in the figure, the strength of the shock $P_{5} / P_{3}$ is less than the strength of the original reflected shock which is $\mathrm{P}_{2} / \mathrm{P}_{1}$. Now, if the shock standoff distance is larger, the reflected compression wave would encounter a greater number of interactions, and with every interaction, its strength would decrease. Although this reflected compression wave strengthens the compression wave originating at the reaction front, the $M_{s}$ is still less than $\left(M_{s 1}\right)_{\max }$ and, therefore, the periodic instabilities are sustained. On the other hand, when the projectile diameter is $2.5 \mathrm{~mm}$, the reflected compression wave has to travel a very short distance before it reaches the reaction front to strengthen the compression wave originating there. Moreover, because of the short shock stand-off distance, it does not encounter many interactions with other compression waves. Although $P_{3} / P_{2}$ of the reflected wave is less than $P_{2} / P_{1}$ of the compression wave reaching the projectile, it is still very strong by the time it reaches the reaction front. Thus, when it overtakes the bow shock, it strengthens the compression wave much more than the preceeding $15 \mathrm{~mm}$ diameter case. This causes $\mathrm{M}_{\mathrm{s}}$ of the compression wave to be much greater than $\left(\mathrm{M}_{\mathrm{s} 1}\right)_{\max }$, and this leads to unattenuated compression waves and, hence, periodicity disappears.

Again, when referring to the Mach 6.46 case with a projectile diameter of $15 \mathrm{~mm}$, a stable reaction front is observed, whereas increasing the diameter to $225 \mathrm{~mm}$ causes the instabilities to reappear. For the $225 \mathrm{~mm}$ case where the shock stand-off distance is much higher than the $15 \mathrm{~mm}$ case, the shock wave reflected off the projectile body becomes much weaker before strengthening the compression wave generated at the new reaction front. Thus, the compression wave generated at the new reaction front has $M_{s}$ less than $\left(M_{s 1}\right)_{\max }$ and, therefore, a cyclic process is sustained. On the other hand, for the projectile diameter of $15 \mathrm{~mm}$ where the 
shock stand-off distance is much smaller, the reflected compression wave from the projectiìe body strengthens the compression wave generated at the new reaction front much more and, therefore, leads to unattenuated compression waves. Consequently, the cyclic process for the $15 \mathrm{~mm}$ diameter and Mach 6.46 case cannot be sustained.

\section{CONCWLSTONS}

Numerical studies with different projectile diameters and Mach numbers indicate that Chapman-Jouge: velocity is not the anily parameter for triggerng the instabilities. The other parameters are induction time, reaction rate constant, projectise diameter, activation energy and heat release. The reason fox the appearance and disappearance of instabilitics cosid be attriouted $\mathrm{s}_{\mathrm{s}}$ attenuated or unattenuated compression waves which depend upon the strength of the reflected compression wave from projectile body, the strength of which in turn depends upon the shock stand-off distance and, hence, the projectile diameter. Thus, it is concluded that a subdetonative case can also lead to a sxabie reaction front by having an appropriate small diameter projectile, and a superdetonative case can also lead to an unstable reaction front by having a larger diameter projectile.

\section{REFERENCES}

1. Cambier, J. L. and Adelman H., "Numerical Simulations of an Oblique Detonation Wave Engine," AIAA Paper 88-0063, January 1988.

2. White, M. E., Drummond, J. P., and Kumar, Ajay, "Evolution and Status of CFD Techniques for Scramjet Applications," AIAA Paper 86-0160, January 1986.

3. Atamanchuk, T. and Sislian J., "On-And-Off Design Performance Analysis of Hypersonic Detonation Wave Ramjets," ALAA Paper 90-2473, July 1990.

4. Zeldovich, Y. B., and Shlyapintokh, I. Y, "Ignition of Explosive Gaseous Mixtures in Shock Waves," Office of Technical Services, U. S. Department of Commerce, Washington, DC, OTS: $50-41$, 553, 1960.

5. Lehr, H. F., "Experiments on Shock-Induced Combustion," Acta Astronautica, Vol. 17, September 1972, pp. 589-586.

6. Ruegg, F. W. and Dorsey, W. W., "A Missile Technique for the Study of Detonation Waves," Journal of Research, Bureau of Standards, Vol. 66c, No. 1, January-March 1962, pp. 51-58.

7. Behrens, H., Struth, W., and Wecken F., "Studies of Hypervelocity Firings into Mixtures of Hydrogen with Air or with Oxygen," Tenth Symposium (International) on Combustion, 1965, pp. 245-252.
8. Chernyi, G. G., "Supersonic Flow Past Bodies with Formation of Detonation and Combustion Fronts," Astro Acta, Vol. 13, 1968, pp. 467.

9. McVey, J. B. and Toong, T. Y., "Mechanism of Instabilities of Exothermi Hypersonic Blunt-Body Flows," Combustion Science and Technology, Vol. 3, 1971, pp $63-76$.

10. Algert, L. R. and Toong, T. Y., "Periodicity in Exothermic Hypersonic Flows about Blunt Projectiles," Acta Astronautica, Vol. 17, September 1972, pp. $539-560$.

11. Yungster, S., Eberhardt, S., and Bruckner, A. P., "Numerrcal Simulation of Shock-Induced Combustion ty yrgh-Speed Projectiles in Detonable Gas Mixtures," AIA A Paper 89.0673, July 1989.

12. Lee, S. and Deiwert. G. S., "Calculation of Non-Equikizrium Hydrogen-Air Reaction with Implicit Flux Vector Spliring Meshod," AIAA Paper 89-1700, $\$ 989$.

13. Wilson, G. I. and MacCormack R, W., "Modelling Supersonic Combustion Using a Fully-Implicit Numerical Method," ALAA Paper 90-2307, July 1990.

14. Sussman, A. M. and Wilson, G. J., "Computation of Chemically Reacting Flow using a Logarithmic form of the Species Conservation Equations," Proceedings of Fourth International Conference on Numerical Combustion, Tampa, FL, December 2-4, 1991, pp. 224-227.

15. Matsuo, A. and Fujiwara T., "Numerical Simulations of Shock-Induced Combustion around an Axisymmetric Blunt Body," AIAA Paper 91-1414, June 1991.

16. Drummond, J. P., Rogers, R. C., and Hussaini, M. Y., "A Detailed Numerical Model of a Supersonic Reacting Mixing Layer," AIAA Paper 86-1427, June 1986.

17. Jachimowski, C. J., "An Analytical Study of the Hydrogen-Air Reaction Mechanism with Application to Scramjet Combustion," NASA TP-2791, 1988.

18. MacCormack, R. W., "The Effect of Viscosity in Hypervelocity Impact Cratering," AIAA Paper 69-354, April-May 1969.

19. Singh, D. J., Carpenter, M. H., and Kumar, A., "Numerical Simulation of Shock-Induced Combustion/Detonation in a Premixed $\mathrm{H}_{2}$-Air Mixture Using Navier-Stokes Equations," AIAA Paper 91-3358, June 1991.

20. Ahuja, J. K., Tiwari, S. N., and Singh, D. J., "Investigation of Hypersonic Shock-Induced Combustion in a Hydrogen-Air System," AIAA Paper 92-0339, January 1992.

21. Anonymous, Rapport-Bericht CO 7/73, Institut Franco-Allenmand De Recherches De Saint-Louis, Kolloquium Uber Gasdetonationen, obgehalten im ISL am 22.10.1973, ISL-Beitrage. 


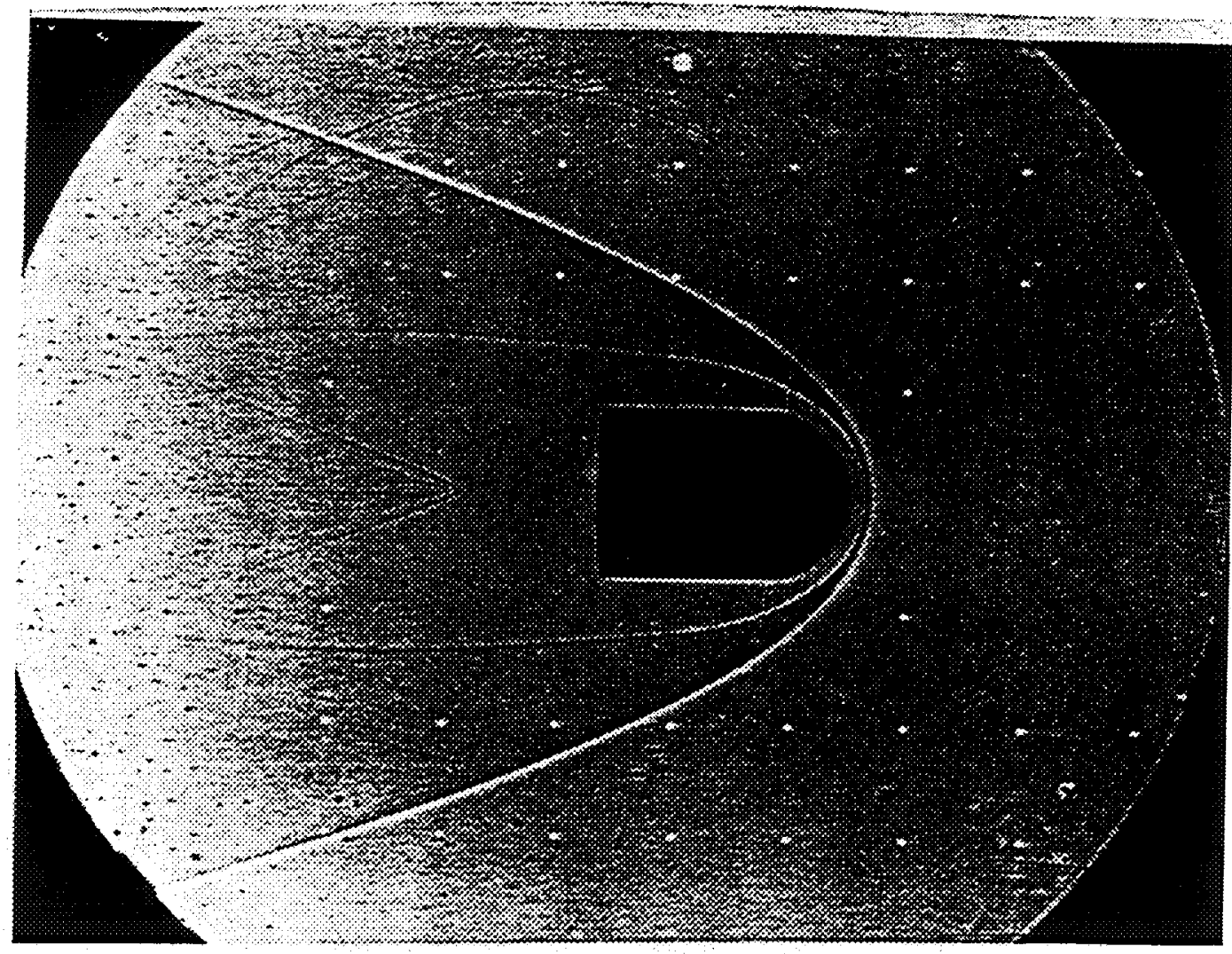

Figure 1 Shadowgraph of a spherical nose projectile moving at Mach 5.11 into a premixed stoichiometric hydrogen-air mixture.

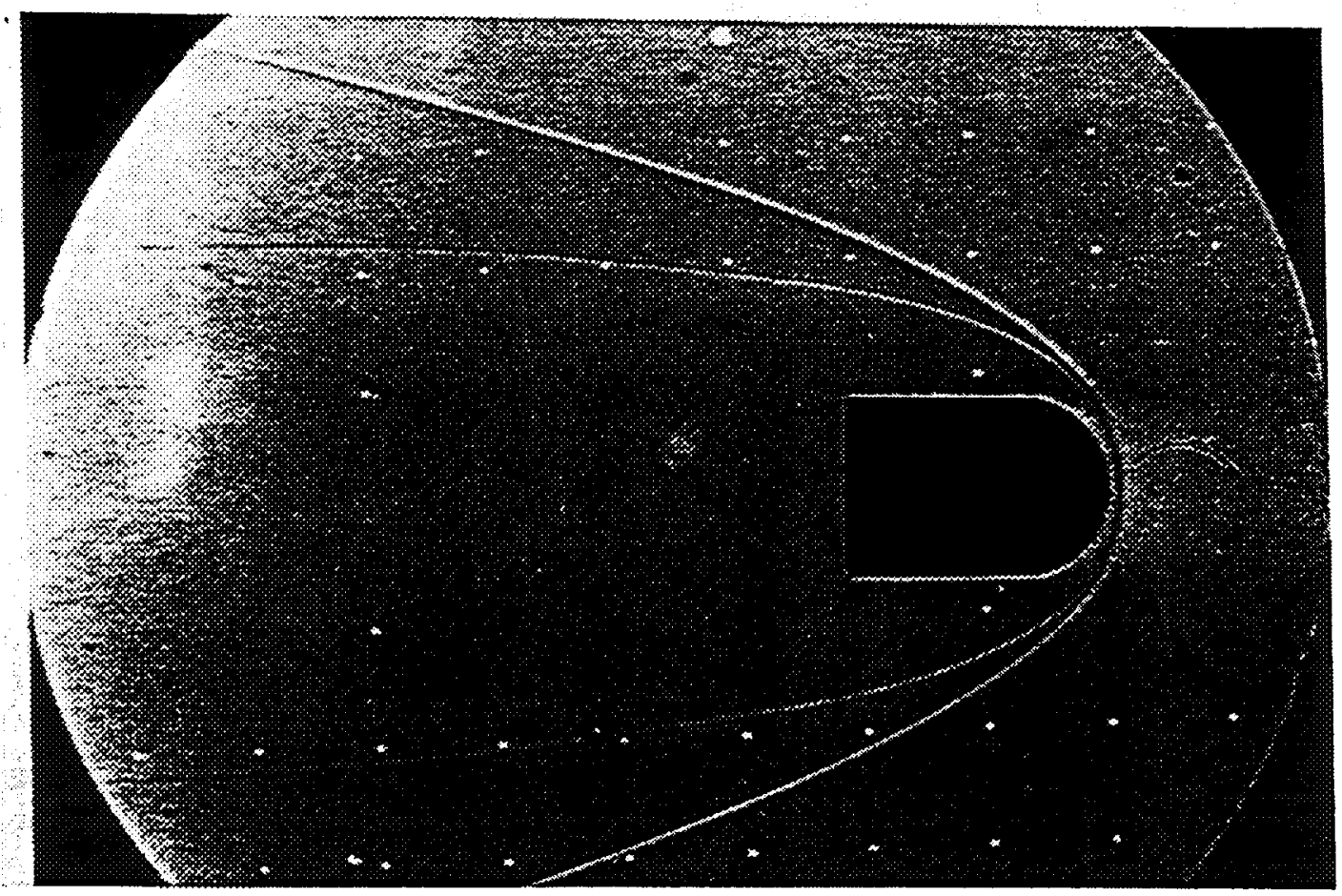

Figure 2 Shadowgraph of a spherical nose projectile moving at Mach 6.46 into a premixed stoichiometric hydrogen-air mixture. 


$$
\frac{5}{5}
$$




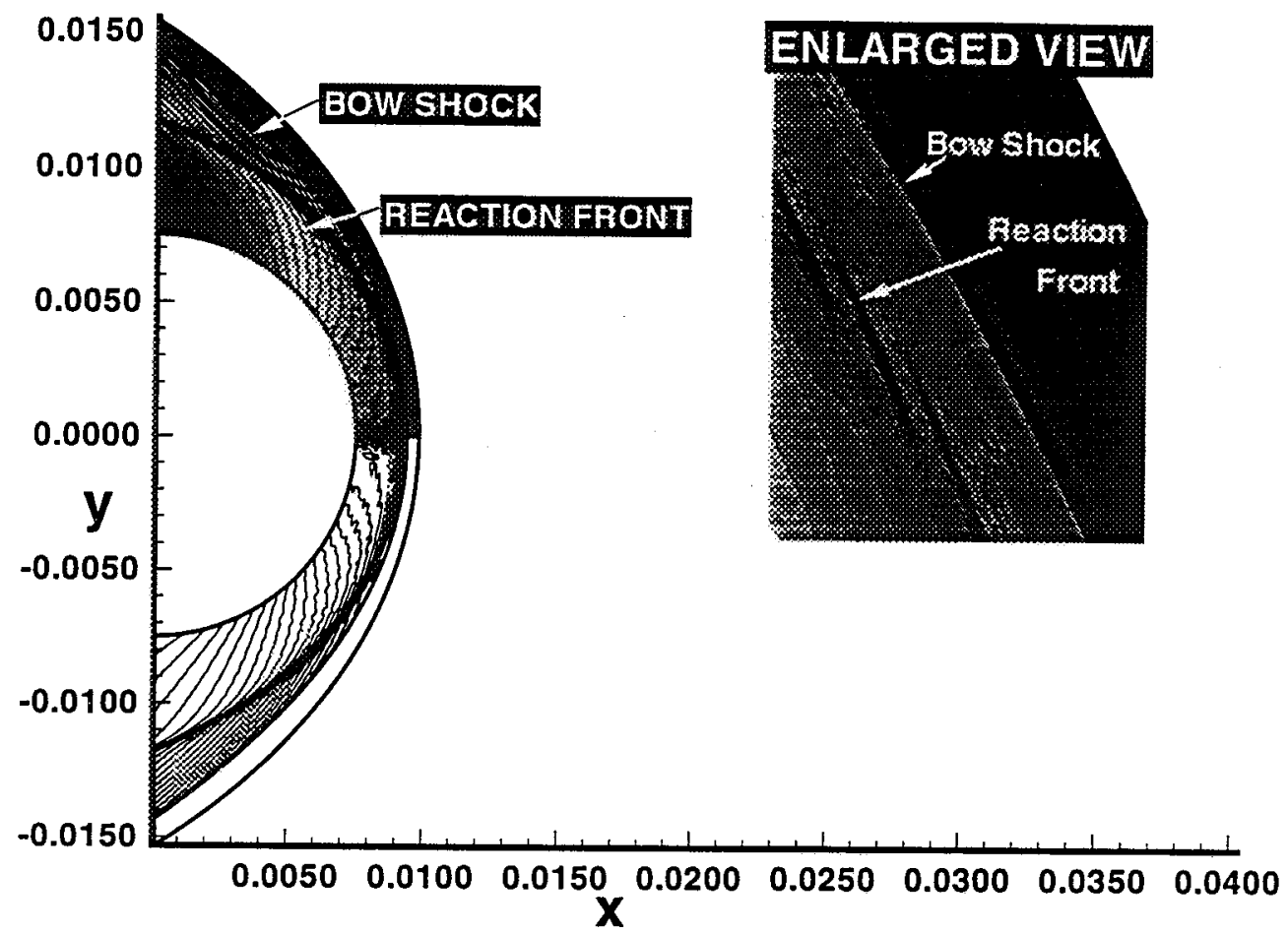

Figure 5 Contour plot of density for Mach 5.11 and projectile diameter $15 \mathrm{~mm}$.

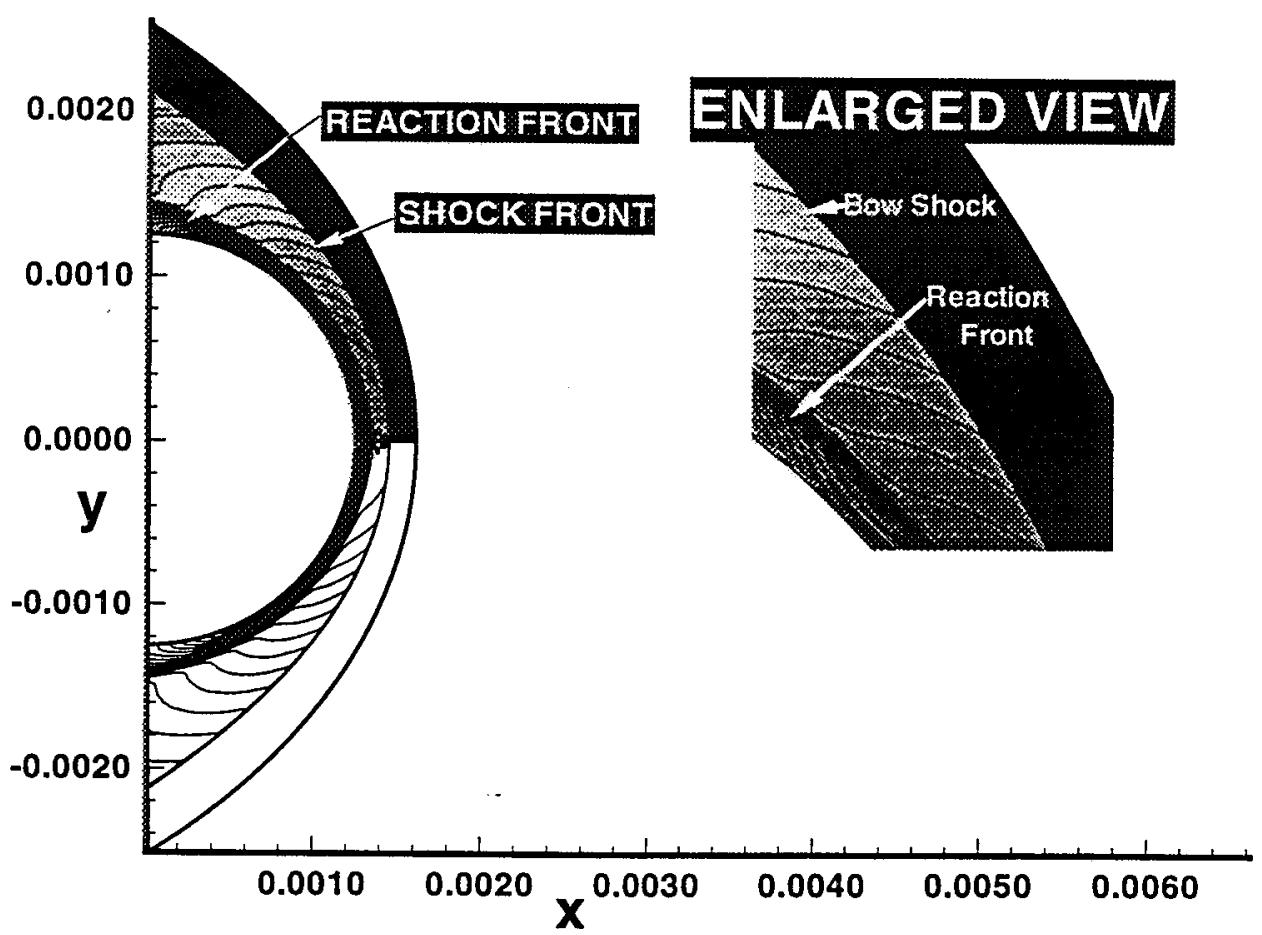

Figure 6 Contour plot of temperature for Mach 5.11 and projectile diameter $2.5 \mathrm{~mm}$. 


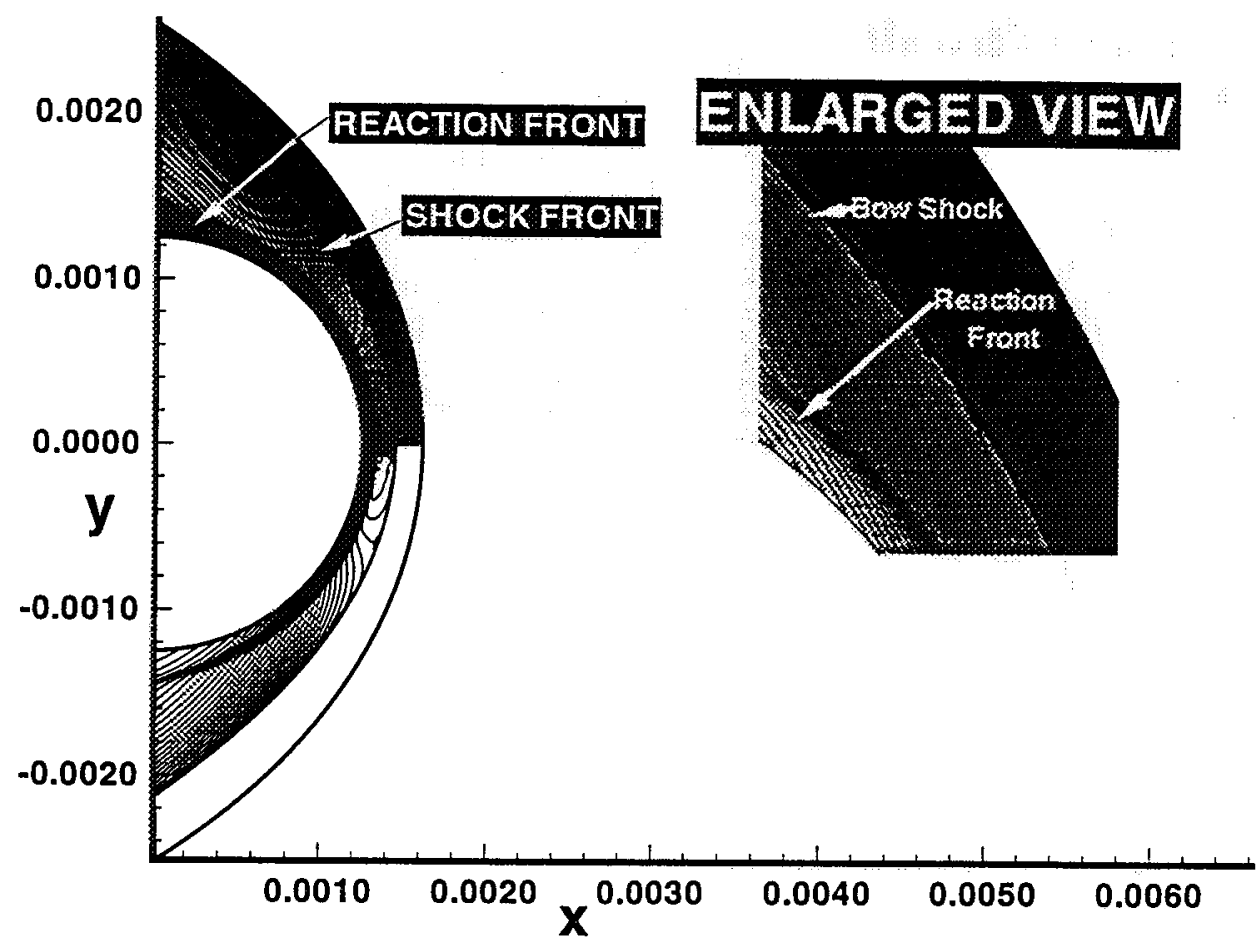

Figure 7 Contour plot of density for Mach 5.11 and projectile diameter $2.5 \mathrm{~mm}$.

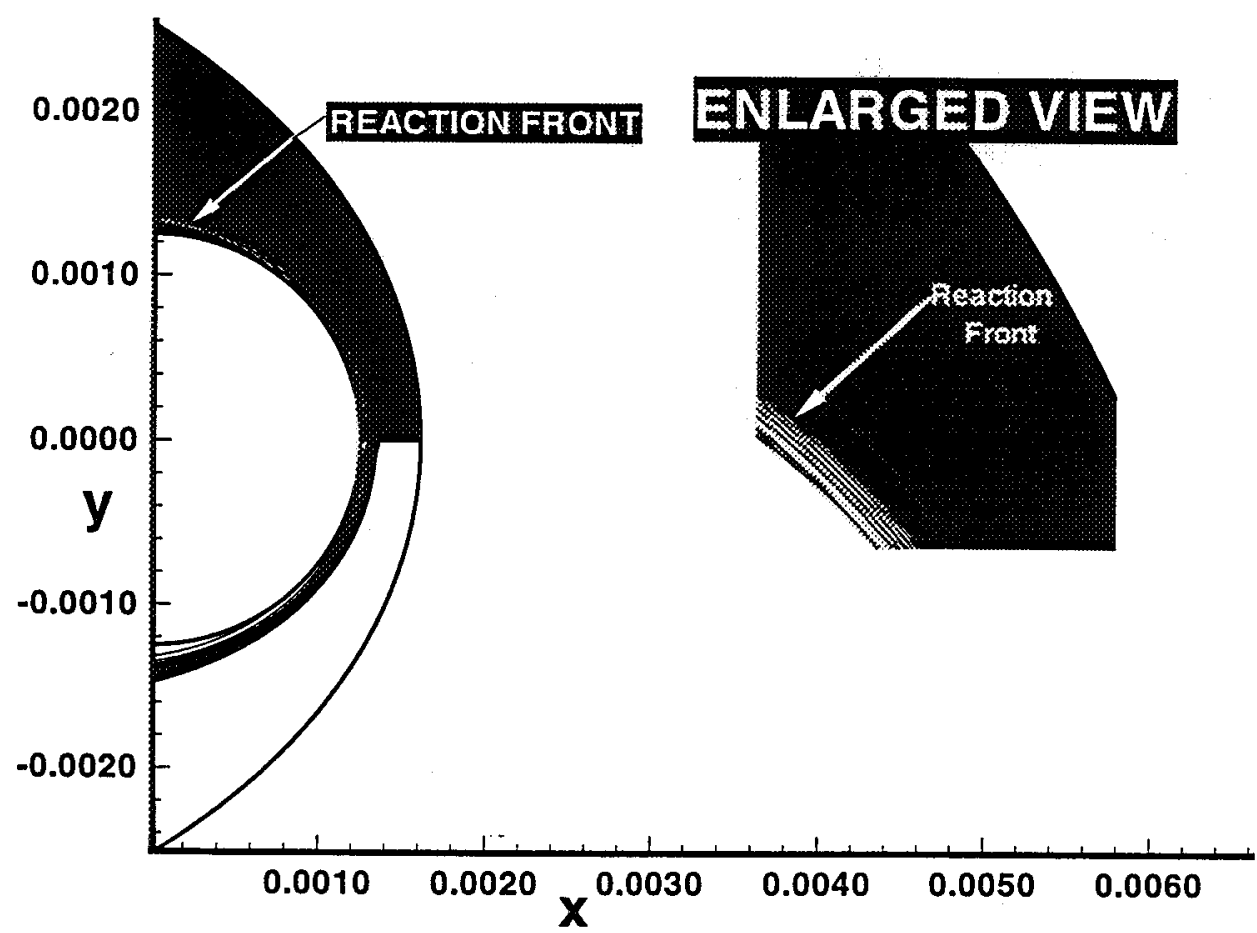

Figure 8 Contour plot of water mass fraction for Mach 5.11 and projectile diameter $2.5 \mathrm{~mm}$. 


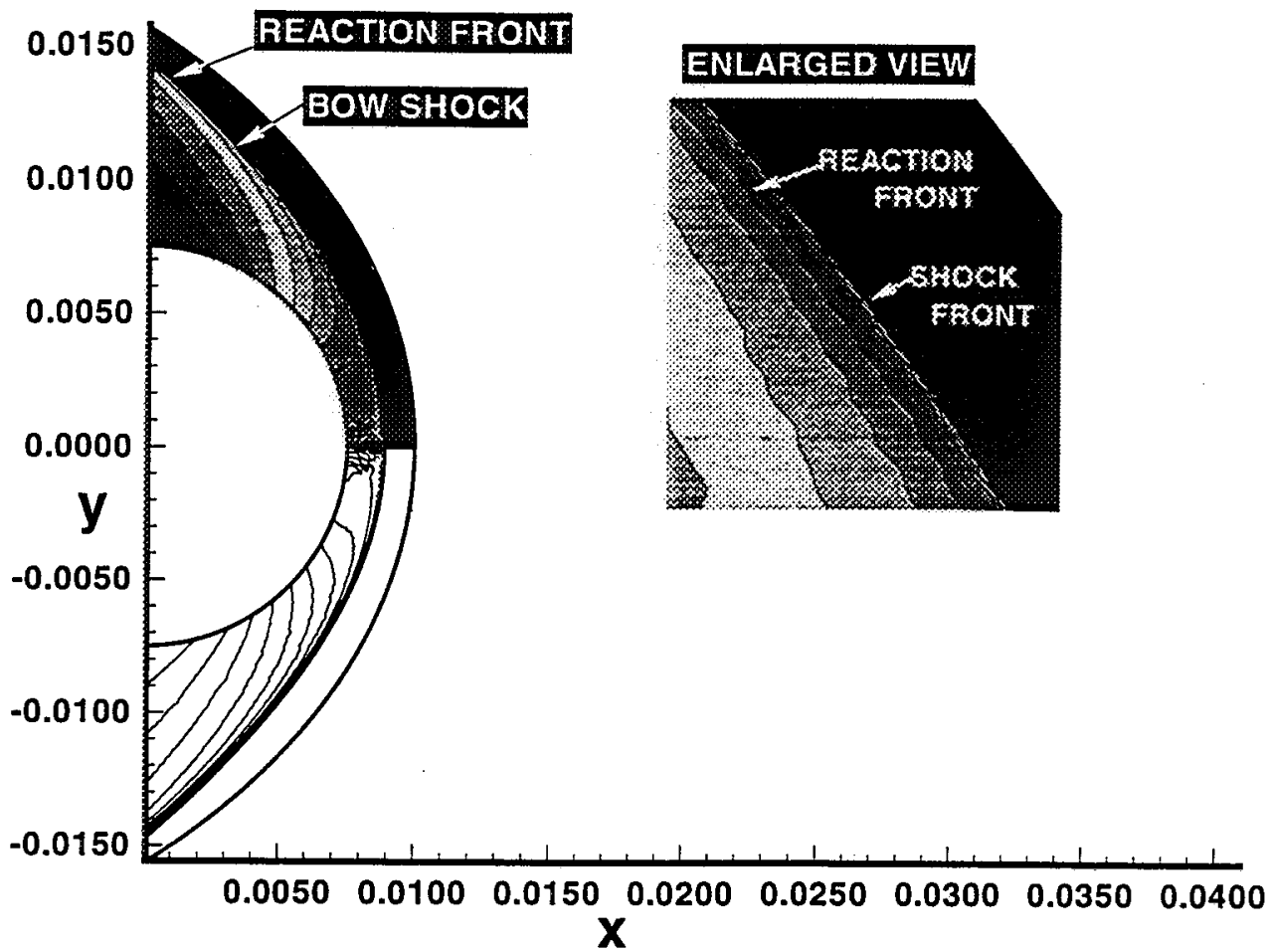

Figure 9 Contour plot of density for Mach 6.46 and projectile diameter $15 \mathrm{~mm}$.

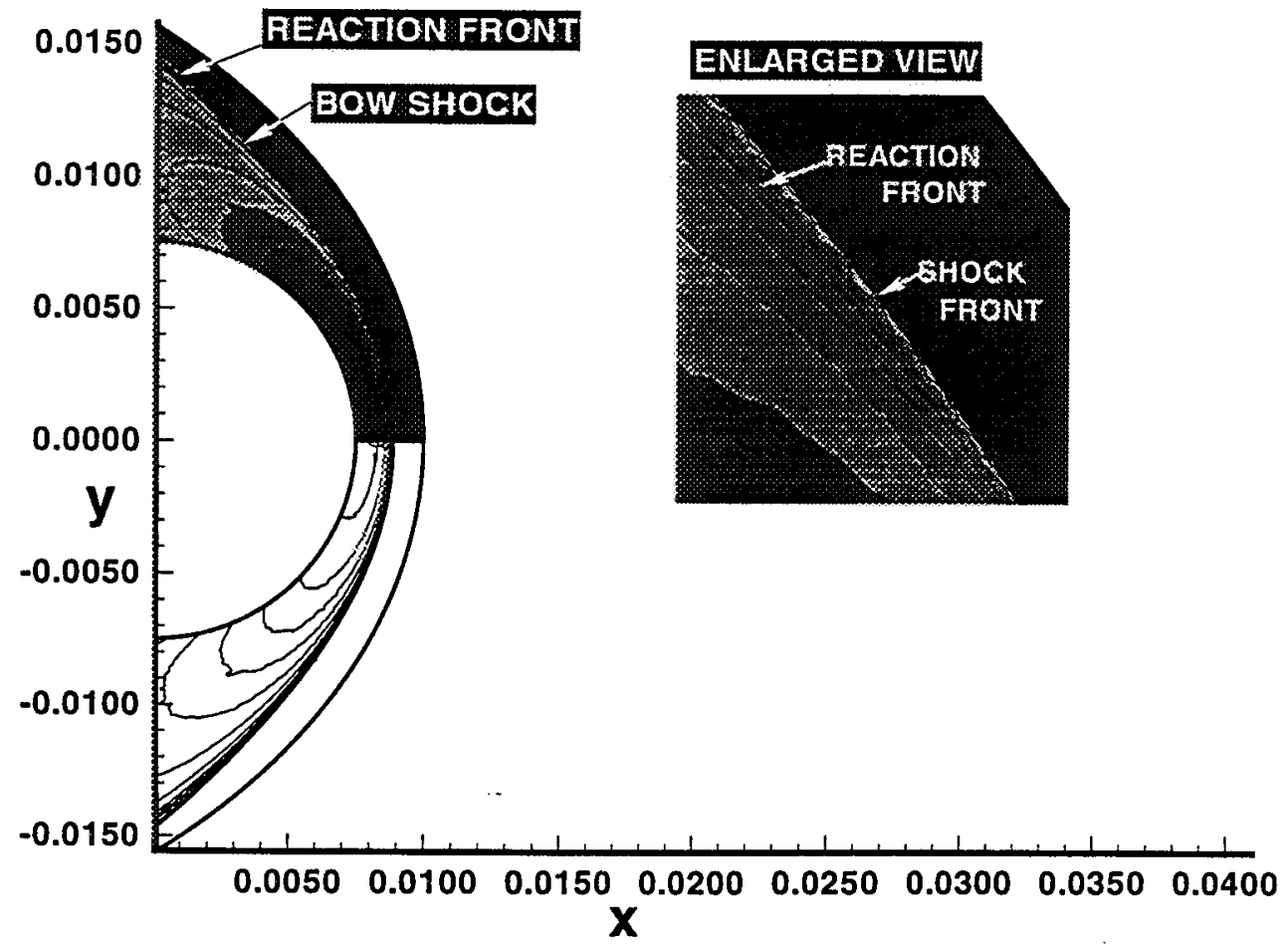

Figure 10 Contour plot of temperature for Mach 6.46 and projectile diameter $15 \mathrm{~mm}$. 


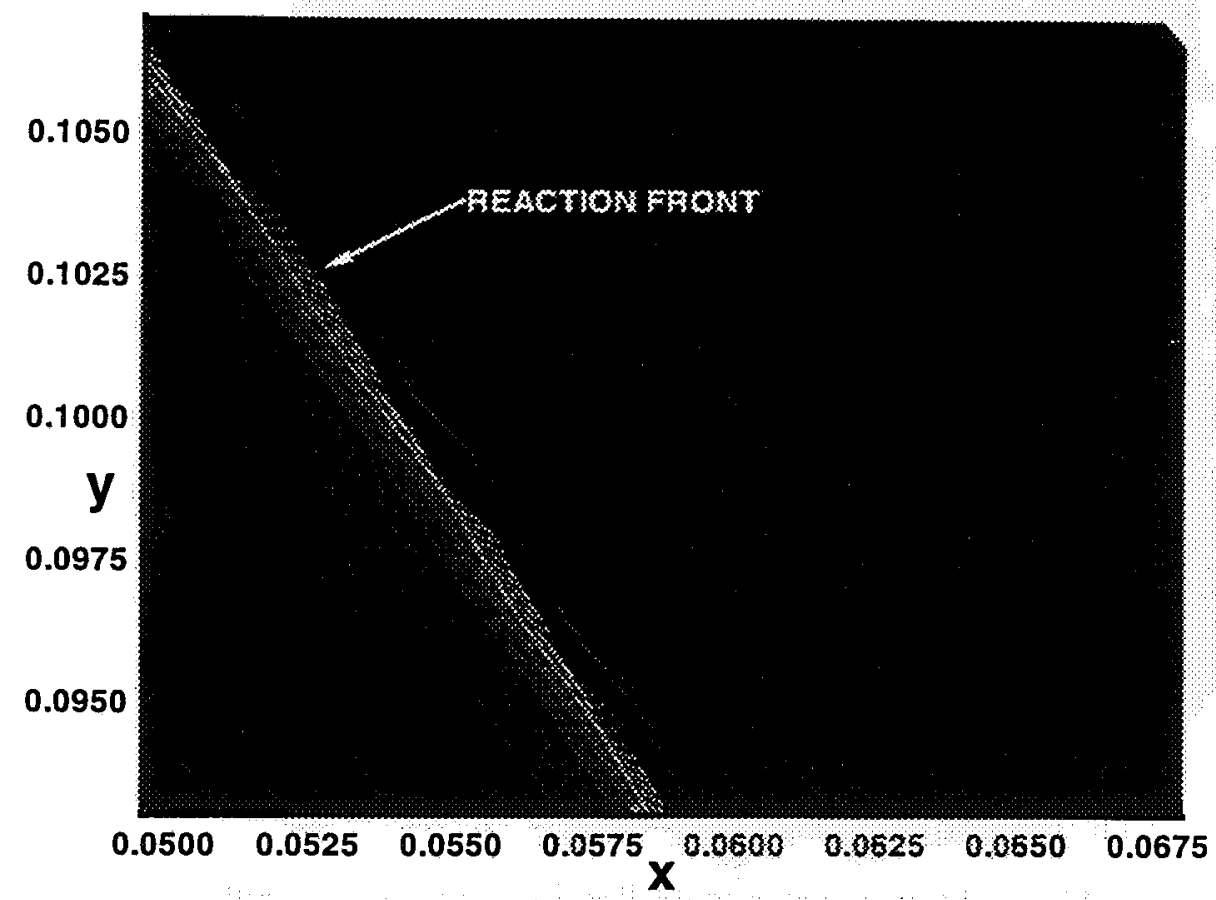

Figure 11 Enlarged view of contour plot of water mass fraction for Mach 6.46 and projectile diameter $150 \mathrm{~mm}$.

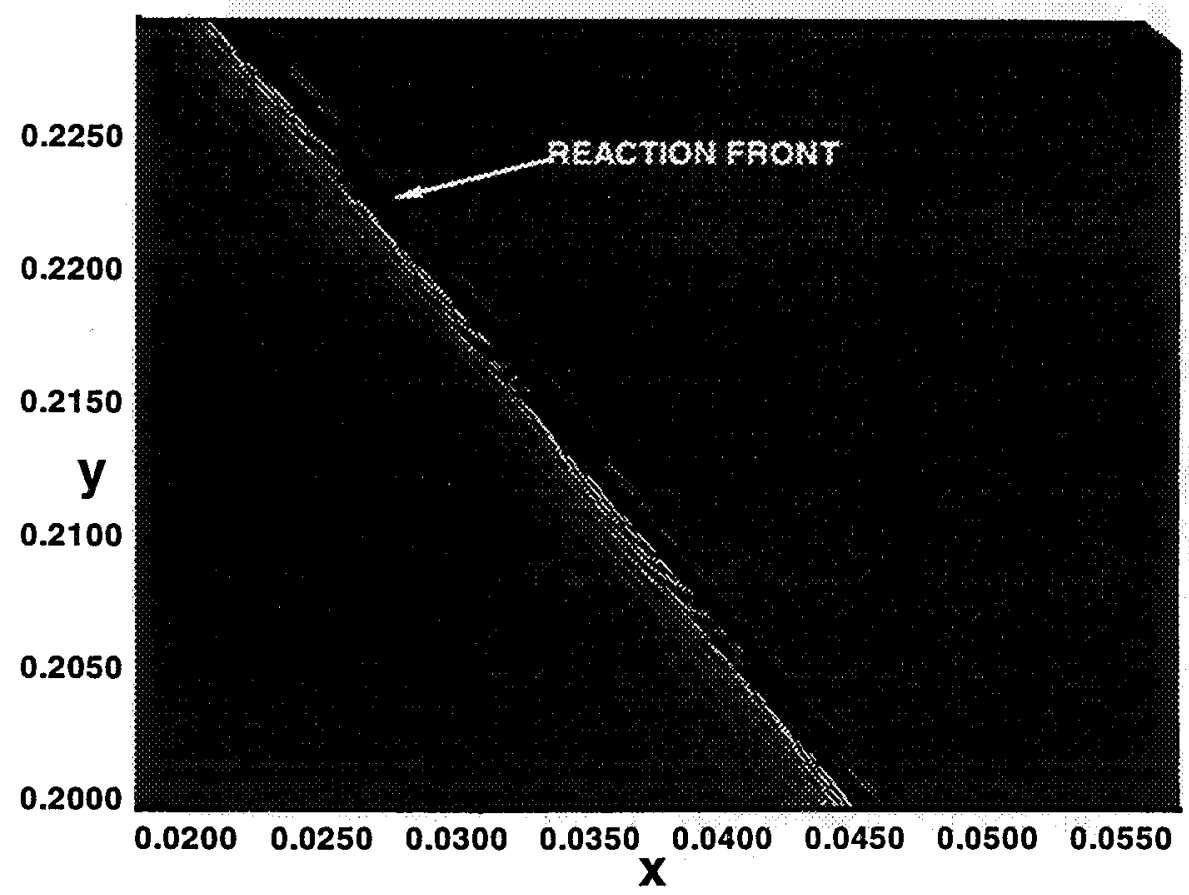

Figure 12 Enlarged view of contour plot of water mass fraction for Mach 6.46 and projectile diameter $225 \mathrm{~mm}$. 


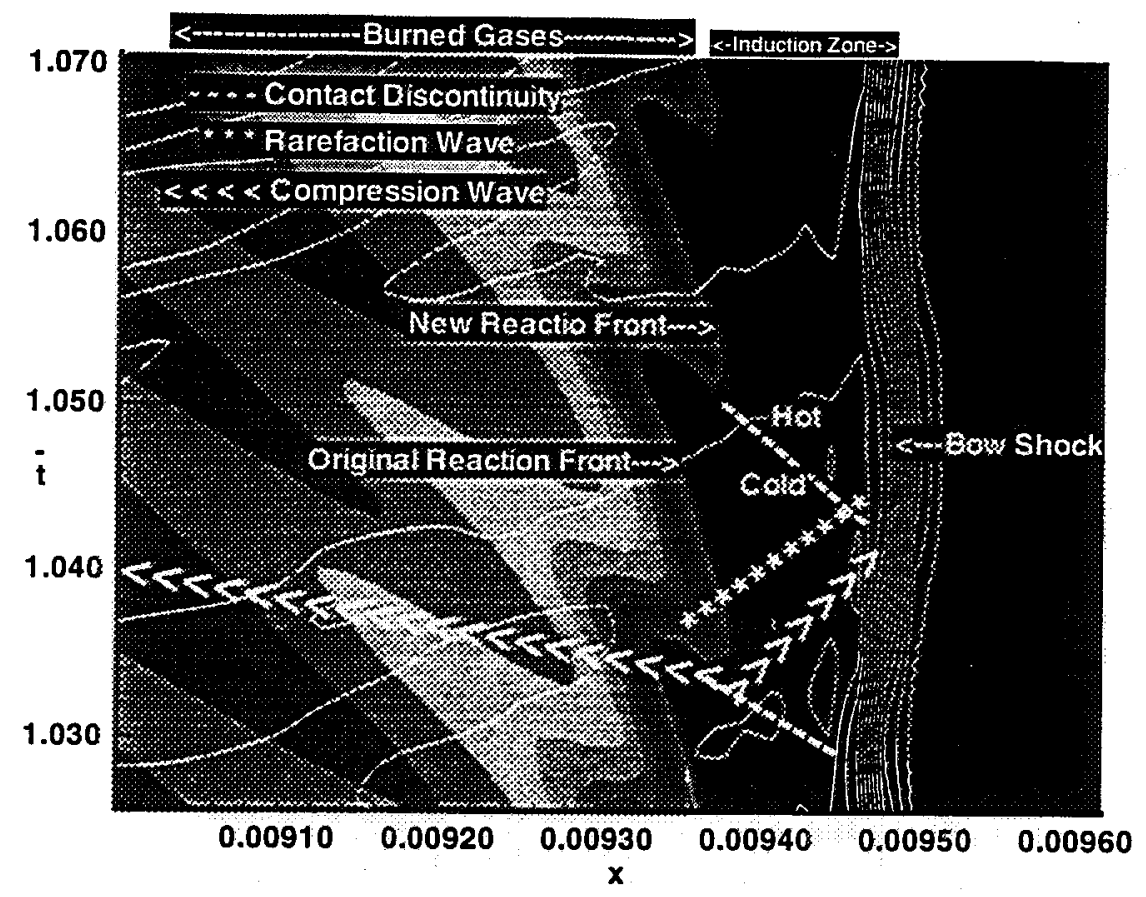

Figure $13 \mathrm{x}$-t Plot of water mass fraction along stagnation streamline for Mach 5.11 and Projectile diameter $15 \mathrm{~mm}$

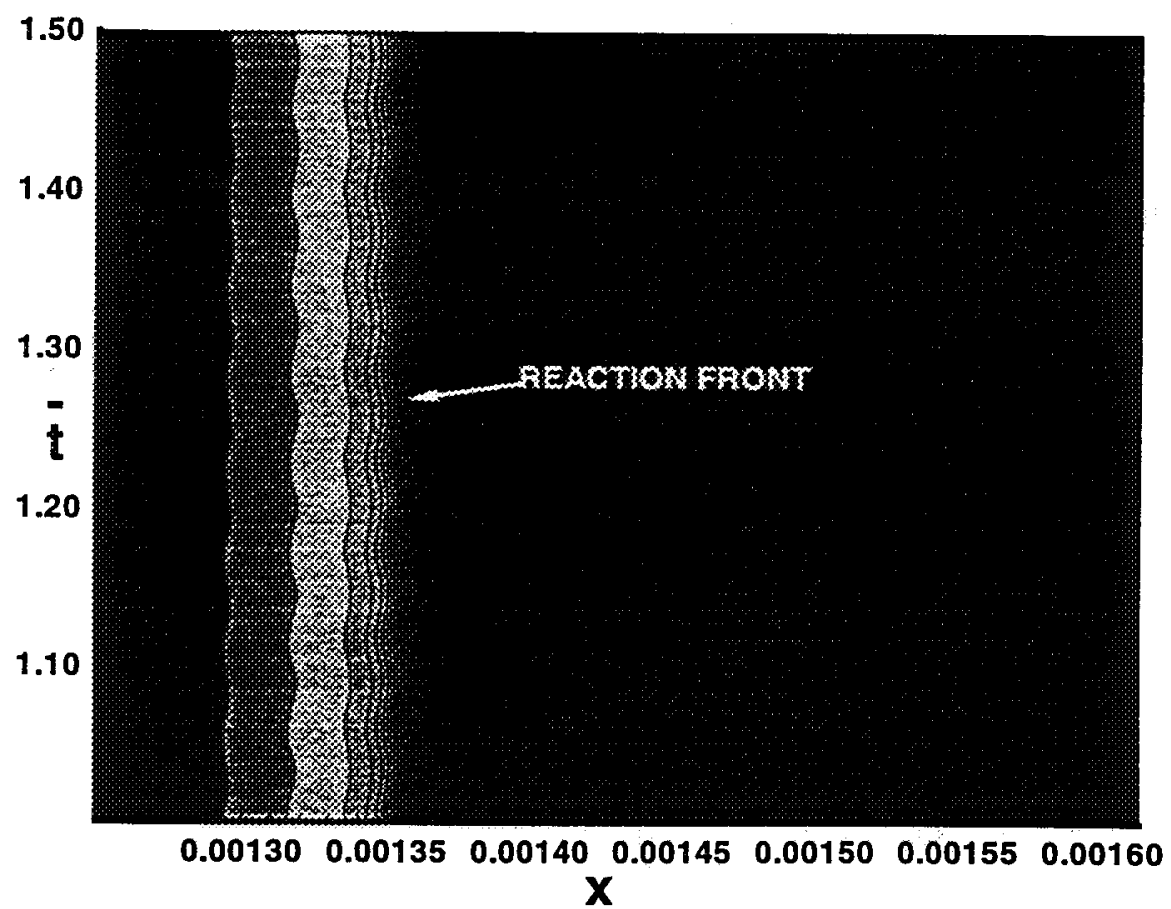

Figure $14 \mathrm{x}$-t Plot of water mass fraction along stagnation streamline for Mach 5.11 and Projectile diameter $2.5 \mathrm{~mm}$ 

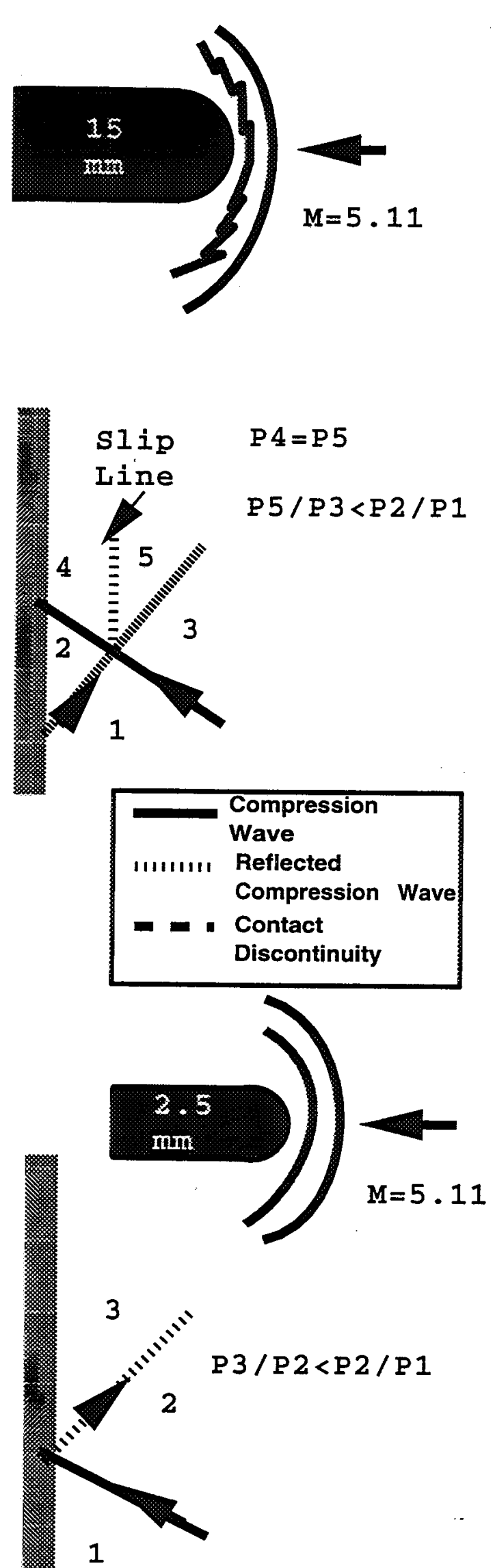

$t$

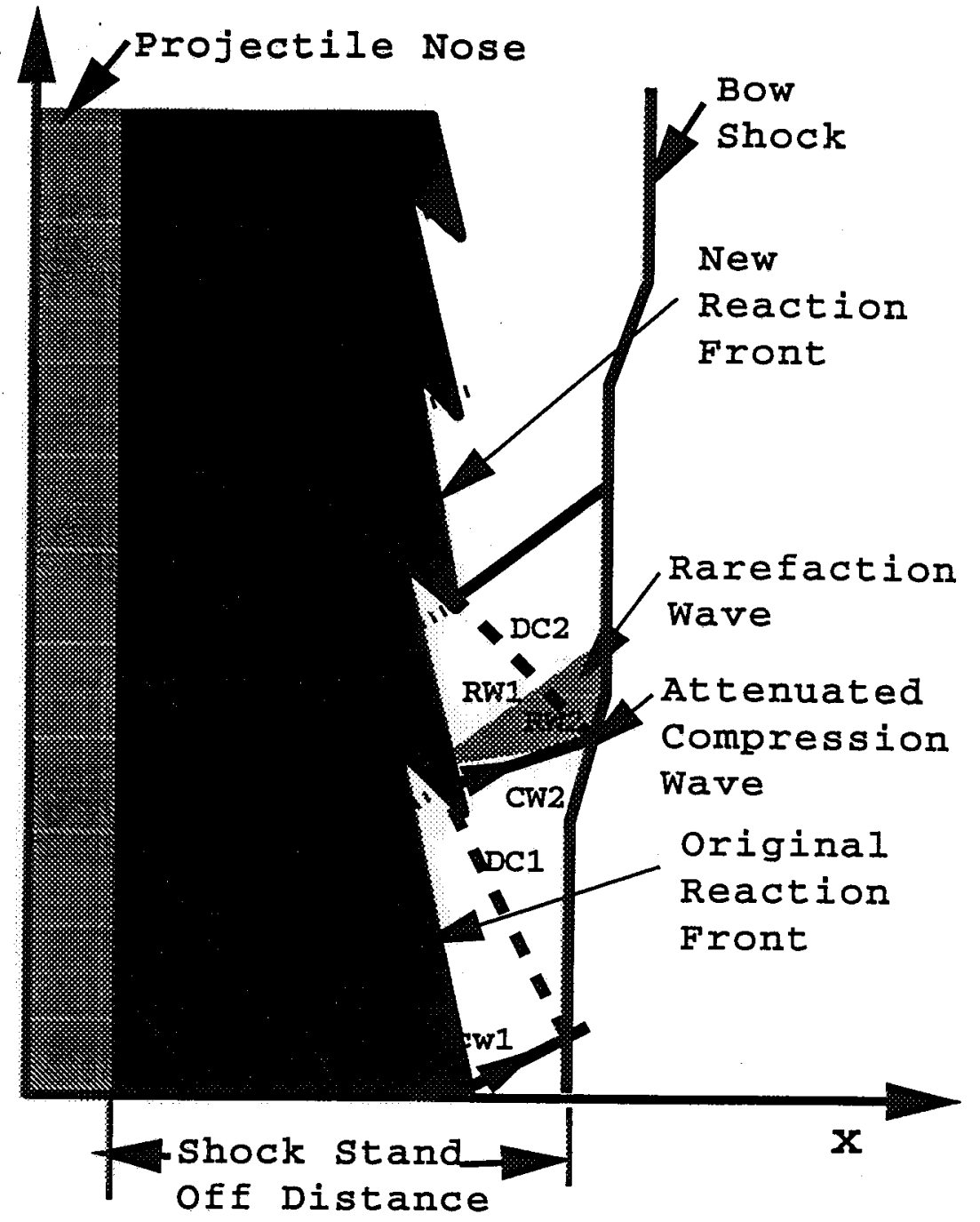

$t$

$\int_{\text {Projectile Body }}^{\text {Burned Gases }}$

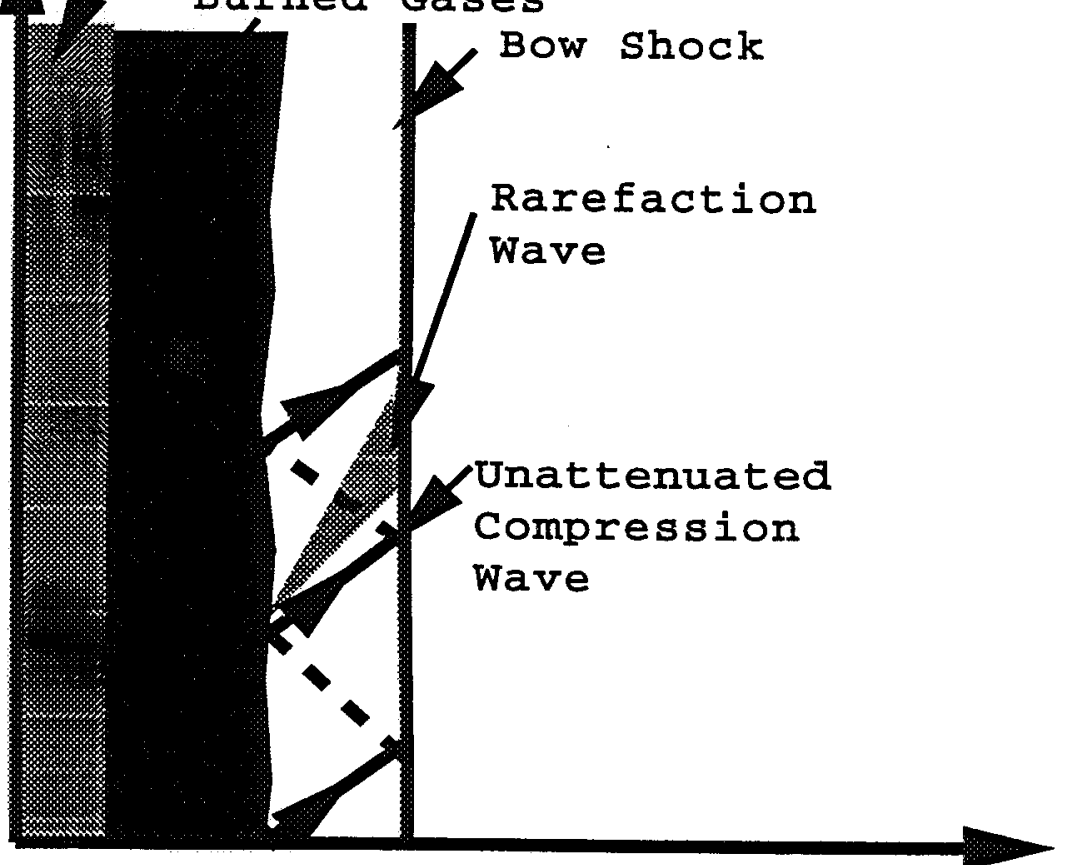

Figure $15 \mathrm{x}$-t Plot of wave-interaction model 